Um ambiente para análise de resultados de avaliações de acessibilidade e usabilidade na Web 



\title{
Um ambiente para análise de resultados de avaliações de acessibilidade e usabilidade na Web
}

\author{
Leandro Agostini do Amaral
}

Orientadora: Profa. Dra. Renata Pontin de Mattos Fortes

Dissertação apresentada ao Instituto de Ciências Matemáticas e de Computação - ICMC-USP, como parte dos requisitos para obtenção do título de Mestre em Ciências - Ciências de Computação e Matemática Computacional. VERSÃO REVISADA 
Ficha catalográfica elaborada pela Biblioteca Prof. Achille Bassi e Seção Técnica de Informática, ICMC/USP, com os dados fornecidos pelo(a) autor(a)

Agostini do Amaral, Leandro
Um ambiente para análise de avaliações de
acessibilidade e usabilidade na Web / Leandro
Agostini do Amaral; orientadora Renata Pontin de
Mattos Fortes. - - São Carlos, 2014.
125 p.
Dissertação (Mestrado - Programa de Pós-Graduação
em Ciências de Computação e Matemática
Computacional) - Instituto de Ciências Matemáticas
e de Computação, Universidade de São Paulo, 2014.
1. Acessibilidade Web. 2. Usabilidade Web. 3.
IHC. I. Pontin de Mattos Fortes, Renata, orient.
II. Título.




\section{Agradecimentos}

Agradeço a Deus, por estar presente em minha vida através de pessoas maravilhosas que cruzam o meu caminho e nele permanecem, sempre deixando ótimas contribuições que servem como combustível para minha caminhada. Em momentos difíceis, Ele me consolou, respondendo prontamente as minhas súplicas e me colocou no caminho correto.

Meus pais, Wilson e Marlene, que vivem em função dos filhos. Sempre zelando pelo nosso presente e futuro, fizeram o possível e o impossível para nos educar, para nos ensinar que o bem e a positividade movem montanhas e mudam o mundo. O que sou, devo em grande parte aos seus ensinamentos e exemplos.

Ao meu irmão Fabio, que por mais longe que esteja e pelas nossas ocupações não nos permitirem ter contato frequente, sempre se fez presente em meu coração. Você é meu exemplo de perseverança, pois sempre buscou por seus sonhos até conquistá-los.

Ao meu grande amigo Thiago, que foi como um irmão para mim, aconselhando e me ajudando a obter grandes conquistas. Sempre acreditou em meu potencial e tenho feito o possível para retribuir essa confiança. Estendo meus votos também a Luanna, sua noiva, que contribuiu muito neste mestrado e a quem quero muito bem.

Não posso deixar de agradecer a minha orientadora Renata, que foi como uma segunda mãe, sempre preocupada e pronta a aconselhar. Soube cobrar quando foi necessário e é a grande responsável pela minha caminhada acadêmica até agora. Uma pessoa maravilhosa a quem devo muito. Também agradeço ao meu grupo de pesquisa, que colaborou com ideias e discussões que contribuíram para execução deste trabalho.

Aos meus amigos, Victor, Alexandre, Felipe, Thaynara, Homero, Gustavo, Marcos, Lemuel, e tantos outros, que me encorajaram quando precisei e que me aguentaram, nos meus dias mais difíceis, sempre se mostrando solícitos.

Agradeço à FAPESP, Fundação de Amparo à Pesquisa do Estado de São Paulo, cujo patrocínio tornou possível a dedicação ao trabalho de pesquisa e redação durante dois anos.

\section{Agradeço vocês de todo o coração!}



"Any fool can write code that a computer can understand. Good programmers write code that humans can understand" Martin Fowler 



\section{Resumo}

A Web apresenta um conteúdo extenso de informações disponibilizado a uma população diversificada de pessoas, as quais podem apresentar as mais diferentes habilidades e exigências. Dessa maneira, garantir a acessibilidade a todo usuário é uma tarefa difícil, mesmo existindo um conjunto extenso de recomendações disponibilizadas pelo World Wide Web Consortium (W3C). Assim, são propostas diferentes ferramentas para avaliação de acessibilidade, que contrapõem os artefatos às diretrizes com a finalidade de obter resultados automatizados, produzindo testes e gerando vários dados, como a localização do problema no código e as falhas especificadas. Para facilitar o processamento desses dados, mediante a disponibilização de uma linguagem comum, o W3C desenvolveu a Evaluation and Report Language (EARL). Dados os problemas acerca das dificuldades em se garantir a acessibilidade para os diferentes perfis de usuários e a necessidade da interpretação dos relatórios em EARL, como colaboração para a avaliação manual, indispensável no contexto de testes de acessibilidade, neste trabalho é proposto um apoio por meio de um Ambiente para Análise de Avaliações de Acessibilidade e Usabilidade na Web (A4U). A partir do estudo de caso realizado, pôde-se validar o ambiente A4U desenvolvido, o qual inclui relatórios de avaliações semiautomáticas, para que o desenvolvedor possa interpretálos e prosseguir com a avaliação manual de acessibilidade e usabilidade. No âmbito do apoio desenvolvido, foram considerados os avanços em acessibilidade, usabilidade, a correlação entre os dois conceitos e a colaboração no desenvolvimento de uma ferramenta denominada AccessibilityUtil ${ }^{1}$, a qual se destina ser uma fonte de práticas de acessibilidade advindas de experiências de desenvolvedores, mediante colaboração em um ambiente Web, relacionando-as com as diretrizes de acessibilidade do W3C. A presente pesquisa contribuiu para a consolidação das questões de acessibilidade e usabilidade, a partir do desenvolvimento do A4U, que viabiliza a avaliação humana de acessibilidade e usabilidade, e a inserção de resultados de avaliações gerados por ferramentas semiautomáticas, conduzindo o avaliador a produzir melhorias em ambas as frentes.

\footnotetext{
${ }^{1}$ http://www.accessibilityutil.com
} 



\section{Abstract}

The Web has a large content of information available to a diverse population of people which may have the more different abilities and requirements. Thus, ensure accessibility to all users is a difficult task, even having an extensive set of recommendations provided by the World Wide Web Consortium (W3C). So, are proposed different tools for accessibility assessment that contrast the artifacts with guidelines in order to obtain automated results, producing tests and generating various data, such as the location of the problem in the code and the specified faults. To facilitate the processing of such data by providing a common language, the W3C developed the Evaluation and Report Language (EARL). Given the issues about the difficulties of ensuring accessibility to the different profiles of users and the necessity of interpreting the EARL reports, as collaboration for indispensable human review in the context of accessibility testing, this paper proposes a support through an Environment for Analyzing results of Assessments of Accessibility and Usability on the Web (A4U). From the case study conducted, it was possible to validate the A4U environment developed, which includes semiautomatic evaluating results, so that the developer can interpret them and proceed with the manual evaluation of accessibility and usability. Developed in support were considered advancements in accessibility, usability, the correlation between the two concepts and collaboration in the development of a tool called AccessibilityUtil, which is intended to be a source of accessibility practices arising from experiences of developers through collaboration a Web environment relating them to the W3C accessibility guidelines. This research contributed to the consolidation of the issues of accessibility and usability, from the development of $\mathrm{A} 4 \mathrm{U}$, which enables the human evaluation of accessibility and usability, and integration of evaluation results generated by semi-automatic tools, leading the reviewer to produce improvements in both fronts. 



\section{Lista de figuras}

Figura 1: Resumo das diretrizes de acessibilidade das WCAG 2.0 dispostas nos 3 níveis de conformidade A, AA e AAA (baseada em GAIGG, 2008)

Figura 2: Tela representativa da ferramenta TAW ……......................................................... 46

Figura 3: Tela representativa da ferramenta Worldspace FireEyes ................................... 47

Figura 4: Tela representativa da ferramenta Total Validator................................................. 48

Figura 5: Tela representativa da ferramenta WaaT ............................................................. 49

Figura 6: Tela representativa da ferramenta AChecker ................................................... 50

Figura 7: Gráfico representativo dos problemas encontrados nas avaliações, pelas diferentes ferramentas, considerando os três níveis de conformidade ............................................... 51

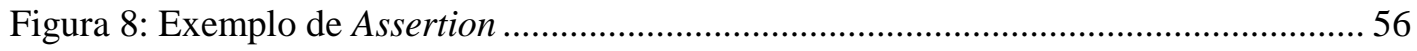

Figura 9: Avaliação com URI ....................................................................................... 56

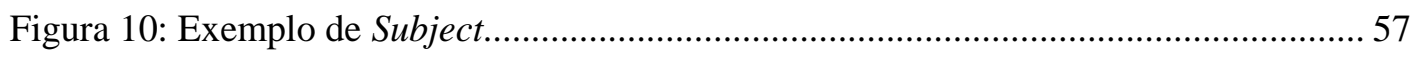

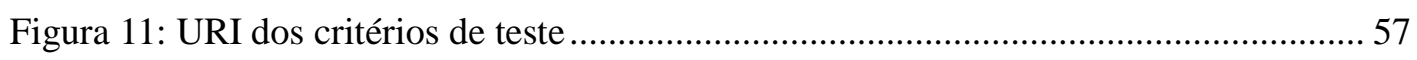

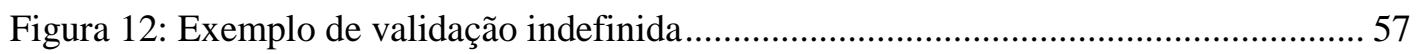

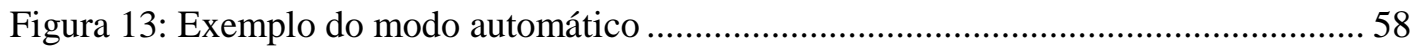

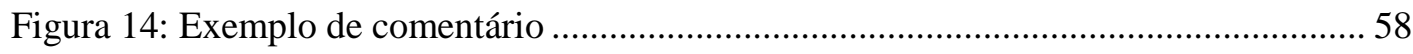

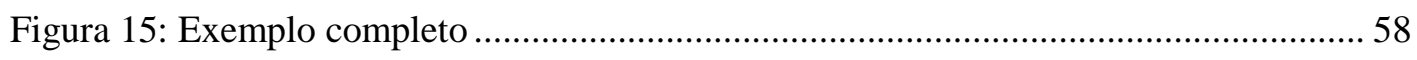

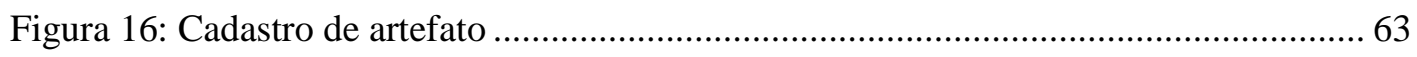

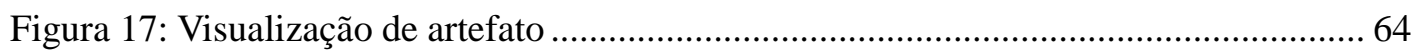

Figura 18: Gráfico de distribuição de problemas cobertos pelas WCAG 2.0 ....................... 76

Figura 19: Diagrama de casos de uso do A4U ……........................................................... 77

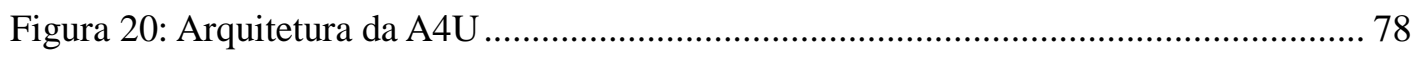

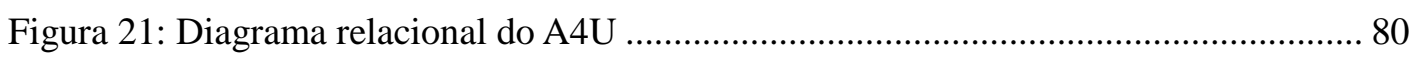

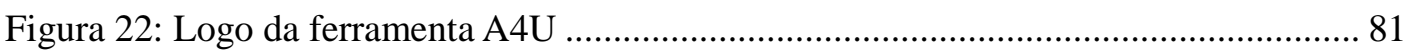

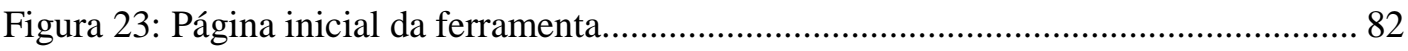


Figura 24: Página inicial visualizada em um dispositivo com dimensões menores 83

Figura 25: Tratamento de erros de formulário. 83

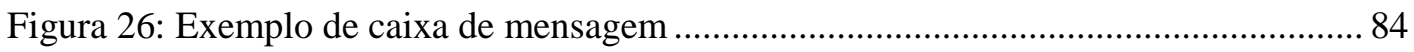

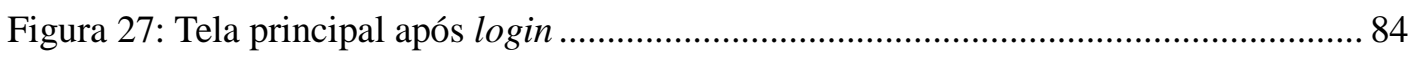

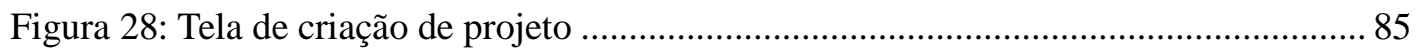

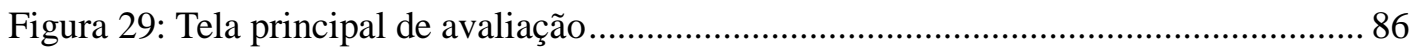

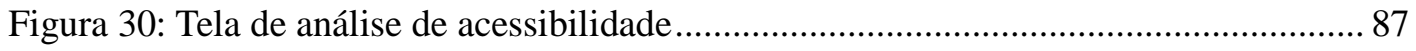

Figura 31: Tela de análise de usabilidade ........................................................................... 88

Figura 32: Representação de problemas resultantes da avaliação por outras ferramentas .. 89

Figura 33: Tela para inclusão de relatórios em EARL...................................................... 90

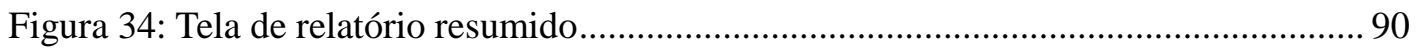

Figura 35: Relatório completo em PDF.............................................................................. 91 


\section{Lista de quadros}

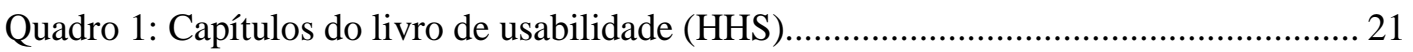

Quadro 2: Quadro descritivo da ferramenta de avaliação de acessibilidade TAW.............. 41

Quadro 3: Quadro descritivo da ferramenta de avaliação de acessibilidade Worldspace FireEyes

Quadro 4: Quadro descritivo da ferramenta de avaliação de acessibilidade Total Validator43

Quadro 5: Quadro descritivo da ferramenta de avaliação de acessibilidade WaaT............. 43

Quadro 6: Quadro descritivo da ferramenta de avaliação de acessibilidade AChecker ...... 44

Quadro 7: Resumo das características das ferramentas....................................................... 45

Quadro 8: Critérios de sucesso para conjunto de deficiências visuais .................................. 66

Quadro 9: Limiares tonais, quadro obtido de REDONDO e CARVALHO (2000).............. 68

Quadro 10: Critérios de sucesso para conjunto de deficiências auditivas ........................... 69

Quadro 11: Critérios de sucesso para conjunto de deficiências cognitivas .......................... 70

Quadro 12: Critérios de sucesso para conjunto de deficiências motoras............................... 72

Quadro 13: Critérios de sucesso para conjunto de transtornos convulsivos......................... 73

Quadro 14: Recomendações resultantes dos filtros utilizados na avaliação......................... 94

Quadro 15: Classificação de expertise dos respondentes em desenvolvimento Web.......... 96

Quadro 16: Quadro com as respostas obtidas pelos usuários............................................. 96

Quadro 17: Resultados de acessibilidade indicando o estado de "Não foi possível verificar"

Quadro 18: Resultados de usabilidade indicando o estado de "Não foi possível verificar" 98

Quadro 19: Resultados das impressões dos participantes pelas respostas ao questionário . 99 


\section{Lista de abreviaturas e siglas}

A4U Ambiente para Análise de Avaliações de Acessibilidade e Usabilidade na Web

ACM Association for Computing Machinery

CSS Cascading Style Sheets

EARL Evaluation And Report Language

e-GOV Governo Eletrônico

e-MAG Modelo de Acessibilidade em Governo Eletrônico

ERT WG Evaluation and Repair Tools Working Group

HHS The Department of Health and Human Services

HTML HyperText Markup Language

IBGE Instituto Brasileiro de Geografia e Estatística

ICMC Instituto de Ciências Matemáticas e de Computação

IHC Interação Humano-Computação

IEEE Institute of Electrical and Electronics Engineers

ISO International Organization for Standardization

LaPES Laboratório de Pesquisa em Engenharia de Software

PHP Hypertext Preprocessor

RDF Resource Description Framework

SGBD Sistema Gerenciador de Banco de Dados

SEA Segment-enrich-annotate paradigm for adapting

StArt State of the Art through Systematic Review

TICs Tecnologias de Informação e Comunicação

UFSCar Universidade Federal de São Carlos

W3C World Wide Web Consortium

WAI Web Accessibility Initiative

WAI-ARIA Accessible Rich Internet Applications

WCAG Web Content Accessibility Guidelines

XML eXtensible Markup Language

YAML Yet Another Multicolumn Layout 



\section{Sumário}

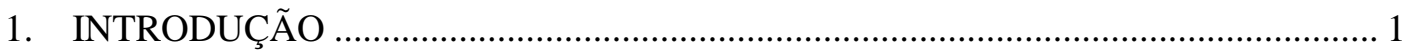

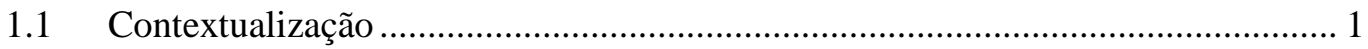

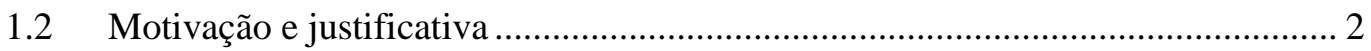

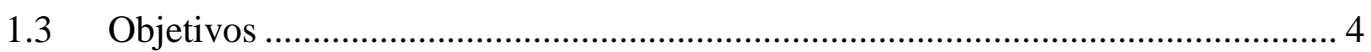

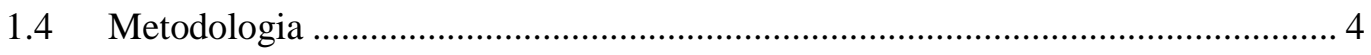

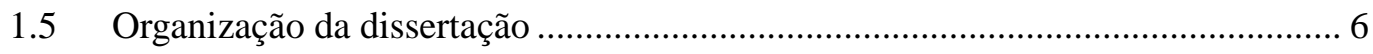

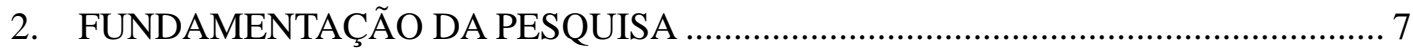

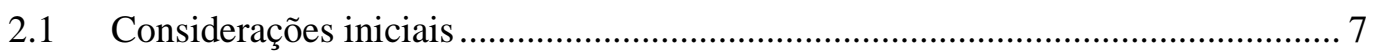

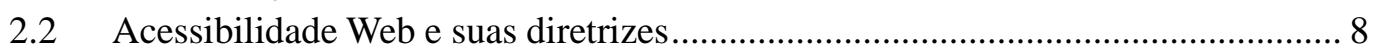

2.2.1 Web Content Accessibility Guidelines (WCAG)............................................... 9

2.2.2 e-MAG - Modelo de Acessibilidade de Governo Eletrônico........................... 12

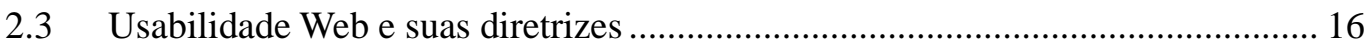

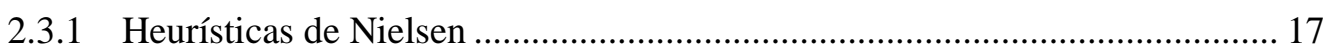

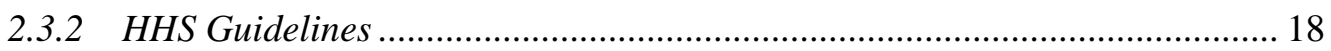

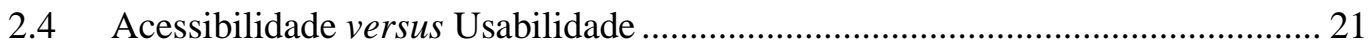

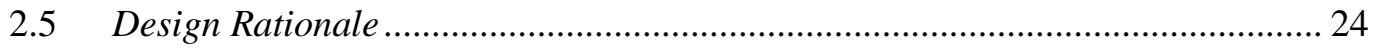

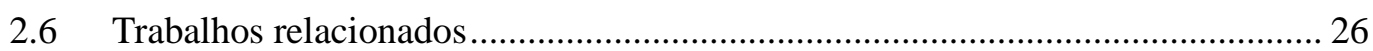

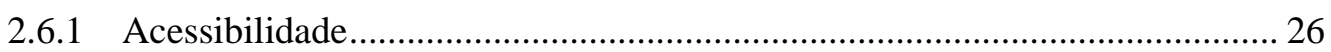

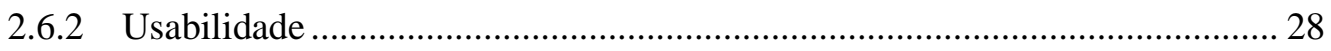

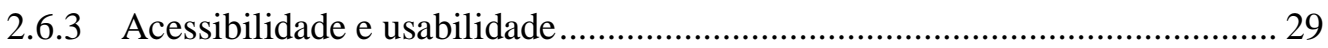

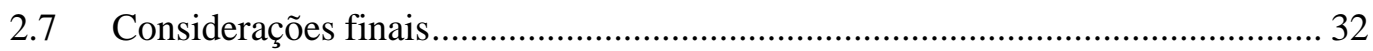

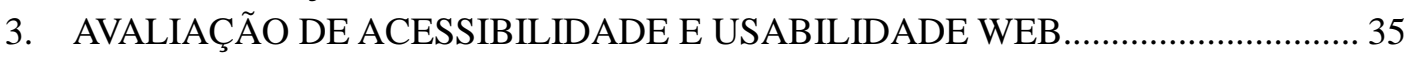

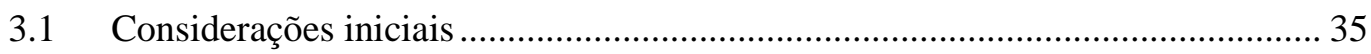

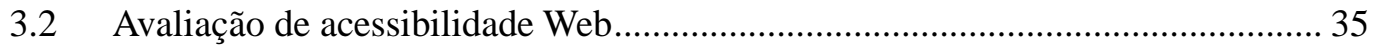

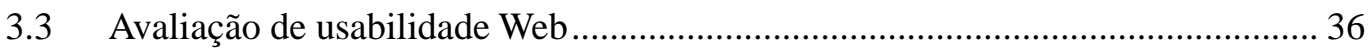

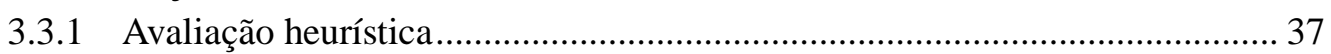

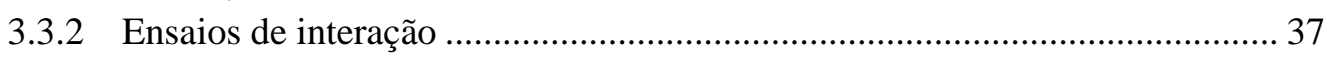

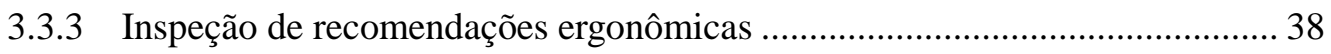

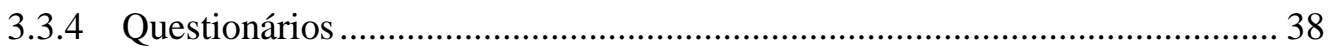

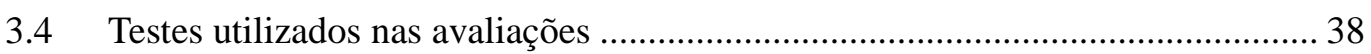

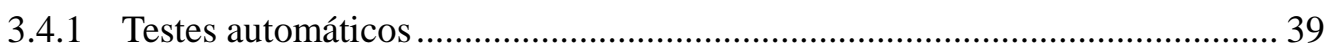

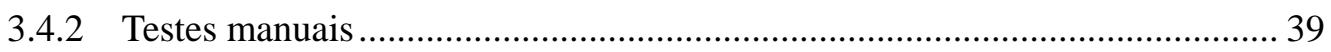

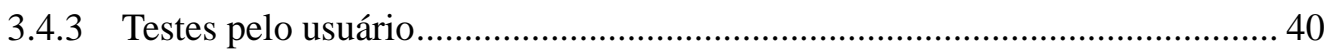

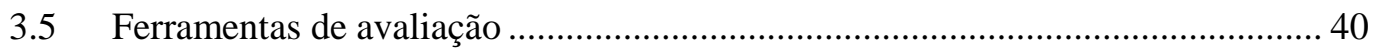

3.5.1 Ferramentas para avaliação de acessibilidade .............................................. 41

3.5.2 Ferramentas para avaliação de usabilidade...................................................... 52

3.6 Evaluation And Report Language (EARL) ..................................................... 53

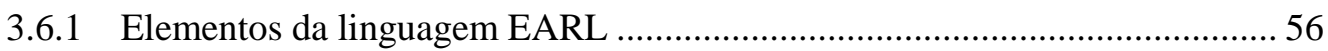

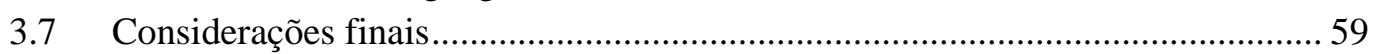

4. AMBIENTE PARA ANÁLISE DE AVALIAÇÕES DE ACESSIBILIDADE E

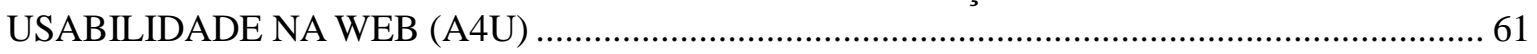

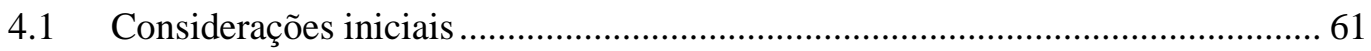




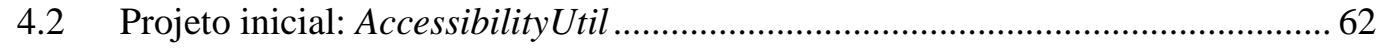

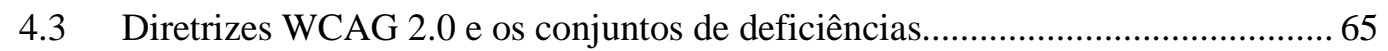

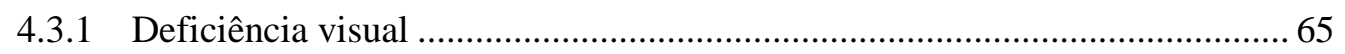

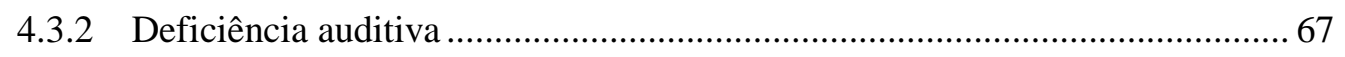

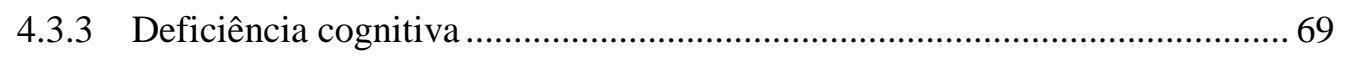

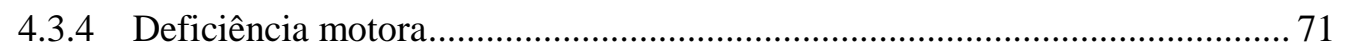

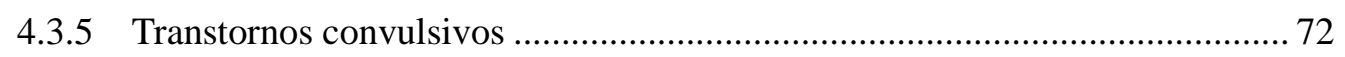

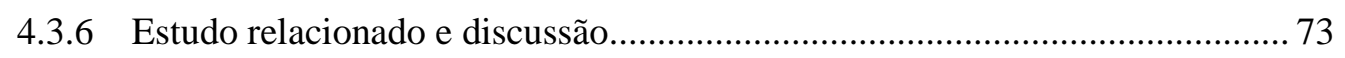

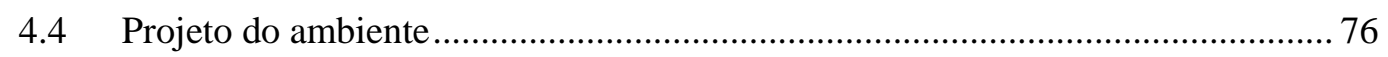

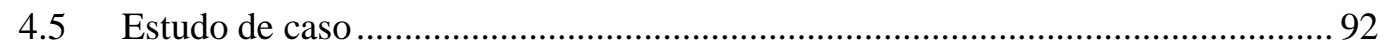

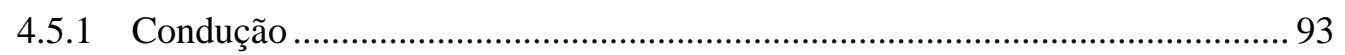

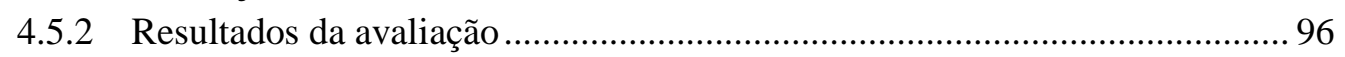

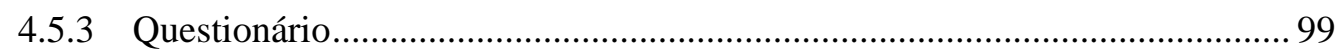

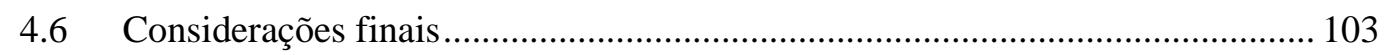

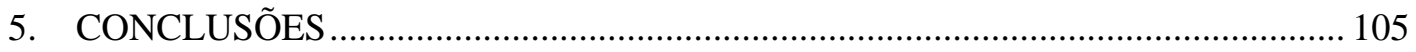

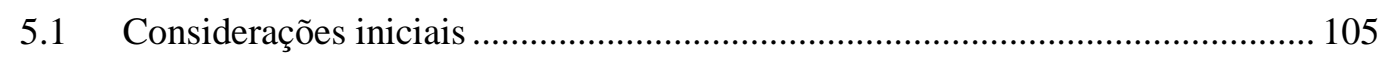

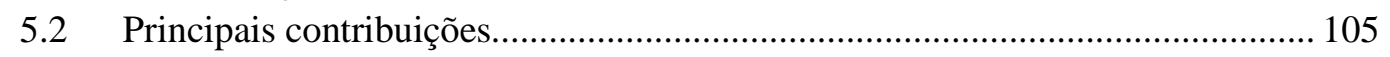

5.3 Lições aprendidas e impressões pessoais .......................................................... 107

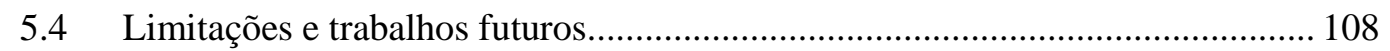

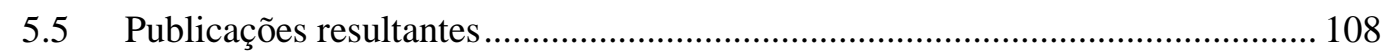

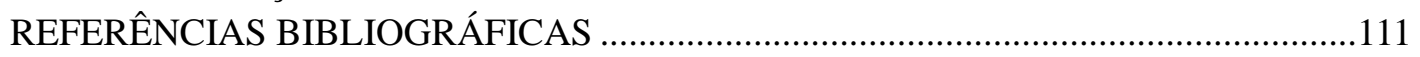

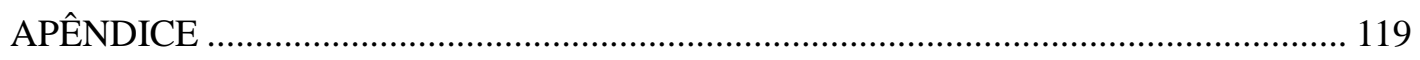

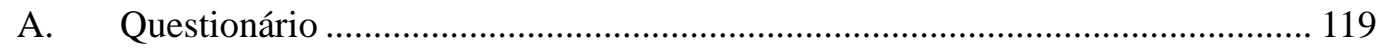

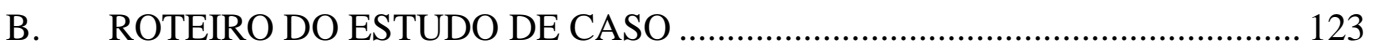

C. TERMO DE CONSENTIMENTO LIVRE E ESCLARECIDO ........................ 125 


\subsection{Contextualização}

Apesar dos avanços relacionados à Internet e dos diferentes trabalhos desenvolvidos envolvendo aspectos para facilitar a navegação por parte dos usuários, percebe-se que ainda há muito a ser feito quando o assunto está relacionado à acessibilidade na Web. Os diferentes perfis de usuários precisam ser atendidos, bem como as pessoas com diferentes dificuldades, sejam estas deficiências físicas ou cognitivas, necessitam de ferramentas que as auxiliem em suas atividades na Internet. Neste sentido, esta dissertação está inserida nas áreas de Acessibilidade e Usabilidade Web, as quais contemplam grande parte das diferentes necessidades dos usuários, incluindo as visuais, auditivas, físicas, de fala, cognitivas e neurológicas.

De fato, há um grande número de pessoas com deficiências que têm seu acesso limitado na Web. Um dos motivos para essa limitação está relacionado à falta de experiência de muitos desenvolvedores sobre as questões que envolvem a acessibilidade. POWER e PETRIE (2007) afirmam que as dificuldades do desenvolvimento, respeitando critérios de acessibilidade, estão relacionadas, em parte, com as ferramentas de autoria, que não devem se limitar à avaliação automática de conteúdo, pois muitos problemas necessitam de intervenção do desenvolvedor, o qual, se inexperiente, apresenta grandes dificuldades para inserí-las durante o desenvolvimento. Como solução, para minimizar as dificuldades do desenvolvedor, POWER e PETRIE (2007) propõem implementar exemplos, templates e folhas de estilos, com o intuito de gerar conteúdo acessível. 
Neste sentido, o desafio envolvendo a área de acessibilidade Web está em garantir que os projetos de aplicações permitam que qualquer usuário possa perceber, entender e interagir com as aplicações, bem como criar e contribuir com conteúdo. Sua importância é notória, pois visa proporcionar oportunidades iguais a todos, tendo em vista o crescente valor do conteúdo disponibilizado no ambiente online para educação, negócios, governo, comércio e lazer. Já o desafio relacionado à área de usabilidade consiste em garantir que o usuário realize, com facilidade, as funcionalidades disponibilizadas pela aplicação. Assim, muitos desenvolvedores e pesquisadores consideram que se a usabilidade for confrontada com a acessibilidade, pode-se configurar um conflito de forças, pois ambas as áreas devem ser atendidas, e ao priorizar uma, a outra pode ser comprometida (LANGDON et al., 2010).

Este trabalho contempla atividades e base teórica para a investigação do potencial da Evaluation And Report Language (EARL), linguagem disponibilizada pelo World Wide Web Consortium (W3C) ${ }^{2}$, ainda em estado Draft, para representar resultados de testes de avaliações em formato padronizado. Deste modo, os resultados tornam-se compreensíveis por outras aplicações que podem utilizá-los para conduzir a uma experiência com maior respeitabilidade aos critérios expostos durante a avaliação. A partir dos resultados formatados nesta linguagem, foi desenvolvido um ambiente para análise que os processa e indica os problemas nas respectivas diretrizes, como contribuição com a avaliação manual de acessibilidade e usabilidade, e também, para a investigação da correlação entre esses dois conceitos.

\subsection{Motivação e justificativa}

A relação entre a acessibilidade e usabilidade é raramente analisada de maneira explícita, seja no contexto da Web ou em outros sistemas baseados em computador (PETRIE e KHEIR, 2007). Somado a isso, a Internet tornou-se um dos mais importantes meios de comunicação e de informação dos dias atuais. Assim, torná-la acessível a todas as realidades e dificuldades é um desafio que precisa ser enfrentado, para possibilitar que qualquer indivíduo seja capaz de usufruir das facilidades e oportunidades que ela oferece.

\footnotetext{
${ }^{2}$ http://www.w3.org/
} 
O site do W3C $^{3}$, principal referência na catalogação de ferramentas de avaliação semiautomáticas que utilizam as Web Content Accessibility Guidelines (WCAG), lista ferramentas e apresenta informações obsoletas. A última alteração desta lista de ferramentas é datada de março de 2006, dois anos anteriores à publicação da recomendação 2.0 das WCAG. Portanto, trata-se de uma questão relevante a realização de uma pesquisa por ferramentas que avaliem sites quanto aos aspectos de acessibilidade, a partir das diretrizes documentadas nas WCAG 2.0.

A pesquisa também compreende a verificação da existência de ferramentas que utilizam a EARL, pois, por esta linguagem estar em estado Draft, pouco se sabe sobre ferramentas que a utilizam. Em junho de 2011 aconteceu a última chamada para revisão da linguagem no estado Draft (W3C, 2011a), o que pode significar sua oficialização em pouco tempo.

O desenvolvimento de um ambiente para análise de scripts EARL e de outros meios de obtenção de resultados de avaliações de ferramentas semiautomáticas colaborará na investigação da correlação entre usabilidade e acessibilidade com o propósito de contribuir para a escolha entre quais critérios seguir no desenvolvimento de sites acessíveis e usáveis. Possibilitará a construção do Design Rationale, que consiste na documentação das tomadas de decisões entre os atores, com o objetivo de desenvolver conteúdo com maior grau de acessibilidade e usabilidade.

Neste contexto, o presente projeto apresenta relevância, uma vez que visa contribuir para:

- Auxiliar desenvolvedores na utilização dos relatórios EARL e no contraste de seus resultados, facilitando tomadas de decisões que resultem em aplicações mais acessíveis e usáveis;

- Auxiliar desenvolvedores na escolha de ferramentas de avaliação de acessibilidade e usabilidade;

- Relacionar técnicas de promoção de acessibilidade, usabilidade e como essas serão disponibilizadas nos relatórios;

\footnotetext{
${ }^{3}$ http://www.w3.org/WAI/ER/tools/
} 
- Relacionar as WCAG 2.0 com os diversos conjuntos de deficiências, de modo a compreender a abrangência das diretrizes documentadas pelo W3C;

- Traduzir as diretrizes de usabilidade do Departamento de Saúde e Serviços Humanos dos Estados Unidos (HHS) para o português;

- Contribuir com a avaliação humana dos conteúdos contrastados com as diretrizes de acessibilidade e usabilidade;

- Investigar a hipótese se é possível ou não obter uma experiência em software com alta usabilidade e acessibilidade, relacionando os conceitos com o propósito de analisar o trade-off aparente.

Em seguida, os objetivos do projeto são delineados, em conjunto com a descrição da organização desta dissertação, para conhecimento prévio do leitor.

\subsection{Objetivos}

Como objetivo principal tem-se a proposta de um apoio para desenvolvedores de aplicações Web, com vistas a analisarem-nas quanto às diversas recomendações de acessibilidade e usabilidade. Foi, portanto, desenvolvido um ambiente para dar suporte a uma análise da correlação entre usabilidade e acessibilidade. O propósito, acerca do desenvolvimento deste trabalho, está em contribuir na tomada de decisões do desenvolvedor, na fase de desenvolvimento, e investigar o trade-off sugerido por profissionais e pesquisadores desta área.

Como objetivos secundários do projeto, têm-se a colaboração no desenvolvimento da ferramenta AccessibilityUtil, a associação dos critérios de sucesso das WCAG 2.0 com os diferentes conjuntos de deficiência, a tradução das diretrizes HHS para o português, a difusão e a promoção do conhecimento sobre acessibilidade e usabilidade na Web.

\subsection{Metodologia}

A fase inicial desta pesquisa esteve voltada ao entendimento da EARL, a partir da documentação do W3C e do estudo das diretrizes das WCAG 2.0, também documentadas no site do Consórcio Internacional. A partir de então, foram levantadas as aplicações de 
avaliação semiautomáticas que consideram as diretrizes de acessibilidade WCAG 2.0 e produzem resultados na linguagem EARL.

Como exemplificação, tais resultados foram obtidos na análise do conteúdo do portal do governo do Estado de São Paulo e, assim, pôde-se inserir os dados encontrados no ambiente $\mathrm{A} 4 \mathrm{U}$, desenvolvido neste trabalho, a partir da proposta e execução de um estudo de caso que validasse o ambiente. A escolha pelo portal do governo de São Paulo foi realizada, devido à existência do Decreto 5.296, publicado em dezembro de 2004, que torna obrigatória a acessibilidade nos portais e sites eletrônicos da administração pública na rede mundial de computadores, para o uso das pessoas com deficiência, garantindo pleno acesso aos conteúdos disponíveis e, também, pelo endereço do portal eletrônico do Governo do Estado de São Paulo estar bem posicionado no ranking da Alexa ${ }^{4}$.

A pesquisa se estendeu ao desenvolvimento de um ambiente para análise de resultados representados na linguagem EARL e resultados de avaliações realizadas pelo próprio ambiente, a partir da integração com a ferramenta open source AChecker, a qual será melhor descrita na Seção 3.5.1.

Como apresentado anteriormente, com vistas a expor a ferramenta desenvolvida aos pesquisadores e desenvolvedores e analisar o portal do Estado de São Paulo, foi proposto e executado um estudo de caso. Após submeter o ambiente à utilização por diferentes desenvolvedores e pesquisadores, os resultados foram confrontados para evidenciar o relacionamento conceitual entre a completude dos critérios de acessibilidade e usabilidade. Adicionalmente, buscou-se, por meio dos resultados do estudo, promover uma discussão a respeito da disposição das diretrizes no ambiente proposto, verificar a clareza empregada na apresentação de cada recomendação aos desenvolvedores, juntamente com sua descrição oficial, bem como, oferecer meios alternativos para tornar a avaliação menos trabalhosa. Foi possível, assim, coletar opiniões acerca da interface construída para a ferramenta desenvolvida neste trabalho, denominada Ambiente para Análise de Avaliações de Acessibilidade e Usabilidade na Web (A4U).

\footnotetext{
${ }^{4}$ Segunda posição entre os portais “.gov.br” - Alexa - The Web Information Company (URL: http://www.alexa.com/)
} 
A pesquisa e o desenvolvimento deste trabalho foram realizados preferencialmente nos laboratórios do Instituto de Ciências Matemáticas e de Computação (ICMC), localizado na USP, Campus São Carlos. Os laboratórios do ICMC dispõem de total infraestrutura para realização do projeto.

\subsection{Organização da dissertação}

No Capítulo 2 são apresentados os conceitos como Acessibilidade, Usabilidade, o Design Rationale e também alguns trabalhos relacionados. No Capítulo 3 são apresentadas as dificuldades e soluções em avaliação automática e humana, além de identificar ferramentas semiautomáticas para avaliação e a linguagem de relatórios Evaluation And Report Language (EARL), utilizada no decorrer do projeto. No Capítulo 4 são descritos o planejamento da ferramenta e sua consolidação; na Seção 4.2 é apresentado o projeto inicial, AccessibilityUtil. Na Seção 4.3 as diretrizes de acessibilidade WCAG são divididas de acordo com os conjuntos de deficiências; enquanto à Seção 4.4 cabe a apresentação do projeto em si, seguida do estudo de caso realizado para sua validação, na Seção 4.5. Por fim, no Capítulo 5 são tecidas as conclusões desta pesquisa. 


\subsection{Considerações iniciais}

Acessibilidade é um assunto que merece ser continuamente tratado, porém ainda observase que é pouco explorado, considerando sua vital importância no que concerne à equiparação de direitos na concepção e incorporação dos produtos e serviços disponibilizados a todas as pessoas. Sobretudo, acessibilidade precisa ser cuidada tanto em ambientes físicos, como nos digitais. A usabilidade, por sua vez, nos vários tipos de Tecnologias de Informação e Comunicação (TICs), abrange um conteúdo mais consolidado e difundido, haja vista seu impacto direto na qualidade das aplicações.

Por conseguinte, como os desenvolvedores de software são os principais responsáveis no processo de desenvolvimento de aplicações Web, estes devem estar cada vez mais cientes da existência de tais temas e conhecer como aplicar os conceitos de acessibilidade e usabilidade durante o desenvolvimento.

Baseado em tais necessidades, neste mestrado é proposto um apoio efetivo para os desenvolvedores, de modo que discutam e troquem experiências sobre estes conceitos. Assim, neste capítulo, são apresentados os conceitos de acessibilidade e usabilidade, a relação entre ambos, o Design Rationale, que se faz presente no registro de decisões no momento de desenvolvimento e também os trabalhos relacionados. 


\subsection{Acessibilidade Web e suas diretrizes}

Acessibilidade Web consiste em tornar um conteúdo disponível a qualquer pessoa, sem qualquer restrição, com o propósito de possibilitar a mesma experiência de aprendizado, lazer e negócios, tanto para usuários com deficiências, quanto para os sem (W3C, 2011b).

Tim Berners-Lee, um dos inventores da Web e diretor do World Wide Web Consortium, define acessibilidade em termos de incapacidade e de universalidade. $\mathrm{O}$ autor afirma que o poder da Web está no acesso por todas as pessoas, não obstante a sua incapacidade, considerando como aspecto essencial o acesso por todos, independentemente da deficiência $\left(\mathrm{WAI}^{5}\right)$. THATCHER (2004) associa o fato da tecnologia ser acessível à condição de ser usada de modo eficaz, tanto por pessoas com deficiências, como pelas que não as apresentam.

PETRIE e KHEIR (2007) afirmam que acessibilidade é um conceito menos claro do que a usabilidade e caracterizam as diretrizes documentadas pelo W3C como condições para se conseguir atingir a "acessibilidade técnica” e poder avaliá-la. Para obter a “acessibilidade usável” definitiva, é necessário o estudo fundamentado em experiências dos usuários finais. Essa afirmação foi resultante da pesquisa conduzida pela Disability Rights Comission (2004), abrangendo 1.000 sites, a qual mostrou pouca relação significativa entre a conformidade com as recomendações das diretrizes WCAG e as medidas de desempenho e satisfação para cinco diferentes categorias de pessoas com deficiência.

Assim, é possível concluir que várias ações devem ser consideradas para serem obtidas boas práticas no desenvolvimento voltado à acessibilidade, não se limitando à completude das diretrizes existentes, mas voltando a análise à utilização do conteúdo pelo usuário final. Ainda, é necessário que as pessoas envolvidas tenham consciência dos benefícios associados à adoção da acessibilidade. Para tanto, tecnologias assistivas devem ser utilizadas, de modo a viabilizar o desenvolvimento de aplicações acessíveis e facilitar sua utilização, por parte dos usuários com algum tipo de deficiência.

Apesar de sua enorme importância às pessoas com deficiência, os recursos de tecnologia assistiva, sozinhos, não garantem o acesso ao conteúdo de uma página da Web.

\footnotetext{
${ }^{5}$ http://www.w3.org/WAI/
} 
Para isso, é necessário que a página tenha sido desenvolvida de acordo com os padrões Web (Web Standards) e as recomendações de acessibilidade, as quais são abordadas nas próximas subseções, sendo apresentadas as diretrizes de acessibilidade do W3C, as WCAG 2.0 e o Modelo de Acessibilidade de Governo Eletrônico (e-MAG), desenvolvido por requisição do Governo Brasileiro, baseado nas WCAG e inserido no âmbito das necessidades locais.

\subsubsection{Web Content Accessibility Guidelines (WCAG)}

As diretrizes WCAG representam regras para produzir conteúdo (textos, imagens, formulários, sons) para a Web, que seja acessível às pessoas com deficiência, incluindo cegueira e baixa visão, surdez e baixa audição, dificuldades de aprendizagem, limitações cognitivas, limitações de movimentos, incapacidade de fala, foto-sensibilidade e suas combinações (W3C, 2009).

Outrossim, para formalizar a definição das diretrizes de acessibilidade do W3C, tem-se sua definição oficial, atribuída às Recomendações de Acessibilidade para Conteúdo Web:

“As diretrizes WCAG 2.0 definem a forma como tornar o conteúdo da Web mais acessível a pessoas com incapacidades. A acessibilidade envolve uma vasta gama de incapacidades, incluindo visuais, auditivas, físicas, de fala, cognitivas, de linguagem, de aprendizagem e neurológicas. Embora estas diretrizes abranjam um grande número de problemas, não têm capacidade para abordar as necessidades de pessoas com todos os tipos, graus e combinações de incapacidades. Estas recomendações também facilitam a utilização do conteúdo da Web por pessoas mais velhas, cujas capacidades estão em constante mudança, devido ao processo de envelhecimento, e facilitam a utilização para os usuários em geral” (W3C, 2009).

Tais diretrizes são direcionadas aos desenvolvedores Web, desenvolvedores de ferramentas para Web e desenvolvedores de softwares de avaliação da acessibilidade. Elas se encontram em um documento na versão 2.0 desde dezembro de 2008. 
As WCAG 2.0 apresentam quatro princípios que constituem a fundamentação da acessibilidade da Web, os quais são: perceptível, operável, compreensível e robusto. A partir desses princípios, 12 recomendações são apresentadas (W3C, 2008).

Princípio 1: Perceptível - A informação e os componentes da interface do usuário têm que ser apresentados aos usuários em formatos que eles os possam perceber.

Isso significa que os usuários devem ser capazes de perceber a informação que está sendo apresentada, não podendo ser imperceptível para todos os seus sentidos. Para sua obtenção, são listadas as seguintes recomendações:

- Recomendação 1.1 - Alternativas em Texto: Fornecer alternativas em texto para qualquer conteúdo não textual, permitindo, assim, que o mesmo possa ser alterado para outras formas mais adequadas à necessidade do indivíduo, tais como impressão em caracteres ampliados, Braille, fala, símbolos ou linguagem mais simples;

- Recomendação 1.2 - Mídias com base no tempo: Fornecer alternativas para mídias com base no tempo, que contemplem o mesmo conteúdo, possibilitando a recuperação da informação por outra fonte;

- Recomendação 1.3 - Adaptável: Criar conteúdos que possam ser apresentados de diferentes maneiras (por exemplo, um layout mais simples), sem perder informação ou estrutura;

- Recomendação 1.4 - Discernível: Facilitar a audição e a visualização de conteúdos aos usuários, incluindo a separação do primeiro plano e do plano de fundo.

Princípio 2: Operável - Os componentes de interface de usuário e a navegação têm que ser operáveis.

Isso significa que os usuários devem ser capazes de operar a interface. A interface de interação não pode exigir interação que o usuário não possa executar. Para sua obtenção, são listadas as recomendações:

- Recomendação 2.1 - Acessível por Teclado: Fazer com que toda a funcionalidade fique disponível a partir do teclado; 
- Recomendação 2.2 - Tempo Suficiente: Fornecer tempo suficiente aos usuários para lerem e utilizarem o conteúdo;

- Recomendação 2.3 - Ataques Epilépticos: Não criar conteúdo de uma forma conhecida que possa causar ataques epiléticos;

- Recomendação 2.4 - Navegável: Fornecer formas de ajudar os usuários a navegar, localizar conteúdos e determinar o local onde estão.

Princípio 3: Compreensível - A informação e a operação da interface de usuário têm que ser compreensíveis.

Isso significa que os usuários devem ser capazes de compreender as informações, bem como o funcionamento da interface do usuário. O conteúdo ou operação não pode ir além de sua compreensão. Para sua obtenção, são listadas as recomendações:

- Recomendação 3.1 - Legível: Tornar o conteúdo de texto legível e compreensível;

- Recomendação 3.2 - Previsível: Fazer com que as páginas Web surjam e funcionem de modo previsível;

- Recomendação 3.3 - Assistência de Entrada: Ajudar os usuários a evitar e corrigir erros.

Princípio 4: Robusto - O conteúdo tem que ser robusto o suficiente para poder ser interpretado de maneira concisa por diversos agentes do usuário, incluindo tecnologias assistivas.

Isso significa que os usuários devem ser capazes de acessar o conteúdo conforme as tecnologias evoluem. Como a tecnologia e os agentes de usuário são frequentemente atualizados, o conteúdo deve permanecer acessível.

- Recomendação 4.1 - Compatível: Maximizar a compatibilidade com atuais e futuros agentes de usuário, incluindo tecnologias assistivas.

Para cada uma das 12 recomendações enumeradas, um número de critérios a serem testados está associado, divididos em três níveis de conformidade: A (nível mínimo), AA (nível médio) e AAA (nível máximo), ilustrados na Figura 1. 


\begin{tabular}{|c|c|c|c|c|}
\hline Principios & Diretrizes & Nivel A & Nível AA & Nível AAA \\
\hline \multirow{4}{*}{ 1. Perceptivel } & 1.1 Alternativas em texto & $1.1 .1[1]$ & & \\
\hline & 1.2 Multimídia baseada no tempo & $1.2 .1-1.2 .3[3]$ & $1.2 .4-1.2 .5[2]$ & $1.2 .6-1.6 .9[4]$ \\
\hline & 1.3 Adaptável & $1.3 .1-1.3 .3[3]$ & & \\
\hline & 1.4 Discernível & $1.4 .1-1.4 .2[2]$ & $1.4 .3-1.4 .5[3]$ & $1.4 .6-1.4 .9[4]$ \\
\hline \multirow{4}{*}{ 2. Operável } & 2.1 Acessivel por teclado & $2.1 .1-2.1 .2[2]$ & & $2.1 .3[1]$ \\
\hline & 2.2 Tempo suficiente & $2.2 .1-2.2 .2[2]$ & & $2.2 .3-2.2 .5[3]$ \\
\hline & 2.3 Ataques epiléticos & $2.3 .1[1]$ & & $2.3 .2[1]$ \\
\hline & 2.4 Navegável & $2.4 .1-2.4 .4[4]$ & $2.4 .5-2.4 .7[3]$ & $2.4 .8-2.4 .10[3]$ \\
\hline \multirow{3}{*}{ 3. Compreensivel } & 3.1 Legivel & $3.1 .1[1]$ & $3.1 .2[1]$ & $3.1 .3-3.1 .6[4]$ \\
\hline & 3.2 Previsivel & $3.2 .1-3.2 .2[2]$ & $3.2 .3-3.2 .4[2]$ & $3.2 .5[1]$ \\
\hline & 3.3 Assistência de entrada & $3.3 .1-3.3 .2[2]$ & $3.3 .3-3.3 .4[2]$ & $3.3 .5-3.3 .6[2]$ \\
\hline 4. Robusto & 4.1 Compativel & $4.1 .1-4.1 .2[2]$ & & \\
\hline
\end{tabular}

Figura 1: Resumo das diretrizes de acessibilidade das WCAG 2.0 dispostas nos 3 níveis de conformidade A, AA e AAA (baseada em GAIGG, 2008)

Como apresentado na Figura 1, para obter a conformidade de Nível A, todos os 25 critérios de sucesso do Nível A devem ser cumpridos, ou uma versão alternativa, em conformidade, deve ser disponibilizada, enquanto o Nível AA é conseguido a partir do cumprimento dos critérios de Nível A somados aos 13 critérios de Nível AA e, o Nível AAA, de maior conformidade, requer obtenção dos critérios de Nível A, AA e dos 23 critérios de Nível AAA.

As WCAG 2.0 foram normatizadas em outubro de 2012, sendo reconhecidas como um padrão ISO/IEC, de identificador 40500:2012 pelo Comitê Técnico Conjunto JTC (Tecnologia da Informação) da Organização Internacional de Normalização (ISO) e da Comissão Eletrotécnica Internacional (IEC) (ISO/IEC, 2012).

Neste contexto, o Governo Brasileiro, visando regular e desenvolver um material padrão a ser seguido para adequação de seus sites administrativos com relação à acessibilidade, propôs o e-MAG, Modelo de Acessibilidade de Governo Eletrônico, que é descrito na próxima subseção.

\subsection{2 e-MAG - Modelo de Acessibilidade de Governo Eletrônico}

No tópico de Governo Eletrônico (e-GOV), o não comprometimento com as questões de acessibilidade inviabiliza o acesso ao conteúdo e aos serviços de poder público por uma parcela da população, influindo diretamente na cidadania. Essa parcela de cidadãos com 
deficiências vêm aumentando, considerando os Censos Demográficos feitos pelo IBGE. Em 2002, 24,5 milhões de pessoas (14,5\% da população brasileira da época) apresentavam alguma deficiência, desse total, 48,1\% apresentavam deficiência visual parcial ou total (CARVALHO, 2008). No Censo Demográfico de 2010, o número de pessoas com deficiências, seja mental, motora, visual ou auditiva, quase dobrou, chegando aos 46 milhões, o que representa $24 \%$ da população e, os idosos passaram a representar $24,1 \%$ da população (IBGE, 2010).

O governo brasileiro, observando a necessidade de uma parcela crescente de pessoas idosas e com deficiência, a partir do Departamento de Governo Eletrônico, em parceria com a ONG Acessibilidade Brasil, disponibilizou a primeira versão do e-MAG em 18 de janeiro de 2005. Em 7 de maio de 2007, a Portaria $\mathrm{n}^{0} 3$ institucionalizou o e-MAG, no âmbito do sistema de Administração dos Recursos de Informação e Informática - SISP, obrigando sua validação nos portais do Governo Brasileiro (E-MAG, 2010).

A versão 3.0 do e-MAG foi elaborada com base na sua versão anterior, apoiando-se nas WCAG 2.0, e considerando as novas pesquisas na área de acessibilidade Web. Mesmo sendo baseada nas WCAG 2.0, as recomendações foram apoiadas considerando as necessidades locais, visando atender as prioridades brasileiras e mantendo-as coerentes com o que existe de mais atual no assunto. Nessa versão do e-MAG,, não se encontram os níveis de conformidade A, AA e AAA, conforme é visto nas WCAG, pois considerando que o Modelo de Acessibilidade de Governo Eletrônico foi focado para páginas do Governo, não são permitidas exceções com relação ao cumprimento das recomendações (E-MAG, 2010).

As 45 recomendações do e-MAG são categorizadas por Marcação, Comportamento (DOM), Conteúdo/Informação, Apresentação/Design, Multimídia e Formulário, e as recomendações são associadas, em suas descrições, aos critérios de Sucesso das WCAG 2.0, nas quais foram baseadas. As recomendações, divididas por suas categorias, são listadas a seguir:

\section{Marcação}

Recomendação 1 - Respeitar os padrões de desenvolvimento Web.

Recomendação 2 - Organizar o código HTML de forma lógica e semântica.

Recomendação 3 - Utilizar corretamente os níveis de cabeçalho. 
Recomendação 4 - Ordenar de forma lógica e intuitiva a leitura e tabulação.

Recomendação 5 - Disponibilizar todas as funções da página via teclado.

Recomendação 6 - Fornecer âncoras para ir direto a um bloco de conteúdo.

Recomendação 7 - Não utilizar tabelas para diagramação.

Recomendação 8 - Separar links adjacentes.

Recomendação 9 - Não abrir novas instâncias sem a solicitação do usuário.

\section{Comportamento (DOM)}

Recomendação 10 - Garantir que os objetos programáveis sejam acessíveis.

Recomendação 11 - Não criar páginas com atualização automática periódica.

Recomendação 12 - Não utilizar redirecionamento automático de páginas.

Recomendação 13 - Fornecer alternativa para modificar limite de tempo.

Recomendação 14 - Não incluir situações com intermitência de tela.

Recomendação 15 - Assegurar o controle do usuário sobre as alterações temporais do conteúdo.

\section{Conteúdo/Informação}

Recomendação 16 - Identificar o idioma principal da página.

Recomendação 17 - Oferecer um título descritivo e informativo à página.

Recomendação 18 - Disponibilizar informação sobre a localização do usuário na página.

Recomendação 19 - Descrever links clara e sucintamente.

Recomendação 20 - Fornecer alternativa em texto para as imagens do sítio.

Recomendação 21 - Fornecer alternativa em texto para as zonas ativas de mapa de imagem.

Recomendação 22 - Disponibilizar documentos em formatos acessíveis.

Recomendação 23 - Em tabelas, utilizar títulos e resumos de forma apropriada.

Recomendação 24 - Associar células de dados às células de cabeçalho em uma tabela.

Recomendação 25 - Garantir a leitura e compreensão das informações.

Recomendação 26 - Disponibilizar uma explicação para siglas, abreviaturas e palavras incomuns.

Recomendação 27 - Informar mudança de idioma no conteúdo. 


\section{Apresentação/Design}

Recomendação 28 - Oferecer contraste mínimo entre plano de fundo e primeiro plano.

Recomendação 29 - Não utilizar apenas cor ou outras características sensoriais para diferenciar elementos.

Recomendação 30 - Permitir redimensionamento de texto sem perda de funcionalidade.

Recomendação 31 - Dividir as áreas de informação.

Recomendação 32 - Possibilitar que o elemento com foco seja visualmente evidente.

\section{Multimídia}

Recomendação 33 - Fornecer alternativa para vídeo.

Recomendação 34 - Fornecer alternativa para áudio.

Recomendação 35 - Oferecer audiodescrição para vídeo pré-gravado.

Recomendação 36 - Fornecer controle de áudio para som.

Recomendação 37 - Fornecer controle de animação.

\section{Formulário}

Recomendação 38 - Fornecer alternativa em texto para os botões de imagem de formulários.

Recomendação 39 - Associar etiquetas aos seus campos.

Recomendação 40 - Estabelecer uma ordem lógica de navegação.

Recomendação 41 - Não provocar automaticamente alteração no contexto.

Recomendação 42 - Fornecer instruções para entrada de dados.

Recomendação 43 - Identificar e descrever erros de entrada de dados.

Recomendação 44 - Agrupar campos de formulário.

Recomendação 45 - Fornecer captcha ${ }^{6}$ humano.

Na próxima seção a usabilidade é abordada, com as heurísticas de Nielsen e as diretrizes HHS.

\footnotetext{
${ }^{6}$ Um teste de desafio cognitivo, para identificar interação humana. É utilizado como ferramenta anti-spam.
} 


\subsection{Usabilidade Web e suas diretrizes}

Usabilidade é definida pela facilidade de um usuário dispor de um serviço oferecido pela aplicação. NIELSEN (2003a) é um dos mais conhecidos pesquisadores e defensores da usabilidade Web e define usabilidade como um atributo de qualidade que avalia quão fáceis as interfaces de usuário são. Em contrapartida, QUESENBERY (2002) disse que os “5 Es de usabilidade” (the 5 Es of usability) provêm a definição mais robusta: effectiveness, efficiency, engaging, error tolerant e easy to learn, ou seja, a eficácia, eficiência, a condição de ser atraente, tolerante a erro e de fácil aprendizado.

A definição formalizada pela ISO/IEC 9421, estabelecida pela Organização Internacional de Normalização, afirma que: "Usabilidade é uma medida da eficiência, eficácia e satisfação com que usuários específicos podem alcançar objetivos especificados em um determinado ambiente”. Desta maneira, diz-se que uma interface apresenta problema de usabilidade se um usuário ou grupo de usuários apresenta dificuldade ao realizar uma tarefa própria da aplicação, pela interface disponibilizada.

A avaliação de usabilidade por ferramentas semiautomáticas, em sua maioria, limita-se à aplicação de conformidade das regras de formalismo de linguagem e verificação de links quebrados, haja vista que uma análise ergonômica é conseguida mais facilmente a partir de testes priorizando a relação humana com a ferramenta. Não há um conjunto de critérios definitivo, padronizado, a fim de se obter usabilidade, contudo há diferentes conjuntos de critérios que colaboram neste sentido.

Alguns exemplos de métricas, obtidos de MELODY (2001), que podem ser verificadas no intuito de se conseguir uma interface com maior grau de usabilidade, são listados a seguir:

- Desempenho do usuário nas tarefas: a partir da análise do comportamento do usuário em frente à aplicação, consegue-se delinear algumas métricas:

o Conclusão das tarefas: se o usuário conseguiu finalizar as tarefas completamente, parcialmente ou não chegou a sua conclusão. As duas últimas condições podem representar indícios de problemas na usabilidade; 
o Tempo na realização das tarefas: o longo período para conclusão de uma tarefa pode representar uma dificuldade em sua realização, indicando uma usabilidade falha;

o Erros: a ocorrência de erros pode representar ausência de informações que conduzam o usuário à conclusão assertiva da tarefa.

- Correspondência às recomendações: existem algumas recomendações que podem ser seguidas durante a criação das interfaces, tais como HHS Guidelines $^{7}$, ISO DIS 9241-1518 ${ }^{8}$ e JISC Guidelines ${ }^{9}$, a fim de evitar problemas conhecidos de usabilidade. Essas recomendações também podem ser utilizadas na avaliação das interfaces.

Dentre outras métricas, está a satisfação do usuário na utilização da aplicação e sua correspondência aos objetivos previamente definidos pelo usuário. Para a avaliação de usabilidade, podem também ser utilizadas as 10 Heurísticas de Nielsen, descritas a seguir.

\subsubsection{Heurísticas de Nielsen}

NIELSEN (1994), com base em 294 erros comuns encontrados em suas análises frequentes em sites, propôs 10 heurísticas de avaliação, a saber:

1. Visibilidade de status do sistema: a aplicação deve estar em comunicação ativa com o usuário, em cada tarefa, a fim de informá-lo sempre o que está acontecendo (feedback);

2. Relacionamento entre a interface do sistema e o mundo real: toda a comunicação do sistema deve ser contextualizada ao usuário, a fim de ser compreensível;

3. Liberdade e controle do usuário: as opções de ação devem ser facilitadas, a fim de que se um usuário se encontrar perdido ou em situações inesperadas, possa retornar a pontos anteriores;

\footnotetext{
${ }^{7}$ http://guidelines.usability.gov/

${ }^{8}$ http://www.iso.org/iso/iso_catalogue/catalogue_tc/catalogue_detail.htm?csnumber=37031

${ }^{9}$ http://www.jisc.ac.uk/uploaded_documents/JISC-HCIDesign-Study-Final.doc
} 
4. Consistência: não utilize expressões ou ícones diferentes para nomear uma mesma tarefa, é preciso utilizar um contexto linear para fácil compreensão;

5. Prevenção de erros: deve-se priorizar a prevenção de erros às boas mensagens de exibição deles;

6. Reconhecimento ao invés de lembrança: procure contextualizar toda situação ao usuário ao invés de remetê-lo a lembranças, antes de executar uma ação;

7. Flexibilidade e eficiência de uso: o sistema deve prover facilidade de uso para os usuários leigos, porém não deve comprometer a utilização por usuários avançados;

8. Estética e design minimalista: as informações transmitidas aos usuários devem ser precisas, simples e naturais. Deve-se evitar a utilização de textos e design exorbitantes, que transmitam mais do que o usuário necessita;

9. Ajuda ao usuário a reconhecer, diagnosticar e sanar erros: as mensagens de erro devem colaborar no sentido de contornar a situação, com redação simples e clara, a fim de não intimidar o usuário;

10. Ajuda e documentação: a interface deve fornecer uma documentação clara, de fácil acesso e a presença de ferramenta para buscas.

As 10 heurísticas se tornaram populares e são utilizadas até os dias atuais como métricas de avaliação e promoção de usabilidade, assim como as diversas recomendações representadas pelos conjuntos HHS Guidelines, ISO DIS 9241-151 e JISC Guidelines. O conjunto HHS Guidelines é apresentado na próxima subseção.

\subsubsection{HHS Guidelines}

HHS é o termo conhecido para as diretrizes de usabilidade que foram criadas pelo Departamento de Saúde e Serviços Humanos dos Estados Unidos, em parceria com a Administração de Serviços Gerais dos Estados Unidos. Essas diretrizes surgiram de um esforço no sentido de identificar abordagens baseadas em pesquisas que resultem em sites altamente ágeis e fáceis de usar, sendo particularmente relevantes para concepção de sites orientados à informação. Elas podem ser aplicadas em todo o amplo espectro de sites, 
orientando sobre uma ampla gama de questões de design e comunicação na Web, no sentido de contribuir para a tomada de decisões certas já no início do desenvolvimento, reduzindo a possibilidade de erros, que podem se tornar caros (HHS, 2006).

Desde a sua introdução, em 2003, as diretrizes têm sido amplamente utilizadas por agências governamentais e do setor privado, implementadas no currículo escolar e traduzidas em várias línguas estrangeiras. Os autores encorajam todos os órgãos do governo dos Estados Unidos a usarem estas orientações para contribuir com uma visão centrada no cidadão e orientada a resultados (HHS, 2006).

As diretrizes são classificadas quanto a sua “importância relativa” para o sucesso de um site e à "força de evidência". Tais métricas foram obtidas pela contribuição de designers Web profissionais, especialistas em usabilidade e pesquisadores acadêmicos, visando contribuir com o desenvolvedor a identificar quais diretrizes apresentam maior impacto sobre o sucesso de sua aplicação (HHS, 2006).

Para determinar a "importância relativa” de cada diretriz, 16 revisores externos foram recrutados. Metade do conjunto desses revisores foi formada por Web designers e a outra metade por especialistas em usabilidade. Cada revisor avaliou as diretrizes, uma a uma, e preencheu suas classificações, com base na questão: “Quão importante é esta diretriz para o sucesso de um site?”. Aquelas diretrizes que foram classificadas como tendo pequena importância para o sucesso de um site foram eliminadas (HHS, 2006).

Para gerar uma classificação de “força de evidência” para as diretrizes, um grupo de oito pesquisadores de usabilidade, praticantes e autores foram recrutados. Esses revisores eram pesquisadores com doutorado, pares de revisores com experiência e conhecedores do projeto experimental. Eles construíram um conjunto de critérios para julgar a força da evidência para cada diretriz, posteriormente utilizado como a escala de “força de evidência” (HHS, 2006).

Os critérios empregados para gerar a estimativa de "força da evidência" são mostrados a seguir, por ordem de maior para menor:

\section{- 5 - Forte apoio à pesquisa}

o provas cumulativas e atraentes, baseadas em pesquisas;

o pelo menos um estudo formal, rigoroso com validade contextual; 
o sem descobertas baseadas em pesquisas conflitantes conhecidas;

o a opinião dos especialistas concordam com a pesquisa.

\section{- 4 - Moderado apoio à pesquisa}

o evidências baseadas em pesquisas cumulativas;

o pode ou não pode estar em conflito com base em resultados de pesquisa;

o opinião de especialistas;

o tendem a concordar com a pesquisa, e

o parece haver um consenso na construção.

\section{- 3 - Fraco apoio à pesquisa}

o evidências baseadas em pesquisas limitadas;

o conflitantes descobertas baseadas em pesquisas podem existir e/ou

o existe um acordo misto de opiniões de especialistas.

- 2 - Forte apoio da opinião de especialistas

o nenhuma evidência baseada em pesquisa;

o os especialistas tendem a concordar, apesar de não haver um consenso;

o apoiam múltiplas opiniões de especialistas em livros didáticos, guias de estilos, etc. e

o geralmente aceitas como "melhores práticas" ou refletem o "estado da arte".

- 1 - Fraco apoio da opinião de especialistas

o nenhuma evidência baseada em pesquisa e

o opiniões de especialistas limitadas ou conflitantes.

As diretrizes compõem o livro Research-Based Web Design \& Usability Guidelines e formam um total de 209, divididas em 18 capítulos, listados a seguir: 


\section{Quadro 1: Capítulos do livro de usabilidade (HHS) ${ }^{10}$}

\begin{tabular}{|c|c|}
\hline 1. Processo de Design e Avaliação & 10. Links \\
\hline 2. Otimizando a Experiência do Usuário & 11. Aparência do Texto \\
\hline 3. Acessibilidade & 12. Listas \\
\hline 4. Hardware e Software & 13. Controles Baseados na Tela \\
\hline 5. A Página Principal & 14. Gráficos, Imagens e Multimídia \\
\hline 6. Layout da Página & 15. Escrita Conteúdo Web \\
\hline 7. Navegação & 16. Organização de Conteúdo \\
\hline 8. Rolagem e Paginação & 17. Busca \\
\hline 9. Cabeçalhos, Títulos e Rótulos & 18. Teste de Usabilidade \\
\hline
\end{tabular}

Considerando acessibilidade e usabilidade, a questão atual, e assunto da próxima seção, está dedicada a discutir sobre a relação envolvida entre esses dois conceitos, ressaltando se existe um complemento ou um trade-off ao buscar atendê-los em um mesmo projeto.

\subsection{Acessibilidade versus Usabilidade}

ALEXANDER (2006) relata que o verdadeiro desafio em design de interface de usuário não é decidir qual o conjunto de orientações deve sobrepujar os outros, mas na compreensão dos requisitos de usuários de diferentes grupos e, também, para encontrar uma maneira de projetar uma interface de usuário que corresponda às suas necessidades.

Praticantes e estudiosos em acessibilidade e usabilidade podem e devem colaborar. Cada um desses grupos tem conhecimento e habilidades que, impreterivelmente, beneficiarão o trabalho do outro.

De acordo com a pesquisa apresentada por ALEXANDER (2006), os praticantes de acessibilidade devem adotar as práticas dos seus congêneres de usabilidade por:

10 Research-Based Web Design \& Usability Guidelines (URL: http://www.usability.gov/how-to-andtools/resources/guidelines_book.pdf) 
- Assegurar que os requisitos de design acessível são explicitados nos requisitos da fase de projetos, identificando os usuários com deficiência como parte do público-alvo para o projeto;

- Envolver-se em pesquisa de design, além de saber aplicar design acessível;

- Adotar e defender métodos centrados no usuário em todas as fases dos seus projetos de design.

Em contrapartida, baseado na mesma pesquisa (ALEXANDER, 2006), os profissionais de usabilidade devem adotar as práticas dos seus congêneres de acessibilidade, conforme segue:

- Tornar os clientes cientes do crescimento do mercado de design acessível;

- Educar os clientes sobre os benefícios do design acessível e utilizar sua responsabilidade profissional para aconselhar os clientes da legislação pertinente, neste caso, os requisitos da legislação contra discriminação;

- Tornar visíveis os utilizadores com deficiência, incluindo-os em suas práticas de design.

Da mesma forma, alguns estudiosos colaboram com afirmações controversas sobre a relação existente entre os dois conceitos. Para THATCHER (2006), problemas de acessibilidade afetam tão somente usuários com alguma disfunção, enquanto PETRIE e KHEIR (2007) afirmam que, frequentemente, usuários com deficiências, assim como os sem deficiências, encontram os mesmos problemas, porém são afetados diferentemente.

A partir de um experimento com a finalidade de identificar a relação entre acessibilidade e usabilidade, SLATIN e LEWIS (2002) observaram que para usuários com deficiência, a aplicação de diretivas de acessibilidade melhora significativamente a experiência nos sites, enquanto que usuários sem deficiências não visualizam diferenças significativas. Tais resultados contribuem para a afirmação de que a acessibilidade não necessariamente aumenta a usabilidade.

ROCHA (2013) defende que a acessibilidade é prejudicada também por questões de usabilidade não cobertas e expõe resultados de seu experimento que reforçam essa afirmação, como: 
- A ausência de padronização dos termos e de expressões diferentes usadas para se referir ao mesmo conteúdo, contradiz a quarta heurística de usabilidade de Nielsen, que prega a consistência e a padronização. Visualmente, é fácil identificar que diferentes termos estão sendo usados para se referir ao mesmo elemento, porém apenas ouvir o rótulo de um objeto ou elemento em um site, por meio do leitor de telas, e saber do que se trata é mais difícil;

- A falta de conformidade com a sétima heurística de usabilidade de BASTIEN e SCAPIN (1993), “Ações Mínimas”, também foi observada. Quanto mais ações forem necessárias para atingir um objetivo, maior a probabilidade de ocorrer erros por parte do usuário;

- Alguns elementos, apesar de dificultar o acesso à informação desejada, não impedem ou comprometem o usuário de executar a função, como, por exemplo, o relato de um usuário com deficiência visual na pesquisa de ROCHA (2013), que ao digitar as primeiras letras em uma lista de opções esperava filtrar mais rapidamente os resultados. Essa questão pode ser vista como uma violação à sétima heurística de usabilidade de NIELSEN (1994): “Flexibilidade e eficiência de uso”. Segundo tal heurística, o sistema deve ser fácil para usuários leigos, mas também deve ser flexível o bastante para usuários avançados, que optam por usar teclas de atalho e outras estratégias para agilizar a navegação.

Considerando as relações envolvidas nos estudos realizados, para se compreender as visões dos desenvolvedores e pesquisadores sobre os problemas de acessibilidade e usabilidade durante as avaliações e, contribuir na identificação da correlação entre os dois conceitos, é importante que haja uma documentação clara que relate os motivos e as tomadas de decisões desses atores. Neste contexto, o registro das discussões e razões sobre cada decisão (denominada Design Rationale) foram considerados para o apoio proposto neste trabalho, conforme visto adiante. 


\subsection{Design Rationale}

Durante os processos de desenvolvimento de software, muitas decisões de projeto não são explicitamente documentadas com sua lógica (TYREE e AKERMAN, 2005), e assim, o conhecimento associado às tomadas de decisão é muitas vezes perdido.

GRUBBER e RUSSEL (1991), MORAN e CARROL (1996) definem Design Rationale como referência ao raciocínio e à descrição que justificam o projeto e as escolhas de estruturas sobre demais alternativas. Somada a essa definição, MACLEAN et al. (1991) e LEE (1997) consideram que Design Rationale não inclui apenas a descrição do artefato em potencial, mas também as justificativas e alternativas das decisões sobre seu projeto, e as argumentações que levaram a elas.

O aprendizado do projeto como um todo e o auxílio aos projetistas para identificar questões, que de outra maneira poderiam passar despercebidas, são contribuições atribuídas ao uso de Design Rationale (HORNER e ATWOOD, 2006), assim como a colaboração na identificação de premissas inadequadas e na diminuição da tendência dos projetistas em não perceber alternativas possíveis em decisões importantes. Segundo DUTOIT et al. (2006), seu uso é empregado, principalmente, para promover a colaboração entre membros de equipe, facilitar a manutenção e o reuso, melhorar a qualidade dos artefatos e transferir conhecimentos.

A utilização do Design Rationale possibilita a criação de um vocabulário comum, a produção de artefatos mais completos em menor tempo, com menor esforço, a manutenção e evolução, garantindo a qualidade do design. Porém, CONKLIN e BURGESSYAKEMOVIC (1996), SHIPMAN e MCCALL (1997) e REGLI et al. (2000) indicam as limitações existentes que não contribuem com sua utilização na prática: as dificuldades dos desenvolvedores de recuperarem informações capturadas, a diferença entre informações que os desenvolvedores gostariam e as que o sistema permite registrar, a generalidade das ferramentas e a não contribuição para a progressão natural das atividades de projeto.

Embora o uso de Design Rationale seja reconhecido como um dos passos mais promissores durante o projeto de software e manutenção, seu uso tem enfrentado obstáculos, em particular no esforço de produzir e manter documentação adicional (LEE, 1997). Neste sentido, GORTON (2006) afirma que a geração de documentação da 
arquitetura é quase sempre uma boa ideia e que a dica é despender apenas o tempo suficiente para produzir a documentação que será útil para os stakeholders do projeto.

Alguns obstáculos foram apresentados por FALESSI et al.(2013), e incluem:

- Mau tempo e benefício atrasado. O período em que são realizadas as decisões de projeto muitas vezes é fundamental para o sucesso geral do mesmo. Pessoas envolvidas em decisões de design estão, geralmente, ocupadas tentando executar outras tarefas mais reconhecidas e essenciais, e para cumprir seus prazos relacionados. Em tais circunstâncias, a documentação é percebida como menos importante e, eventualmente, é desconsiderada;

- Previsibilidade a informação. Consumidores e produtores de Design Rationale muitas vezes são pessoas diferentes. As pessoas que são responsáveis pela evolução de um projeto de software geralmente não são os criadores originais. Por isso, o produtor precisa de documentação para prever quais informações os consumidores necessitarão no futuro. Como resultado, o produtor terá de documentar toda a informação que possa ser útil;

- Esforço exagerado. Existe o costume de se concentrar em maximizar os benefícios para o consumidor, em vez de minimizar o esforço do produtor. Isso resulta em um esforço substancial a ser gasto em atividades de documentação e manutenção. Essa sobrecarga pode ser minimizada, selecionando cuidadosamente os itens de informação do Design Rationale a serem capturados;

- Benefícios pouco claros. Os tomadores de decisão muitas vezes não sabem como o Design Rationale vai apoiar atividades específicas;

- Falta de motivação. A desmotivação pode surgir a partir da ausência de benefícios diretos ou falta de interesse pessoal. As pessoas encarregadas por documentar e manter artefatos de Design Rationale não estão muito motivadas, porque elas não se beneficiam diretamente do Design Rationale. Os especialistas podem não estar interessados em fazer seu valioso conhecimento explícito, pois podem perceber que ele seja um ativo. Em outras palavras, alguns especialistas podem não ver nenhuma vantagem clara em documentar Design Rationale; 
- Falta de maturidade. Somente algumas ferramentas estão disponíveis para apoiar o Design Rationale e a maioria delas são imaturas [BURGE e BROWN, 1998; CONKLIN e BEGEMAN, 1988; LEE e KRUCHTEN, 2007; JANSEN et al., 2008];

- Inconsistências potenciais. Design Rationale e os projetos devem ser mantidos atualizados e alinhados para evitar possíveis inconsistências quando o projeto for modificado ou quando as decisões mudarem.

A fim de amadurecer e mapear as contribuições no contexto dos conceitos envolvidos com esta pesquisa, realizou-se um levantamento dos trabalhos relacionados, assunto da próxima seção.

\subsection{Trabalhos relacionados}

Nesta seção são apresentados os trabalhos relacionados, em ordem cronológica, separados pelas categorias de acessibilidade, usabilidade e ambas. Os trabalhos foram resumidos de maneira a enfatizar as metodologias, métodos e técnicas para prover um desenvolvimento de aplicações Web, visando a acessibilidade, a usabilidade, ou mesmo, correlacionando os dois conceitos. Tal separação foi necessária, de maneira a obter resultados que aproximem o entendimento de como a acessibilidade e a usabilidade podem estar interligadas, seja de maneira complementar, com intersecções, ou representando um trade-off, no qual ao priorizar um conceito, o outro é prejudicado. A partir disso, buscou-se identificar a área estudada e justificar a pesquisa, através de trabalhos já validados.

\subsubsection{Acessibilidade}

Usuários que são cegos têm sua experiência em navegação dificultada em muitos sites que apresentam demasiado número de links ou hierarquias profundas. Eles são penalizados uma vez que a informação buscada está escondida em múltiplas camadas ou de maneiras indiretas. Nesses ambientes de hipertexto não lineares, onde muitas estruturas coexistem e evoluem, o desafio está em descobrir como os vários tópicos e unidades de informações evoluíram e como eles se relacionam. Isso requer mecanismos que possam, por exemplo, segmentar, enriquecer e anotar o conteúdo, e assim, facilitar a indexação, recuperação, ranking, e apresentação de unidades de informação apropriadas (ou segmentos) para o usuário (CANDAN et al., 2009). 
Nesse contexto, CANDAN et al. (2009) apresentam a abordagem Segment-enrichannotate (SEA), para adaptação de conteúdo digital, com o objetivo de melhorar a acessibilidade. O paradigma tem como base a segmentação, que está relacionada à extração de unidades de informação de páginas para a adaptação dinâmica; enriquecimento, que é a propagação de palavras chave relevantes entre as unidades de informação relacionadas, para permitir que elas, individualmente, sejam consideradas com o contexto apropriado e; anotação, que designa a marcação de unidades de informação com palavras chave descritivas (não diretamente disponíveis a partir do conteúdo) para o acesso a tarefas apoiadas e guiadas.

No sentido de validá-la, a abordagem foi instanciada na ferramenta iCare-Assistant, um sistema de apoio para ajudar estudantes cegos no acesso à Web e aos materiais do curso eletrônico. A partir de avaliações feitas pelos autores da pesquisa, envolvendo alunos cegos, identificou-se que a sobrecarga de navegação foi reduzida significativamente, permitindo que os usuários cegos pudessem acessar o sistema de cursos online de forma eficaz.

Desse modo, o conhecimento adquirido pela SEA pode ser utilizado na segmentação de conteúdo em unidades coerentes, para facilitar a indexação, recuperação e classificação, bem como para orientar os usuários através de segmentos que sejam relevantes para seus objetivos de navegação.

Em outro estudo na área de acessibilidade, KOUTSABASIS et al. (2010) afirmam que a utilização de ferramentas e especificações para assegurar a acessibilidade na Web requerem conhecimentos específicos e, frequentemente, os desenvolvedores necessitam de orientações técnicas. A partir disso, foi proposta uma metodologia simples e prática, na visão dos autores, para avaliação da acessibilidade Web, e como as ferramentas e especificações podem ser utilizadas.

A metodologia proposta para alcançar a manutenção de acessibilidade consiste em: (a) identificação de necessidades dos utilizadores e criação de metas de acessibilidade; (b) avaliação de acessibilidade Web e processo de redesign e; (c) o estabelecimento e acompanhamento da política de acessibilidade.

Os mesmos autores defendem, ainda, uma abordagem prática para avaliação de acessibilidade Web, que fornece recomendações para os métodos e ferramentas a serem 
utilizados, assim como os processos de manutenção. Eles afirmam que essa abordagem é necessária para investigar o fato de que os desenvolvedores, com o atual conjunto de ferramentas de acessibilidade Web e especificações, necessitam de conhecimentos técnicos para a sua compreensão e aplicação.

Os dois trabalhos aqui expostos identificaram esforços no sentido de aprimorar a acessibilidade, tendo como público alvo os desenvolvedores, seja no desenvolvimento em aplicações com estruturas complexas ou na colaboração para manutenção da acessibilidade. Em seguida, os trabalhos envolvendo usabilidade são apresentados.

\subsubsection{Usabilidade}

No estudo em usabilidade realizado por FØLSTAD et al. (2012), identificou-se que a análise é uma parte fundamental da realização de avaliações de usabilidade e que, no entanto, ainda é pouco estudada de maneira sistemática. Neste sentido, falta orientação de como fazer as pesquisas apoiarem a análise dos desenvolvedores e perde-se a oportunidade da área acadêmica e do mercado contribuírem entre si, pois a análise de pesquisa acadêmica, incluindo ferramentas, formas e formatos estruturados, segundo os autores, não parece ter um impacto direto na prática.

A pesquisa tem por objetivo identificar práticas de análise e, consequentemente, gerar conhecimento sobre como os métodos e ferramentas baseadas em pesquisa apoiam tais práticas. Desta maneira, foram entrevistados 155 profissionais, considerando a análise na avaliação mais recente em usabilidade que eles fizeram, e a principal questão estudada foi: “Qual é o estado da arte, na prática, da análise de avaliação de usabilidade?”.

Dos resultados obtidos, os envolvidos na análise veem a necessidade de reforçar a confiabilidade da avaliação e, que as práticas de análise evoluem à medida que os desenvolvedores se adaptam às ferramentas e aos métodos adequados para as necessidades de seu contexto de avaliação.

Em particular, os resultados do presente estudo devem ser complementados com estudos observacionais e estudos de caso de análise real. A pesquisa de usabilidade pode fornecer contribuições valiosas para a evolução futura das práticas de análise. Entretanto, para que isso ocorra, é preciso um grau muito maior no sentido de direcionar os esforços de pesquisa às necessidades dos profissionais de usabilidade. 
O estudo aqui indicado contribuiu na identificação da problemática que consiste no avanço independente, no que concernem os âmbitos da pesquisa e da prática. Tal evidência favorece os esforços apresentados nesta dissertação, ao incluir desenvolvedores no estudo de caso, de maneira a validar o ambiente A4U, cujo foco é o próprio desenvolvedor.

A seguir, são discutidos os trabalhos que abordam os conceitos de acessibilidade e usabilidade, em paralelo, como apoio na identificação da relação entre eles.

\subsubsection{Acessibilidade e usabilidade}

O pesquisador WATTENBERG (2004) afirma que a boa experiência em acessibilidade e usabilidade só é adquirida, utilizando uma metodologia assistiva durante a implementação das diretrizes. Adicionalmente, o autor apresenta as recomendações WCAG como base de condução do desenvolvimento de aplicações acessíveis.

Nesse objetivo de se obter boa experiência em acessibilidade e usabilidade, como KOUTSABASIS et al. (2010), WATTENBERG (2004) também afirma que há falta de treinamento e compreensão, não só com relação às diretrizes, como também na utilização das ferramentas de avaliação, por parte dos designers de aplicações Web.

Com o objetivo de contribuir nessa compreensão por parte do designer, provendo métodos eficientes na descoberta e na apresentação dos problemas, o grupo Digital Media Access Group at the University of Dundee buscou, em vão, por uma ferramenta simples, pois as que encontraram não se enquadraram nessa necessidade. Há inúmeras combinações de tecnologias, atributos de design e aplicações para o mesmo método trabalhar em diferentes situações, tornando difícil a simplificação dessas questões, a fim de contribuir com seu entendimento.

O melhor método, apresentado e assim definido por WATTENBERG (2004), para avaliar a usabilidade e a acessibilidade de um produto, foi a partir da observação de seu uso por um diferente grupo de pessoas. Porém, há uma baixa adesão ao uso de tecnologias assistivas, pois os usuários com deficiências encontram dificuldades e há pouco esforço em se integrar essas tecnologias ao estilo de vida, ambiente social, à estrutura familiar e em atividades em comunidade dessa população. 
Como lacuna da área, WATTENBERG (2004) afirma que é necessário pesquisar como os usuários com deficiência utilizam e aprendem, enquanto usam as tecnologias assistivas.

Já em outro estudo, envolvendo a comparação de acessibilidade e usabilidade, PETRIE e KHEIR (2007) afirmam que os dois conceitos, raramente, são explicitamente analisados, quer no contexto Web ou em outros sistemas baseados em computadores. Os autores citam a ISO 9241, como uma definição precisa e amplamente aceita para representar usabilidade de produtos/websites. Ainda afirmam que os critérios de acessibilidade não estão tão claros quanto à validade e eficácia na experiência dos usuários com deficiências, pois as recomendações WCAG enfrentam dificuldades em relação a sua confiabilidade na usabilidade de pessoas com deficiência.

Como base nessa afirmação, os mesmos autores apresentam um estudo realizado em mais de 1.000 websites. Como resultado é apresentado que não foi encontrada nenhuma relação significativa entre a conformidade com as diretrizes WCAG e uma série de medidas de desempenho e satisfação do usuário por cinco diferentes categorias de pessoas com deficiência. O estudo aponta a questão de que as recomendações WCAG foram construídas com uma base fraca de estudos empíricos, o que resulta nesses problemas de confiabilidade e na eficácia das diretrizes, no papel de adequar o design da aplicação a todas as populações.

Contribuindo com a comparação entre os dois conceitos, THATCHER et al. (2003) afirmam que acessibilidade é um subconjunto de usabilidade e que, portanto, problemas relacionados à acessibilidade são problemas de usabilidade. Porém, os autores afirmam que problemas de usabilidade afetam a população em geral, enquanto os de acessibilidade priorizam os usuários com deficiência em relação aos outros usuários, garantindo uma relação complexa entre esses dois conceitos.

Nesse contexto, PETRIE e KHEIR (2007) afirmam que essa relação pode ser vista como três áreas distintas: problemas que afetam apenas pessoas com deficiências, chamada de "acessibilidade pura"; problemas que afetam apenas pessoas sem deficiências, chamada de “usabilidade pura” e problemas que afetam ambas as populações, chamada de “usabilidade universal”. 
Outro estudo envolvendo os dois conceitos foi feito por SEVILLA et al. (2007), que consideraram uma população com retardo mental, a fim de obter um estudo empírico relacionado com aplicações normais e adaptadas para essa população. Neste estudo foi observada a importância da adaptação das aplicações para as necessidades das diferentes populações de deficiência.

Neste sentido, os autores indicaram que é necessário estudar cada implicação cognitiva para relacionar critérios específicos no esforço de tornar as aplicações acessíveis a este público, com deficiência cognitiva.

No experimento realizado por eles, a usabilidade foi avaliada considerando um adendo de critérios, pela ISO-9241. Os critérios foram obtidos a partir da observação de eventos e foi apresentada uma fórmula para avaliação, a qual consiste na adição e subtração do número de eventos que foram codificados por observadores independentes. A partir desse experimento prático, observou-se que a avaliação de usabilidade e acessibilidade está intimamente ligada à observação na utilização da aplicação pela população que se deseja observar.

Já, considerando as deficiências visuais, ROCHA e LIMA (2010) apresentaram uma pesquisa sobre a relação entre acessibilidade e usabilidade de websites do governo brasileiro, para pessoas com deficiência visual e afirmaram que o número de sites com problemas de acessibilidade ainda é muito grande. Também relacionaram a usabilidade como diretamente ligada à acessibilidade, de maneira que ela seja prejudicada pelo baixo grau de conformidade de websites em acessibilidade.

O Governo Brasileiro aderiu, a partir do ano 2000, ao Governo Eletrônico (egovernment), fazendo uso das TICs e da Web para democratizar o acesso as suas informações e serviços. Entretanto, os resultados desta iniciativa são comprometidos pela exclusão digital, causada pelo acesso limitado às TICs, pelo analfabetismo digital e pela falta de acessibilidade dos websites.

O acesso à Web pelas pessoas com deficiência visual acontece através de tecnologias assistivas, softwares leitores de tela, capazes de ler o conteúdo exibido e transformá-lo em saída de áudio. Porém, para que esses leitores produzam resultados coerentes, que colaborem para o entendimento do conteúdo disponibilizado, o website precisa estar de acordo com recomendações de acessibilidade, as quais podem ser avaliadas por 
validadores automáticos, entretanto, apenas eles, não identificam todos os problemas em uma interface.

Para investigar a correlação de acessibilidade e usabilidade de websites para pessoas com deficiências visuais, o estudo considerou as seguintes etapas: (i) avaliação de acessibilidade; (ii) capacitação dos usuários e (iii) avaliação da usabilidade. No estudo, a metodologia para a pesquisa foi apresentada, porém não demonstrou os resultados finais, que deveriam apontar o relacionamento direto entre os dois conceitos. Assim, uma pesquisa adicional foi realizada, adicionando a dissertação de mestrado de ROCHA (2013) como trabalho relacionado. Esta, por sua vez, apresentou informações mais precisas e resultados mais concretos.

Na dissertação de mestrado de ROCHA (2013), a partir de entrevistas, o autor identificou o que por ele já era esperado, que a acessibilidade na Web depende do relacionamento entre os diversos componentes, porém os participantes, ainda que indiretamente, perceberam e mencionaram a interdependência, sobretudo entre os navegadores e os leitores de tela. Outro resultado que surpreendeu o autor foi que os usuários com deficiência visual apontaram problemas de usabilidade como problemas de acessibilidade.

Os relatos da influência da experiência e das habilidades dos usuários já eram esperados na pesquisa, assim como os relatos de violações às diretrizes de acessibilidade, ainda que sem referências diretas a elas, posto que a maioria dos participantes as desconheciam, mas enfrentaram barreiras de acessibilidade quando elas não eram seguidas.

Considerando os estudos aqui apresentados, pode-se observar que a relação entre acessibilidade e usabilidade ainda é uma questão em aberto, o que contribui para a justificativa desta pesquisa de mestrado. Adiante, são tecidas as considerações finais do capítulo.

\subsection{Considerações finais}

Os conceitos aqui descritos e os dados observados por meio dos trabalhos relacionados foram utilizados como base para o desenvolvimento da pesquisa e projeto do Ambiente para Análise de Avaliações de Acessibilidade e Usabilidade na Web (A4U). 
A necessidade de exploração dos conceitos deste Capítulo ficou clara, para auxiliar a definição dos termos incorporados ao projeto do ambiente $\mathrm{A} 4 \mathrm{U}$, pois deste modo pode-se contribuir com uma maior elucidação dos contrastes, assim como buscar identificar os pontos de convergência dos conceitos.

Como resultado da pesquisa por trabalhos relacionados, foi possível encontrar um embasamento importante nos critérios de usabilidade, a partir de sua padronização na ISO 9241. Por meio destes trabalhos, foi possível também confirmar que as técnicas para obtenção de acessibilidade em produtos e serviços estão atreladas firmemente na observação da população a ser atingida, a partir da adaptabilidade do conteúdo.

Mesmo que em outros estudos, autores refiram-se à acessibilidade como um subconjunto da usabilidade, há casos em que um conceito sobrevive separadamente, ou seja, pessoas com deficiência acabam sendo menos favorecidas na experiência de navegação e interação com aplicações Web. Assim, foi possível observar que a relação desses conceitos ainda é pouco explicitamente analisada.

Existem limitações de confiabilidade, tanto em consideração às diretrizes, como às ferramentas de avaliação, e a compreensão das diretrizes não é objetiva. Somada a essas limitações, foi possível observar a lacuna que existe entre o ambiente acadêmico e o profissional, no que tange à avaliação de usabilidade e o apelo em se direcionar as pesquisas ao contexto profissional.

No âmbito dos problemas identificados na área, a pesquisa aqui descrita, por meio da dissertação, prioriza identificar a relação entre acessibilidade e usabilidade, focando o desenvolvedor, como usuário final.

Adiante, são estudados os métodos de avaliação de acessibilidade, usabilidade e as ferramentas semiautomáticas que contribuem nesse sentido. 



\section{AVALIAÇÃO DE ACESSIBILIDADE E USABILIDADE WEB}

\subsection{Considerações iniciais}

Para uma avaliação de acessibilidade e usabilidade efetiva é necessária a combinação de inúmeras disciplinas e habilidades, a partir de técnicas de conformidade com padrões, diretrizes, além do acompanhamento por usuários finais durante o processo. Neste capítulo são apresentados métodos de avaliação e ferramentas para os dois conceitos. Adicionalmente é apresentada a linguagem de relatório EARL, que algumas dessas ferramentas utilizam para representar os resultados das avaliações de maneira a se tornarem legíveis por máquina e, assim, possibilitar que funcionalidades possam ser construídas por esforços computacionais, tais como a visão comparativa entre inúmeros relatórios, que será almejada no projeto aqui exposto.

\subsection{Avaliação de acessibilidade Web}

Avaliação de acessibilidade corresponde a uma avaliação sobre quão bem aplicações Web podem ser utilizadas por pessoas com deficiências e como são consideradas em diferentes cenários. Segundo ABOU-ZAHRA (2008), a avaliação de acessibilidade Web pode estar presente em algumas situações, como segue: 
- Um desenvolvedor Web visando verificar a conformidade do desenvolvimento com padrões de acessibilidade requeridos;

- Um autor de conteúdo Web investigando a conformidade da informação publicada com os padrões, com o objetivo de ser compreendida pelo maior número de pessoas;

- Um webdesigner que quer aprender questões de acessibilidade em design, a fim de usá-las no processo de criação;

- Um gerente de projetos Web que deseja explorar algumas questões potenciais de acessibilidade no site, para estimar seu desempenho;

- Uma organização que almeja determinar se suas páginas Web se encontram nos padrões, para garantir acessibilidade ou encontrar falhas neste quesito.

As avaliações não devem se limitar à fase de produção, pois a geração de conteúdo após o produto ter sido liberado contribui com a aplicação em geral, podendo incorporar falhas aos padrões e diretrizes estabelecidos durante o desenvolvimento. Exemplos para essa questão são as postagens em blogs, fóruns, wikis, ou em ferramentas interativas; enquanto a ferramenta segue os requisitos de acessibilidade, o conteúdo inserido pode conter problemas, como a falta da descrição textual em imagens. Desta maneira, as avaliações devem acompanhar todo o período de existência das aplicações, a fim de garantir procedência nos requisitos. Por depender de uma avaliação contínua ou restrição regrada na inserção e alteração desse conteúdo, o desafio em se garantir acessibilidade torna-se ainda maior.

\subsection{Avaliação de usabilidade Web}

Os métodos utilizados para avaliação de usabilidade consistem, em grande parte, em testes empíricos com a participação de usuários e testes de inspeção. Os testes de inspeção são efetuados a partir da análise por um especialista (expert), em busca de incompatibilidades que afetem a usabilidade na aplicação, como acontece na avaliação heurística.

A participação de usuários se dá por meio de questionários ou pelo acompanhamento do usuário na execução de tarefas na aplicação. Nas subseções a seguir, são apresentados os métodos mais utilizados para avaliação de usabilidade. 


\subsubsection{Avaliação heurística}

A avaliação heurística foi criada por NIELSEN e MOLICH (NIELSEN, 2003b) e é caracterizada pela inspeção sistemática da aplicação em relação à usabilidade. Um avaliador avalia a interface de uma aplicação Web, a partir dos princípios de usabilidade denominados heurísticas, as quais foram apresentadas na Seção 2.3.1.

Para aumentar a confiabilidade das avaliações e evitar vieses, é indicado que mais de um avaliador faça a verificação, individualmente, para então, ao final, apresentarem seus resultados e contrastarem com as outras avaliações. NIELSEN indica o número de 3 a 5 avaliadores como o de maior custo/benefício (NIELSEN, 2003b).

Durante a avaliação, que tem duração média de uma a duas horas, o próprio avaliador pode tomar nota ou este papel pode ser atribuído a um observador, que acompanha as interações do avaliador e pode colaborar respondendo as dúvidas a respeito do protótipo. Após todos os avaliadores terem finalizado suas obrigações, os observadores têm a tarefa de reunir os resultados, que são representados em uma lista de problemas, bem como os princípios violados e as respectivas intensidades de gravidade de usabilidade, em um único documento.

\subsubsection{Ensaios de interação}

Neste método de inspeção, usuários são assistidos a partir de filmagem. O ideal é que a interação na tela do computador seja focalizada em conjunto com o rosto do usuário. Para tanto, existem salas especiais que contribuem nessa tarefa, até com a utilização de espelhos falsos (LEEDY e ORMROD, 2005).

Os usuários podem seguir um cenário de teste, previamente moldado pelos avaliadores, ou interagir livremente na aplicação, sendo instruídos a falarem a todo tempo o que estão pensando, estimulados por perguntas dos avaliadores.

É importante contribuir com um ambiente propício para evitar transtornos aos usuários, enfatizando que não são eles os principais alvos de teste, mas sim a aplicação, e os mesmos devem estar colaborando por vontade própria. 


\subsubsection{Inspeção de recomendações ergonômicas}

As recomendações ergonômicas, ou guidelines e checklists, foram elaboradas como resultados de pesquisas em psicologia, ciência cognitiva e ergonomia. Estas podem ser utilizadas na concepção e avaliação da interface (WINCKLER e PIMENTA, 2002).

A inspeção consiste em um ou mais avaliadores analisando, minuciosamente, se as recomendações são seguidas na utilização da aplicação. Considerando a difícil aplicabilidade de algumas recomendações, ferramentas automáticas não podem contribuir e a avaliação pode exigir um conhecimento profundo por parte do condutor. Para tanto, podem ser utilizadas as checklists, que são pontos objetivos a serem seguidos e que requerem menos esforços para compreensão e identificação. Porém, por serem muito objetivas, podem ser constituídas por centenas de pontos a serem averiguados, contribuindo significativamente com o tédio dos inspetores.

Alguns conjuntos de recomendações, já mencionados (Seção 2.3), são: HHS Guidelines, ISO DIS 9241-151 e JISC Guidelines.

\subsubsection{Questionários}

Questionários são utilizados para obter informações a respeito da experiência do usuário com a aplicação, a fim de identificar seu grau de satisfação durante o uso, traçar o perfil, tanto funcional como pessoal de cada usuário, além de contribuir na identificação de problemas encontrados, documentando-os nesse formato. Os questionários possibilitam a análise simultânea em inúmeros locais distintos (BRANDÃO e MORAES, 2006).

Estes podem ser disponibilizados online, possibilitando atingir um número elevado de usuários. Porém, os resultados precisam ser cuidadosamente analisados, a fim de se obter uma conclusão a respeito da usabilidade. Isso pode despender um tempo elevado e um grande esforço por parte do avaliador.

\subsection{Testes utilizados nas avaliações}

Existem diferentes tipos de teste que, se combinados, podem garantir a qualidade de software, considerando acessibilidade e usabilidade. Em geral, há três técnicas básicas de teste: o teste automático, feito através de ferramentas de avaliação sem a interação humana, o teste manual, feito através da percepção humana (geralmente por pessoas habilitadas na 
área) e, também, o teste pelo usuário final, ou seja, o usuário com deficiência, no caso de se estar testando a acessibilidade da aplicação (HARPER e YESILADA, 2008).

\subsubsection{Testes automáticos}

Os testes automáticos avaliam apenas conceitos bem definidos, de uma lista de diretrizes referente aos padrões de acessibilidade e usabilidade. Existe uma limitação computacional nesta técnica de avaliação, já que, por exemplo, em imagens é custoso verificar o contraste de cor entre o conteúdo principal e o plano de fundo, pois identificar o cenário automaticamente é difícil (WebAIM, 2013d).

Os testes automáticos podem ser diferenciados em:

- Avaliação sintática: o teste analisa a estrutura sintática do conteúdo, por exemplo: se tags de imagem "IMG" contém o atributo " $A L T$ ", para conteúdo textual descritivo;

- Análise heurística: baseada nas heurísticas de Nielsen, são examinados a semântica no conteúdo Web, o leiaute, a linguagem natural e de marcação. Esta avaliação colabora com alertas para avaliadores humanos, a fim de aumentar a validade e confirmar o potencial das questões de usabilidade e acessibilidade;

- Análise indicativa: estima a performance das aplicações Web, a partir de métricas estatísticas e técnicas de perfis. São bastante úteis para avaliações em grande escala.

\subsubsection{Testes manuais}

Embora os testes semiautomáticos sejam de grande importância para identificar falhas rapidamente, estes devem servir apenas como apoio na avaliação (PETRIE e KHEIR, 2007). A visão humana é essencial para validar os resultados apresentados e aprimorar a avaliação, haja vista que, em muitos casos, as ferramentas não são capazes de discernir entre a conformidade ou não de critérios ergonômicos (PETRIE e KHEIR, 2007).

Para diferentes situações, são necessários distintos perfis ou a combinação entre eles: 
- Avaliações por leigos: são executadas por leigos em contexto de acessibilidade e usabilidade, como também pelos autores de conteúdo, para verificar se o conteúdo multimídia é efetivo e correto ou se as imagens estão descritas pelo atributo “ $A L T$ ”, por exemplo;

- Avaliações por técnicos: frequentemente realizadas por desenvolvedores Web, com o mínimo de conhecimento em acessibilidade e usabilidade, ao verificarem se a linguagem de marcação segue as recomendações, a partir de ferramentas de avaliações;

- Avaliação por especialistas: são pessoas com profundo conhecimento da interação humana com questões relacionadas à Web, bem como as inúmeras questões de acessibilidade que devem ser interpretadas para se obter a usabilidade universal.

\subsubsection{Testes pelo usuário}

Os testes realizados por usuários finais amplificam as avaliações e servem como complemento às duas técnicas já apresentadas (PETRIE e KHEIR, 2007). Usuários representantes das diversas categorias de gênero, idade ou deficiências são assistidos diante da utilização da ferramenta, a fim de encontrar comprometimento durante a execução de alguma tarefa disponibilizada pela aplicação.

Em qualquer teste que envolva usuários finais, é preciso classificar os perfis de cada um, relacionados às expertises, a fim de evitar conclusões precipitadas diante de dificuldades apresentadas por eles na utilização do site. Por exemplo, um usuário inexperiente na utilização de computador não deve representar gravidade em questões de usabilidade e acessibilidade, caso tenha dificuldades nas execuções das tarefas, em seus primeiros acessos.

\subsection{Ferramentas de avaliação}

Existem inúmeras ferramentas semiautomáticas para, a partir de conjuntos de critérios, avaliarem aplicações Web (VANDERDONCKT et al., 2004). No estudo aqui exposto, o foco será as que tratem acessibilidade e usabilidade. Considerando a estagnação do 
conteúdo que lista as principais ferramentas de avaliação pelo W3C desde $2006^{11}$, faz-se necessário um maior aprofundamento na pesquisa, a fim de se obter ferramentas que tenham sido criadas desde então. Aqui se entende por semiautomática, a ferramenta que necessita de interação humana para concretizar a avaliação.

\subsubsection{Ferramentas para avaliação de acessibilidade}

Os objetivos da catalogação, aqui realizada, foram, além de comparar as funcionalidades presentes em cada aplicação, verificar a existência de softwares de avaliação que utilizem os critérios do W3C em sua última versão, mas que também habilitassem a representação dos resultados na linguagem EARL.

No primeiro momento são apresentados os quadros descritivos de cada ferramenta, a fim de sumarizar suas características e identificar rapidamente os benefícios de cada uma. Em seguida as ferramentas são relacionadas a partir da avaliação do portal do governo do Estado de São Paulo. A escolha pelo portal foi devido à obrigatoriedade dos sites administrativos governamentais estarem de acordo com as recomendações de acessibilidade e-MAG, que é baseada nas WCAG 2.0 e pelo site estar bem posicionado no ranking de sites mais acessados do Brasil, com domínios governamentais, segundo a Alexa - The Web Information Company ${ }^{12}$, conforme já dito na Seção 1.4.

\section{I) Web Accessibility Test (TAW)}

Quadro 2: Quadro descritivo da ferramenta de avaliação de acessibilidade TAW

\begin{tabular}{|l|l|}
\hline Responsável: & Fundação CTIC \\
\hline Endereço: & http://www.tawdis.net/ \\
\hline Conjunto de critérios avaliados: & $\begin{array}{l}\text { WCAG } 1.0 \text { [Nível A, AA e AAA], WCAG 2.0 [Nível } \\
\text { A, AA e AAA] (Beta) e MobileOK (Beta) }\end{array}$ \\
\hline Idiomas: & Inglês, espanhol, galego, catalão \\
\hline Dados de entrada: & URL \\
\hline
\end{tabular}

\footnotetext{
${ }^{11}$ http://www.w3.org/WAI/ER/tools/complete

12 http://www.alexa.com
} 


\begin{tabular}{|l|l|}
\hline Output: & Relatório em HTML \\
\hline Licença de uso: & Freeware \\
\hline Disponibilidade: & Online e Desktop \\
\hline
\end{tabular}

No Quadro 2 são apresentadas as características da TAW, que faz uso dos dois conjuntos de critérios do W3C, porém se encontra em Beta com relação às diretrizes WCAG 2.0.

\section{II) Worldspace FireEyes}

Quadro 3: Quadro descritivo da ferramenta de avaliação de acessibilidade Worldspace FireEyes

\begin{tabular}{|l|l|}
\hline Responsável: & Deque System \\
\hline Endereço: & http://www.deque.com/products/fireeyes/ \\
\hline Conjunto de critérios avaliados: & $\begin{array}{l}\text { Conjunto de critérios avaliados: Section 508, WCAG } \\
1.0 \text { [Nível A, AA e AAA], WCAG 2.0 [Nível A e AA] }\end{array}$ \\
\hline Idioma: & Inglês \\
\hline Dados de entrada: & URL \\
\hline Output: & Relatório no plugin \\
\hline Licença de uso: & Freeware \\
\hline Disponibilidade: & Plugin para o navegador Firefox \\
\hline
\end{tabular}

Já, no Quadro 3, o plugin para o navegador Firefox, Worldspace FireEyes, é descrito. Nota-se, que, assim como a ferramenta anterior, possibilita a verificação de aplicações a partir dos dois conjuntos de critérios do W3C para acessibilidade. Entretanto, não contempla a avaliação a partir dos critérios com o nível de conformidade mais elevado, o AAA. Adicionalmente, viabiliza a análise a partir dos critérios da Section 508. 
III) Total Validator

Quadro 4: Quadro descritivo da ferramenta de avaliação de acessibilidade Total Validator

\begin{tabular}{|l|l|}
\hline Responsável: & Total Validator \\
\hline Endereço: & http://www.totalvalidator.com \\
\hline Conjunto de critérios avaliados: & $\begin{array}{l}\text { Section 508, WCAG 1.0 [Nível A, AA e AAA], WCAG } \\
2.0 \text { [Nível A, AA e AAA] }\end{array}$ \\
\hline Idioma: & Inglês \\
\hline Dados de entrada: & URL \\
\hline Output: & Relatório em HTML \\
\hline Licença de uso: & $\begin{array}{l}\text { Freeware para a versão básica e Shareware a versão } \\
\text { Pro }\end{array}$ \\
\hline Disponibilidade: & Desktop e extensão para navegadores Chrome e Firefox \\
\hline
\end{tabular}

Com relação à Total Validator, ferramenta apresentada no Quadro 4, além de suportar avaliações a partir das versões 1.0 e 2.0 das WCAG, também possibilita a validação a partir da Section 508. Ela pode ser encontrada na versão Desktop ou por meio de extensões dos navegadores Chrome e Firefox.

IV) Web Accessibility Assessment Tool (WaaT)

Quadro 5: Quadro descritivo da ferramenta de avaliação de acessibilidade WaaT

\begin{tabular}{|l|l|}
\hline Responsável: & CERTH/ITI \\
\hline Endereço: & http://www.accessible-project.eu/index.php/waat.html \\
\hline Conjunto de critérios avaliados: & WAI-ARIA, CSS e WCAG 2.0 [Nível A, AA e AAA] \\
\hline Idioma: & Inglês \\
\hline Dados de entrada: & URL \\
\hline
\end{tabular}




\begin{tabular}{|l|l|}
\hline Output: & Relatório em HTML, em PDF e em EARL \\
\hline Licença de uso: & Open Source \\
\hline Disponibilidade: & Desktop e online \\
\hline
\end{tabular}

Como destaque na ferramenta WaaT, apresentada no Quadro 5, pode-se observar a representação dos resultados na linguagem EARL.

V) AChecker

Quadro 6: Quadro descritivo da ferramenta de avaliação de acessibilidade AChecker

\begin{tabular}{|l|l|}
\hline Responsável: & Atutor - earning Management Tools \\
\hline Endereço: & http://atutor.ca/achecker/ \\
\hline Conjunto de critérios avaliados: & $\begin{array}{l}\text { Section 508, WCAG 1.0 [Nível A, AA e AAA], WCAG } \\
2.0 \text { [Nível A, AA e AAA] }\end{array}$ \\
\hline Idioma: & Inglês \\
\hline Dados de entrada: & URL \\
\hline Output: & Relatório em HTML, EARL \\
\hline Licença de uso: & Open Source \\
\hline Disponibilidade: & Online \\
\hline
\end{tabular}

Em similaridade com a ferramenta WaaT, a AChecker, descrita no Quadro 6, também reproduz os resultados em EARL. Outra característica importante é que, por ser implementada em PHP, pode ser facilmente integrada ao projeto do ambiente A4U, possibilitando a avaliação semiautomática pelo próprio ambiente.

\subsubsection{Relação entre as ferramentas}

Em virtude do conteúdo dinâmico do portal, é importante ressaltar que as avaliações, apresentadas nesta dissertação, aconteceram no dia 22 de fevereiro de 2014, de maneira que fosse avaliado o mesmo material para todas as análises. A avaliação foi 
dividida em três etapas, para cada ferramenta: I) a avaliação é feita considerando o nível de conformidade A das WCAG 2.0; II) a avaliação é feita considerando o nível de conformidade AA, que contempla também os critérios de sucesso do nível A e III) a avaliação é feita considerando o nível de conformidade AAA, que contempla também os níveis de conformidade AA e A.

Como exposição geral das características das ferramentas é apresentado o Quadro 7 a seguir, no qual têm-se especificados os níveis de conformidade dos dois conjuntos de diretrizes WCAG, a observância do conjunto de critérios Section 508, a obtenção de relatórios em EARL e a licença ao qual o software está atribuído.

Quadro 7: Resumo das características das ferramentas

\begin{tabular}{|c|c|c|c|c|c|c|c|c|c|}
\hline \multirow{2}{*}{ Ferramenta } & \multicolumn{3}{|c|}{ WCAG 1.0} & \multicolumn{3}{|c|}{ WCAG 2.0} & \multirow{2}{*}{ Section 508} & \multirow{2}{*}{ EARL } & \multirow{2}{*}{ Licença } \\
\hline & A & $\overline{\mathrm{AA}}$ & $\overline{\text { AAA }}$ & A & $\overline{\mathrm{AA}}$ & $\overline{\mathrm{AAA}}$ & & & \\
\hline Web Accessibility Test (TAW) & $\mathrm{X}$ & $\mathrm{X}$ & $\mathrm{X}$ & $\mathrm{x}$ & $\mathrm{x}$ & $\mathrm{x}$ & & & Freeware \\
\hline Worldspace FireEyes & $\mathrm{x}$ & $\mathrm{x}$ & $\mathrm{x}$ & $\mathrm{x}$ & $\mathrm{x}$ & & $\mathrm{x}$ & & Freeware \\
\hline Total Validator & $\mathrm{x}$ & $\mathrm{x}$ & $\mathrm{X}$ & $\mathrm{x}$ & $\mathrm{x}$ & $\mathrm{x}$ & $\mathrm{x}$ & & Freeware \\
\hline Web Accessibility Assessment Tool (WaaT) & & & & $\mathrm{x}$ & $\mathrm{x}$ & $\mathrm{X}$ & & $\mathrm{x}$ & Open source \\
\hline AChecker & $x$ & $x$ & $x$ & $x$ & $x$ & $x$ & $x$ & $x$ & Open source \\
\hline
\end{tabular}

A TAW apresenta uma interface limpa e de fácil compreensão, conforme se pode verificar na Figura 2. A data de execução da avaliação considera a configuração de hora do servidor e, na interface, um thumbnail da tela do conteúdo sendo avaliado é apresentado. As tecnologias HTML e CSS são obrigatoriamente avaliadas em conjunto com a acessibilidade, quanto a sua sintaxe, podendo estender, opcionalmente, à sintaxe da linguagem JavaScript.

Em primeiro momento, uma tela resumida dos resultados da avaliação é exibida, porém a ferramenta disponibiliza a opção para detalhar os resultados da avaliação. No conteúdo resumido, a ferramenta realça as limitações pelos princípios de acessibilidade das WCAG, categorizando-os por problemas efetivos, advertências que requerem esforço humano e não revisados, que necessitam de atenção total do avaliador humano, pois a ferramenta não pode verificar. 


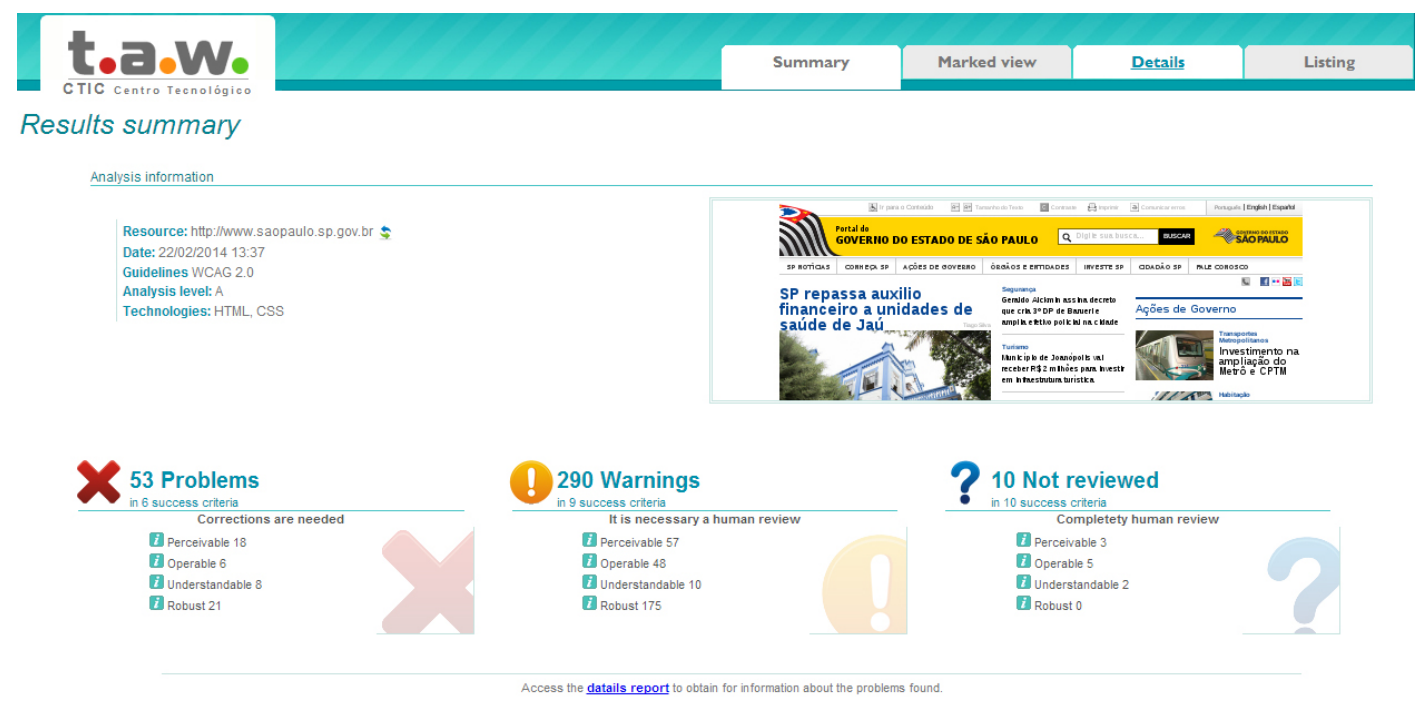

Figura 2: Tela representativa da ferramenta TAW

A avaliação realizada pela TAW resultou em 53 problemas, 290 advertências e 10 não revisados, totalizando 29 critérios de sucesso afetados. Desses, 15 são cobertos por problemas e/ou advertências. A ferramenta não disponibiliza página personalizada para impressão.

A Worldspace FireEyes, por sua vez, é uma extensão integrada ao add-on FireBug, do navegador da Mozilla, Firefox. Sua utilização está condicionada ao cadastro no site da companhia.

A interface da extensão, exibida na Figura 3, não é intuitiva, mas existe a comunicação com o servidor no qual seu cadastro está associado, podendo carregar o relatório, visualizá-lo e interagir com ele a partir da interface Web, que se mostra mais amigável.

As opções de avaliação são diversas, incluindo a opção de se avaliar os critérios da Section $508^{13}$, elementos WAI-ARIA, conteúdo PDF e Flash, estendendo-se à avaliação de conteúdos dinâmicos, a partir de eventos de mouse, teclado e mudança de foco. Nenhuma documentação de apoio foi encontrada para identificar o que é avaliado, por exemplo, no conteúdo PDF e em Flash.

\footnotetext{
${ }^{13}$ http://www.hhs.gov/web/508/
} 


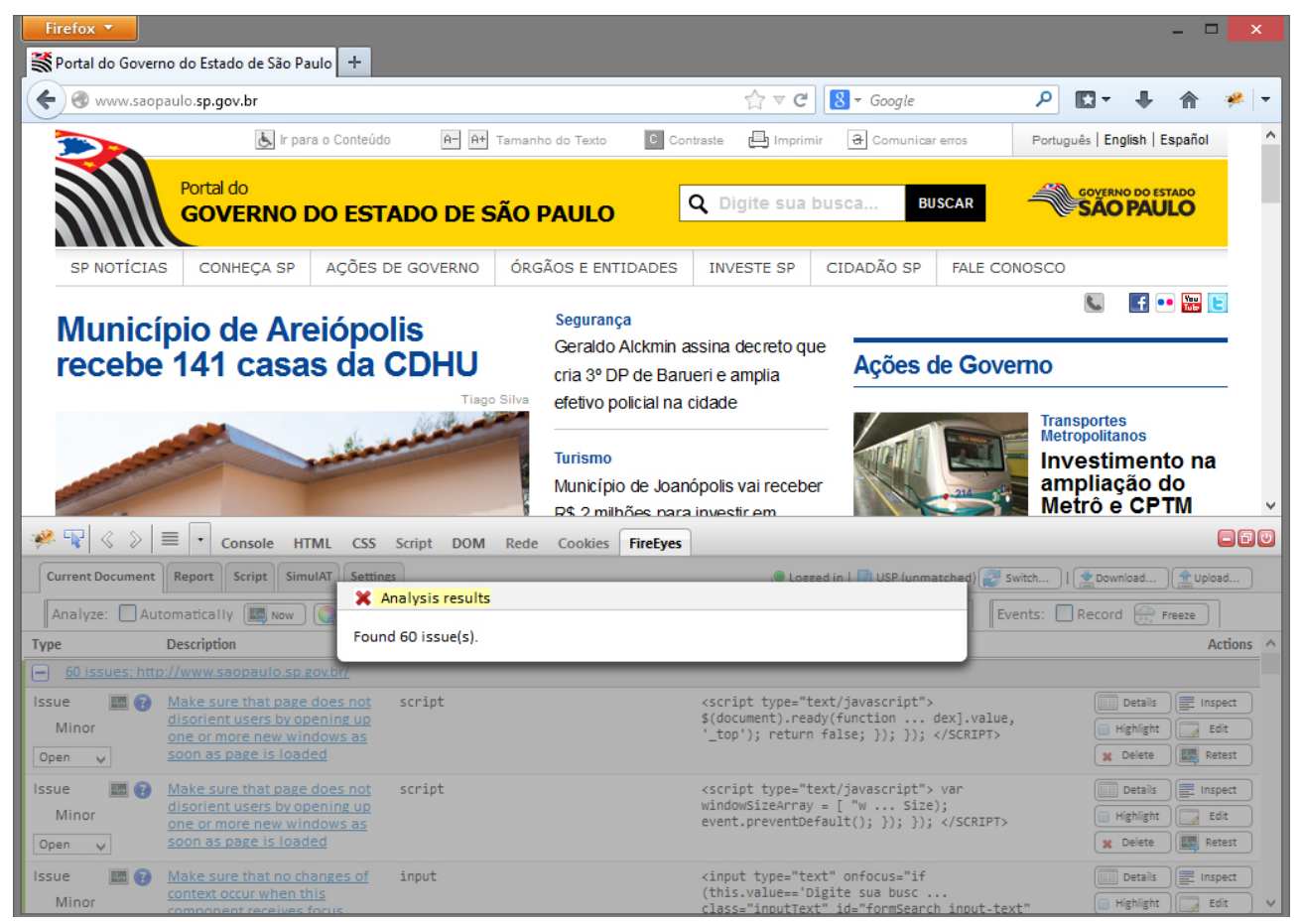

Figura 3: Tela representativa da ferramenta Worldspace FireEyes

A avaliação realizada pela Worldspace FireEyes resultou em 60 questões, atingindo 8 critérios de sucesso das WCAG 2.0 como problemas efetivos e três critérios necessitando avaliação manual. Desses, apenas um não foi coberto pelos problemas efetivos.

A outra ferramenta aqui pesquisada foi a Total Validator, que apresenta uma interface bastante amigável, conforme indicado na Figura 4. Sua versão básica, gratuita, apresenta muitas opções bloqueadas, porém atende o objetivo principal da pesquisa, validando páginas pelos critérios das WCAG 2.0. A ferramenta também avalia a sintaxe HTML e verifica se existem links quebrados. Os resultados são gerados em uma página HTML. Houve problema na instalação da versão para Windows, uma vez que a mesma não é compatível com a versão 7 do Java. 


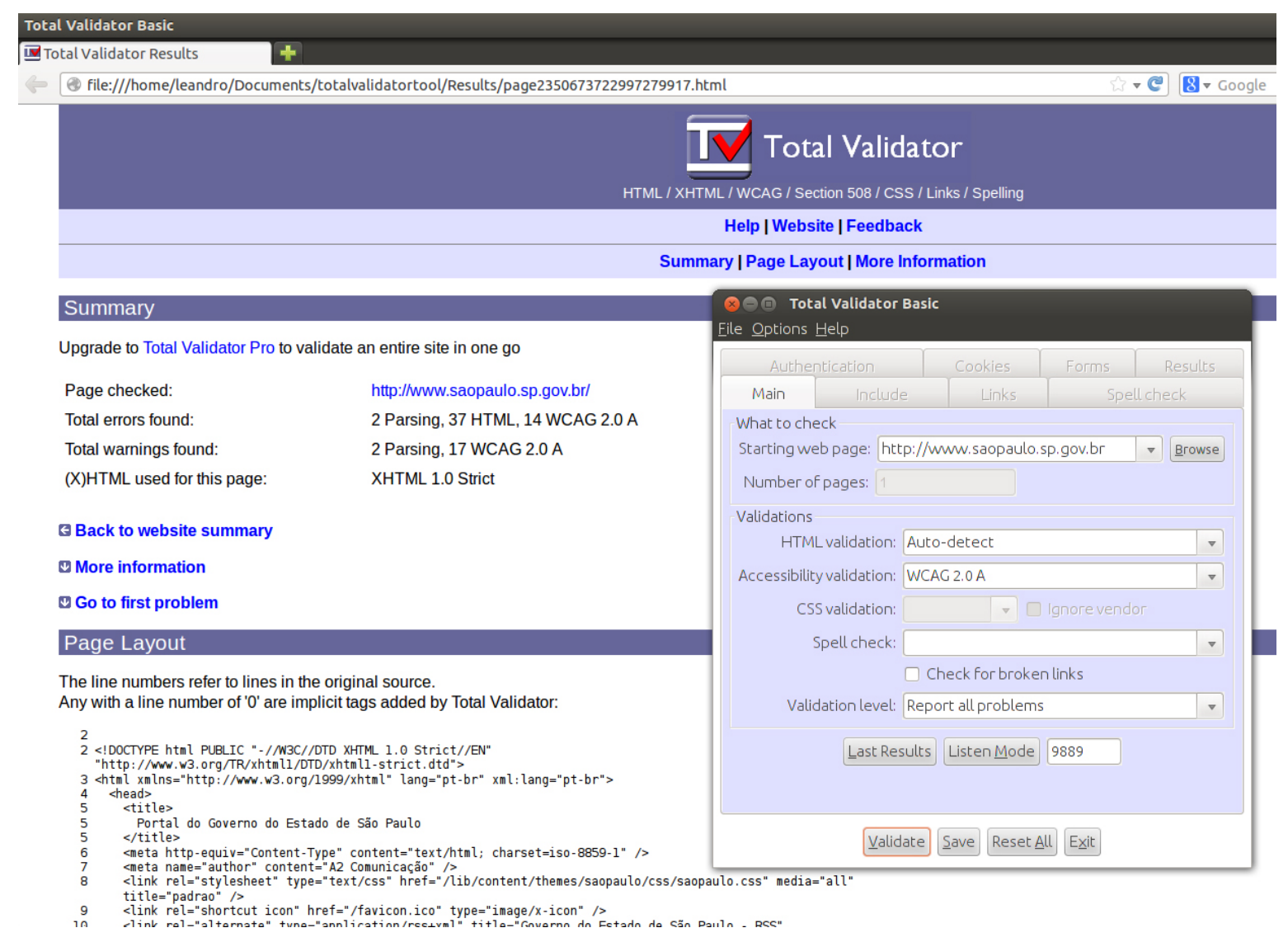

Figura 4: Tela representativa da ferramenta Total Validator

A avaliação pela Total Validator retornou 16 erros efetivos e 17 alertas para verificação manual, atingindo 7 critérios de sucesso por erros e 5 por alertas, sendo que 4, dos 5, já são cobertos pelos problemas.

A WaaT, posteriormente avaliada, também apresenta uma interface de fácil compreensão, exibida na Figura 5. Em sua versão gratuita, conforme as demais ferramentas, avalia apenas uma página do site. Além dos critérios de acessibilidade das WCAG 2.0, a ferramenta também avalia quanto à conformidade da Accessible Rich Internet Applications (WAI-ARIA). Seu relatório pode ser salvo em PDF, em EARL ou $\mathrm{RDF} / \mathrm{XML}$. Por fim, o software exibe a porcentagem de cobertura do site sobre as recomendações de acessibilidade testadas. 


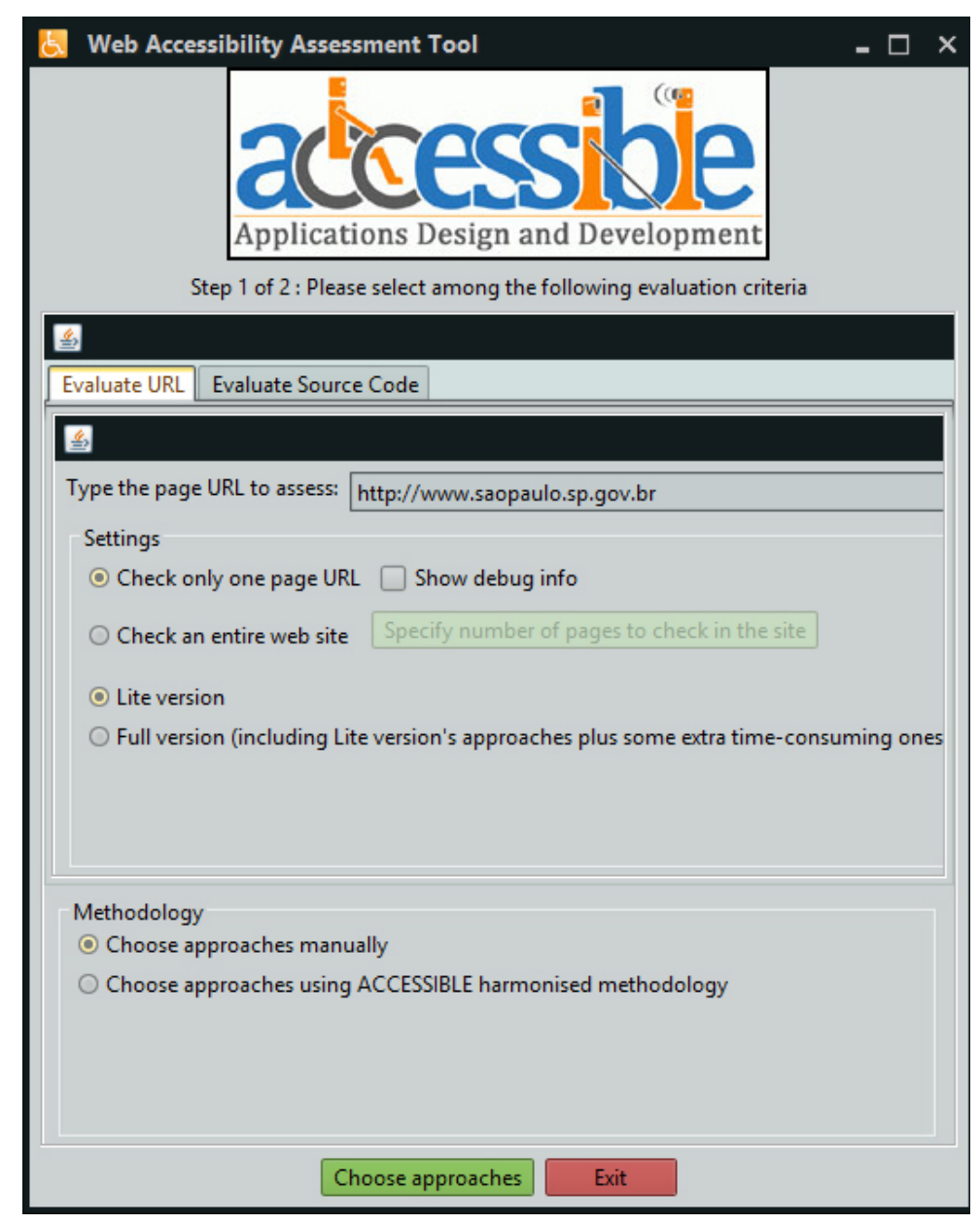

Figura 5: Tela representativa da ferramenta WaaT

Na avaliação para o nível de conformidade A, a ferramenta WaaT exibiu 46 erros efetivos e 64 alertas de necessidade de verificação manual, por especialistas. Apenas um Critério de sucesso foi atingido pelos problemas encontrados, enquanto outros 5 foram relacionados aos alertas.

Por fim, a ferramenta AChecker foi utilizada para a avaliação do portal. Esta apresenta interface intuitiva, conforme se pode ver na Figura 6, implementa as recomendações de acessibilidade das WCAG 2.0 e possibilita a validação da sintaxe do HTML e do CSS. O resultado é categorizado em:

I) Problemas conhecidos: são problemas que foram identificados com certeza de serem barreiras de acessibilidade;

II) Prováveis problemas: são problemas que têm sido identificados como possíveis barreiras, porém requerem uma decisão humana e; 
III) Potenciais problemas: são problemas que o AChecker não pode identificar, que requerem uma decisão humana. A avaliação pode ser exportada para PDF, EARL, HTML e The Comma Separated Value (CSV).

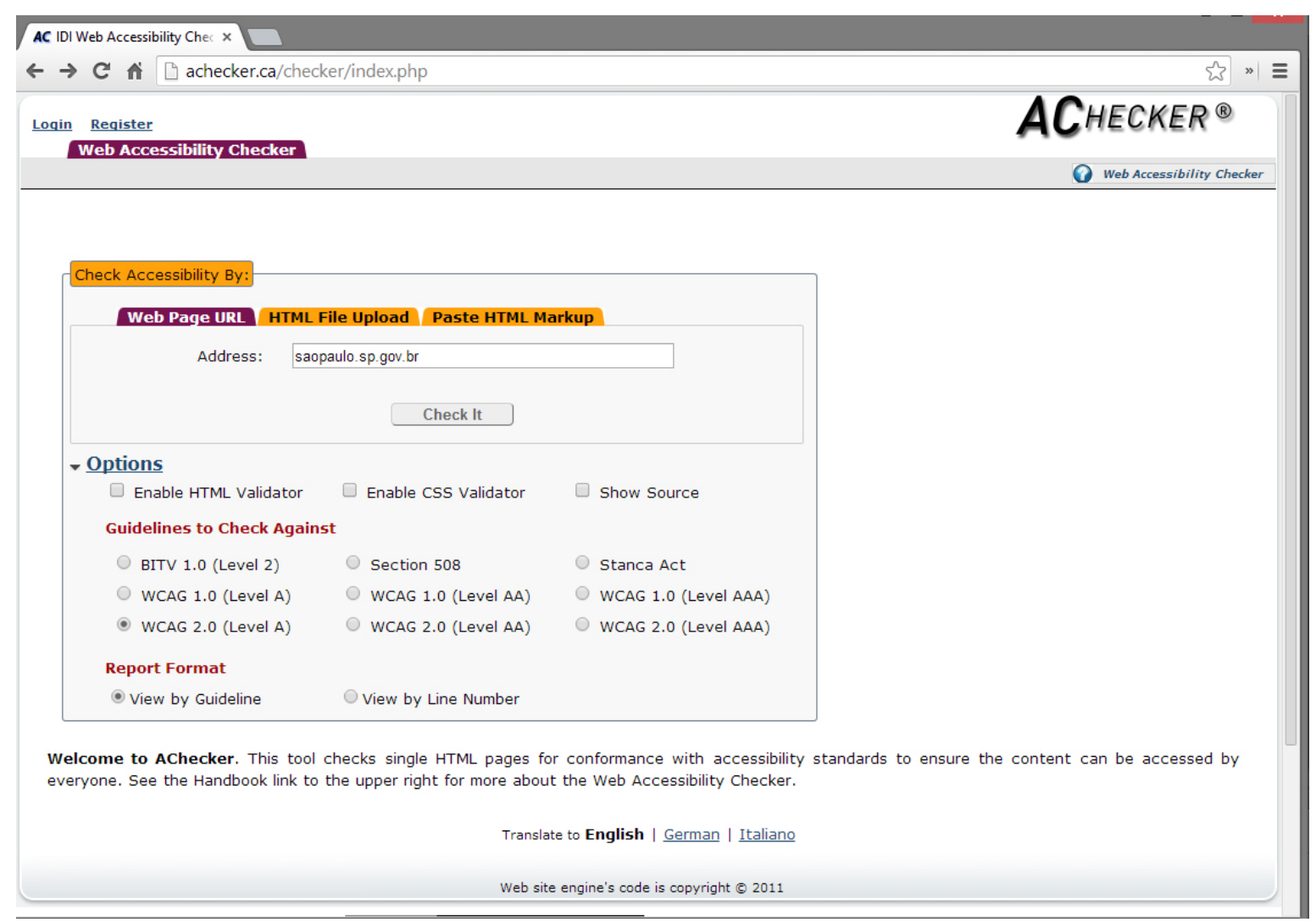

Figura 6: Tela representativa da ferramenta AChecker

Os resultados obtidos pela avaliação do AChecker foram 13 problemas conhecidos e 418 potenciais problemas, afetando 3 critérios de sucesso pelos problemas conhecidos e 11 critérios pelos potenciais problemas.

Relacionando os resultados obtidos em todas as avaliações e considerando o número de questões, constituído pela soma dos problemas encontrados e dos alertas de cada ferramenta, para os três níveis de conformidade, tem-se o gráfico exibido na Figura 7. 


\section{Problemas identificados}

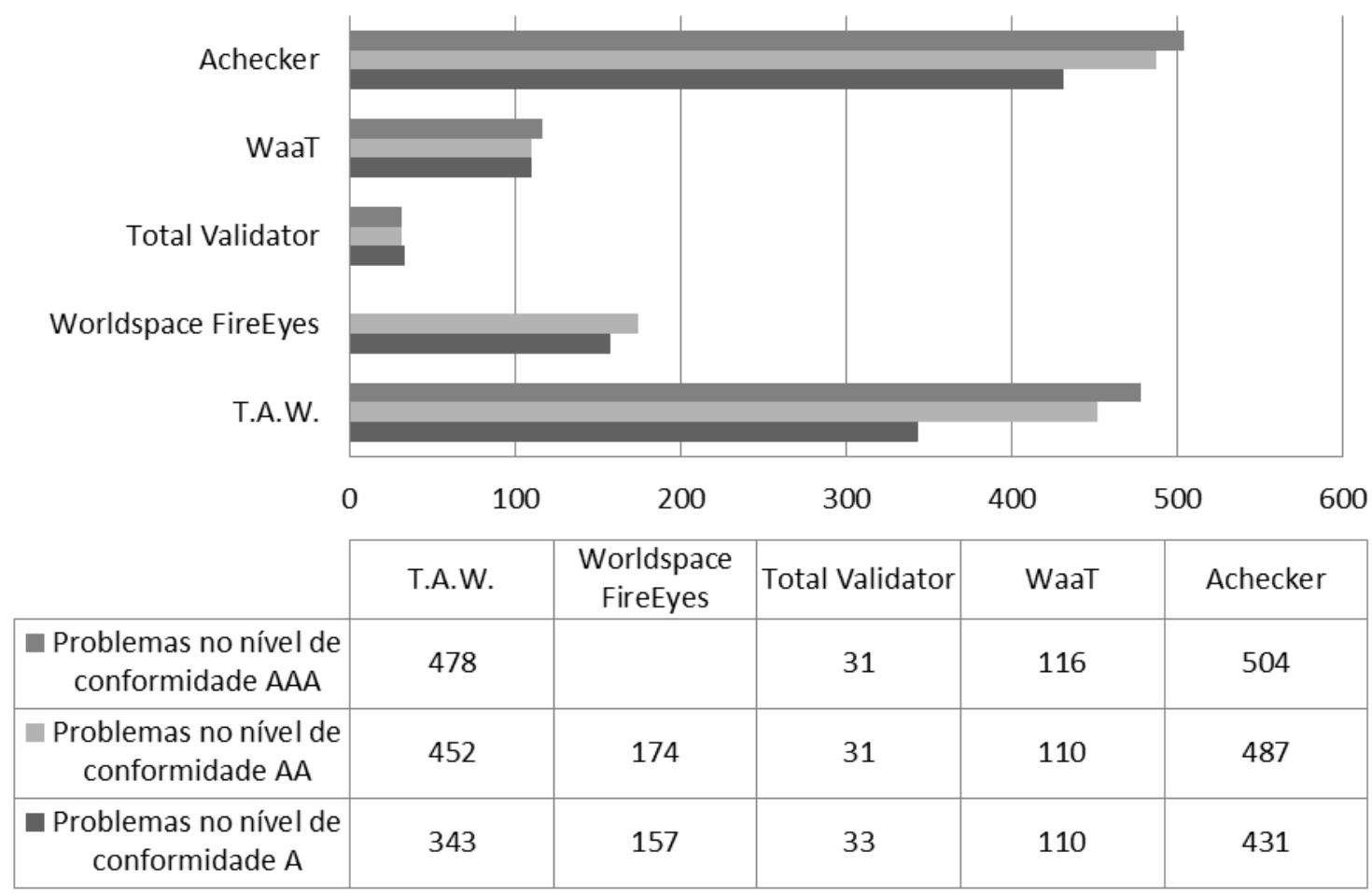

Figura 7: Gráfico representativo dos problemas encontrados nas avaliações, pelas diferentes ferramentas, considerando os três níveis de conformidade

Todas as ferramentas se mostraram bastante funcionais e com resultados expressivos, no que concerne a avaliação de acessibilidade a partir das WCAG 2.0. Entretanto, como se pode observar, no gráfico da Figura 7, a diferença entre o número de questões exibidas pelas cinco ferramentas é marcante, o que valoriza ainda mais a avaliação manual, uma vez que as ferramentas podem gerar resultados de falso positivo, falso negativo, ou mesmo não qualificar problemas por limitações técnicas.

Na avaliação utilizando a WaaT foi observado uma inconsistência, pois ao considerar que o nível de conformidade A está contido no conjunto do nível de conformidade AA, que por sua vez está contido no AAA, sua avaliação do nível A não deve ultrapassar o número de questões obtidas nas demais avaliações. A avaliação não simultânea provavelmente contribuiu para isso, pois o site é dinâmico, podendo ter alterado seu conteúdo no intervalo das avaliações. Em relação aos níveis de conformidade, apenas o Worldspace FireEyes não contempla os três níveis. 
Em análise aos resultados da avaliação, a ferramenta Web Accessibility Assessment Tool foi escolhida como sendo a que melhor se adequa aos requisitos do ambiente A4U. Tal conclusão foi baseada na análise das características das ferramentas encontradas e presenciando a dificuldade em se identificar softwares que atendam aos requisitos aqui explorados, que correspondem à utilização das WCAG 2.0 como diretrizes confrontadas com o elemento a ser avaliado e a produção de resultados na linguagem específica EARL, além da eficácia, boa apresentação e licença Open Source.

Neste sentido, a WaaT será sugerida aos usuários que queiram submeter avaliações no ambiente A4U, utilizando relatórios EARL. Adicionalmente, a ferramenta AChecker, por apresentar as mesmas características evidenciadas da WaaT e por ser implementada na linguagem PHP, foi incorporada no ambiente A4U desenvolvido, de modo que o objeto avaliado pelo usuário, seja analisado primeiramente pelo próprio ambiente A4U, através da integração com a AChecker.

Adiante são identificadas as ferramentas de usabilidade e a dificuldade em tornar automática a avaliação da percepção dos usuários.

\subsubsection{Ferramentas para avaliação de usabilidade}

Existem ferramentas de avaliação, assim como acontece em acessibilidade, para avaliar automaticamente a usabilidade em um site. Entretanto a maioria delas não faz análise ergonômica, que diz respeito à capacidade de trabalho perceptivo, cognitivo e motor do usuário, limitando-se à validação da sintaxe HTML. Como exemplo, pode-se citar o Boddy ${ }^{14}$, Dr. Watson ${ }^{15}$ e o Lift ${ }^{16}$.

Bobby: desenvolvida pela CAST, suporta inspeção automática e manual de recomendações de usabilidade e a compatibilidade entre navegadores. Pode ser utilizada em sua versão online ou Desktop.

Dr. Watson: desenvolvida pela Addy \& Associates, disponível apenas na versão online, verifica o código HTML, validando os links, tempo de download de páginas,

\footnotetext{
${ }^{14}$ http://www.cast.org/bobby

${ }^{15}$ http://watson.addy.com

${ }^{16}$ http://www.jimthatcher.com/lifteval.htm
} 
compatibilidade com ferramentas de busca, popularidade de links, número de palavras no contexto e correção ortográfica.

Lift: desenvolvida pela UsableNet, em sua versão online, permite desenvolvedores testarem e corrigirem problemas de acessibilidade e usabilidade, incluindo tempo de navegação, qualidades das imagens, etc.

Atualmente as ferramentas de avaliação de acessibilidade já compõem a análise de sintaxe de linguagem, contribuindo, neste sentido, para a usabilidade que outras ferramentas verificam, apoiada na conformidade da sintaxe. Deste modo, como ocorre em acessibilidade, o estudo humano voltado ao usuário final é mais que obrigatório no âmbito de avaliação de usabilidade.

Na próxima seção, a linguagem de relatórios EARL é descrita e exemplos de utilização de sua sintaxe são exibidos, de maneira a entender como os relatórios podem ser compreendidos pela máquina, e por sua vez, pelo ambiente proposto nesta dissertação.

\subsection{Evaluation And Report Language (EARL)}

A EARL é uma linguagem que define um vocabulário para expressar resultados de testes. Ela permite a qualquer pessoa, aplicação de software ou organização, representar resultados para qualquer teste de conteúdo contra um conjunto de critérios pré-definidos pelo avaliador e seu nível de cumprimento.

O conteúdo do teste é representado por um site, um usuário ou qualquer outra entidade. O conjunto de critérios é composto por orientações de acessibilidade, gramáticas formais ou outros modelos de requisitos. Assim, a EARL é flexível, considerando o contexto ao qual pode ser aplicada (W3C, 2011a).

A EARL não deve ser utilizada como um vocabulário compreensivo para descrever procedimentos de teste, critérios de teste ou requisitos de teste, mas sim, preferencialmente, para descrever resultados de teste. Um dos principais objetivos da EARL é ser um método de interoperabilidade de dados de armazenamento de avaliação. Por isso, é um requisito importante que ela seja simples o suficiente para ser aplicada com apenas um entendimento claro do modelo completo. 
Uma definição mais precisa para esta linguagem, conforme apresentada pelo W3C (2013a): a EARL é um framework baseado em Resource Description Framework (RDF) para gravação, transmissão e processamento de dados sobre as avaliações manual e automática de recursos. O objetivo do framework é fornecer formatos de avaliação e descrições genéricas que possam ser utilizadas em ferramentas genéricas de avaliação e de relatórios.

O Grupo de Trabalho Evaluation and Repair Tools Working Group (ERT WG) ${ }^{17}$ escolheu RDF, padrão do W3C para metadados, como o método de gravação das avaliações EARL e, como tal, criou uma normativa RDF Schema da linguagem. Uma das razões para sua escolha é não ser limitada quanto a eXtensible Markup Language (XML). A ordem e estrutura do código não são fixas e a linguagem possibilita mesclar elementos com outros vocabulários ou aumentar o vocabulário da EARL.

A EARL oferece flexibilidade para descrever os diferentes tipos de afirmações, como as realizadas pelas ferramentas automatizadas de testes, por avaliadores humanos, ou os feitos de ensaio sobre os casos de teste genérico ou específico.

ABOU-ZAHRA (2004) expõe alguns casos de uso para a EARL, os quais são:

\section{Combinar relatórios:}

Ferramentas de avaliação de acessibilidade Web variam muito em sua capacidade para testar pontos de verificação das WCAG. A EARL fornece um formato de dados normalizado que permite resultados do teste de avaliação totalmente automatizados, utilizando ferramentas semiautomáticas ou manuais, que podem ser coletados em um único repositório. Isso permite que revisores possam se integrar facilmente em diversos instrumentos de avaliação do processo de revisão e maximizar o número de validações que são avaliadas com o auxílio de ferramentas.

2. Comparar resultados de teste:

Permite que os resultados de testes, oferecidos por diferentes instrumentos de avaliação, possam ser comparados uns contra os outros. A partir de ferramentas para comparação, o revisor pode preferir resultados de

\footnotetext{
${ }^{17}$ http://www.w3.org/WAI/ER/
} 
aplicações específicas para determinadas diretrizes. Essas ferramentas também colaboram no sentido de minimizar as taxas de falsos negativos (não identificação de erros existentes) e falsos positivos (identificação incorreta).

\section{Ferramentas de avaliação comparativas:}

Considerando que os resultados dos testes são representados em um formato uniforme em EARL, esses podem ser comparados a um conjunto de resultados conhecidos como corretos.

\section{Mineração de dados:}

O formato padronizado incentiva a criação de ferramentas de processamento de dados para analisar, classificar, priorizar ou inferir os resultados dos testes de acordo com as diferentes políticas.

\section{Relatórios:}

Os resultados dos testes podem conter informações completas para diferentes utilizadores finais. A estrutura bem definida de EARL permite exibições personalizadas de dados, a partir do mesmo conjunto.

6. Integração com ferramentas de autoria:

Além de gerar relatórios com os resultados dos testes, as ferramentas de autoria poderiam utilizar a propriedade de legibilidade por máquina da EARL e contribuir com os desenvolvedores, para encontrar e corrigir erros a partir de mensagens adequadas.

\section{Interação com Web Browsers:}

Ferramentas de avaliação de acessibilidade podem avaliar conteúdos e fornecer resultados detalhados, a partir do browser, e esse, por sua vez, compara as preferências do usuário aos resultados de acessibilidade e readaptam o conteúdo de acordo.

\section{Integração em Máquinas de busca:}

Máquinas de busca podem fazer uso de relatórios EARL para responder as solicitações do usuário de acordo com suas preferências, similar aos navegadores Web. 
Outros usos: adicionalmente aos usos anteriormente descritos, com a EARL é possível contrastar avaliadores e ferramentas, avaliar o progresso com o tempo e encontrar o site mais acessível. Espera-se, assim, que a linguagem EARL possa ser a base para outros vocabulários.

Atualmente, a EARL está em fase de desenvolvimento, porém em junho de 2011 houve a última chamada para a revisão em estado Draft. Desde 2001 ela é suficiente para expressar 95\% das avaliações feitas pelas ferramentas semiautomáticas (W3C, 2011a).

Na sequência, é descrita a estrutura da sintaxe utilizada pela linguagem, com exemplos, desenvolvidos nesta dissertação, como resultados para facilitar a compreensão.

\subsubsection{Elementos da linguagem EARL}

Um relatório em EARL dispõe de um grupo de tags para identificar a ferramenta (Tool), a pessoa avaliadora (Person), o conteúdo avaliado (WebContent) e uma série de declarações (Assertor) que contêm o resultado de uma avaliação. Na Figura 8 é apresentado um caso de teste que respeita o critério meramente ilustrativo "testcase”. Este teste foi avaliado manualmente, ou seja, por inspeção do usuário avaliador, pois o modo da avaliação (moderdf) está atribuído como manual.

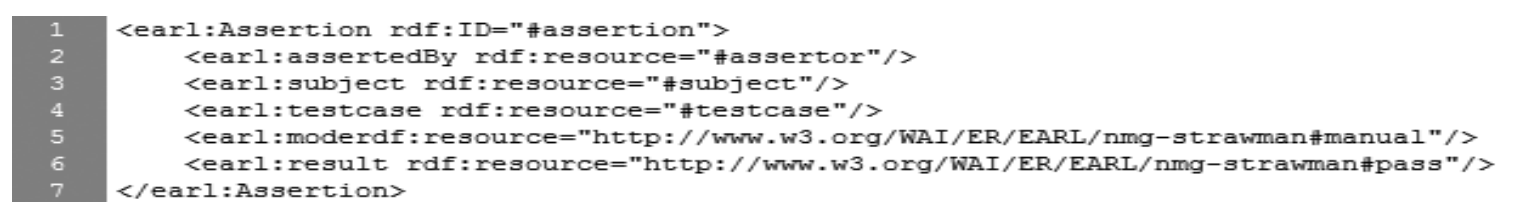

Figura 8: Exemplo de Assertion

Conforme apresentado na Figura 8, o assertor pode incluir informação sobre quem ou o que executa o teste (avaliadores humanos, ferramentas de análise de acessibilidade automáticas, ou combinação desses).

O test subject pode incluir conteúdo Web, como páginas Web, vídeos e applets; software, como ferramentas de autoria e usuários ou outras aplicações sendo testadas. O conteúdo da Figura 9 corresponde a um exemplo de subject utilizando Uniform Resource Identifier (URI) e a Figura 10, o conteúdo especificado.

1 <earl:subject rdf: resource="http://example.net/\#item"/>

Figura 9: Avaliação com URI 


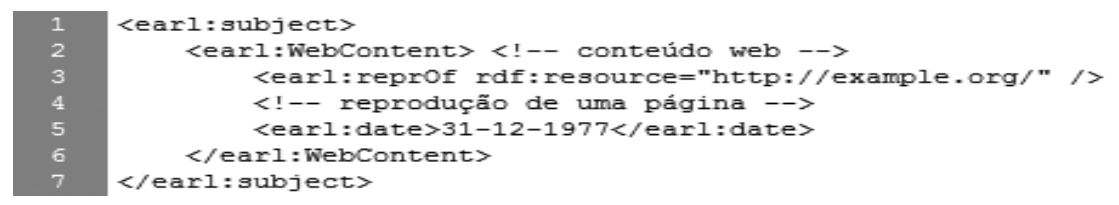

Figura 10: Exemplo de Subject

O test criterion (critério de teste) pode ser uma especificação, um conjunto de provas automáticas, uma validação de linguagem (HTML, CSS), os pontos de validação WCAG, etc. A EARL supõe que cada caso de referência tem um URI, como exibido na Figura 11.

1 <earl: testCase rdf: resource="http://example.org/tests\#number1"/>

Figura 11: URI dos critérios de teste

O test result indica o resultado do teste, que pode incluir informações contextuais, tais como mensagens de erro ou locais relevantes dentro do tema do ensaio. Como resultado da validação, tem-se:

- Pass - Passou;

- Fail - Falhou;

- $\quad$ NotTested - Não testado;

- CannotTell - Indefinido;

- NotApplicable - Não é aplicável.

A seguir, na Figura 12, é apresentado um teste em que a ferramenta não pode concluir com exatidão se o critério é ou não respeitado, atribuindo “CannotTell” ao resultado, ou seja, o teste é indefinido.

1 <earl:result rdf: type"http://www.w3.org/WAI/ER/EARL/nmg-strawman\#CannotTell"/>

Figura 12: Exemplo de validação indefinida

O mode, maneira de decidir o resultado, indica como se chegou ao resultado: inicialmente o modo é automático, já que os resultados são obtidos pela ferramenta.

- Manual: uma pessoa decide; 
- Automático: uma ferramenta decide;

- Por inferência - heurística: um resultado obtido por inferência a partir de outros resultados.

Na Figura 13 tem-se um exemplo de linha de código na EARL representando o resultado decidido automaticamente.

1 〈earl:mode rdf: resource="http://www.w3.org/WAI/ER/EARL/nmg-strawman\#automatic"/>

Figura 13: Exemplo do modo automático

O comentário (message) é útil como campo de texto livre para destacar impressões interessantes ou outra informação desejada pelo autor do relatório. Na Figura 14 é apresentado um exemplo de um comentário livre utilizando a opção message.

1 <earl:message>Nenhum comentário - foi bem avaliado.</earl:message>

Figura 14: Exemplo de comentário

Nas opções de configuração, para identificar quem fez avaliações manuais, são dispostos campos para introduzir o nome da pessoa avaliadora e seu endereço de e-mail.

Para ilustrar a utilização das estruturas explicadas individualmente, segue o modelo completo em EARL na Figura 15.

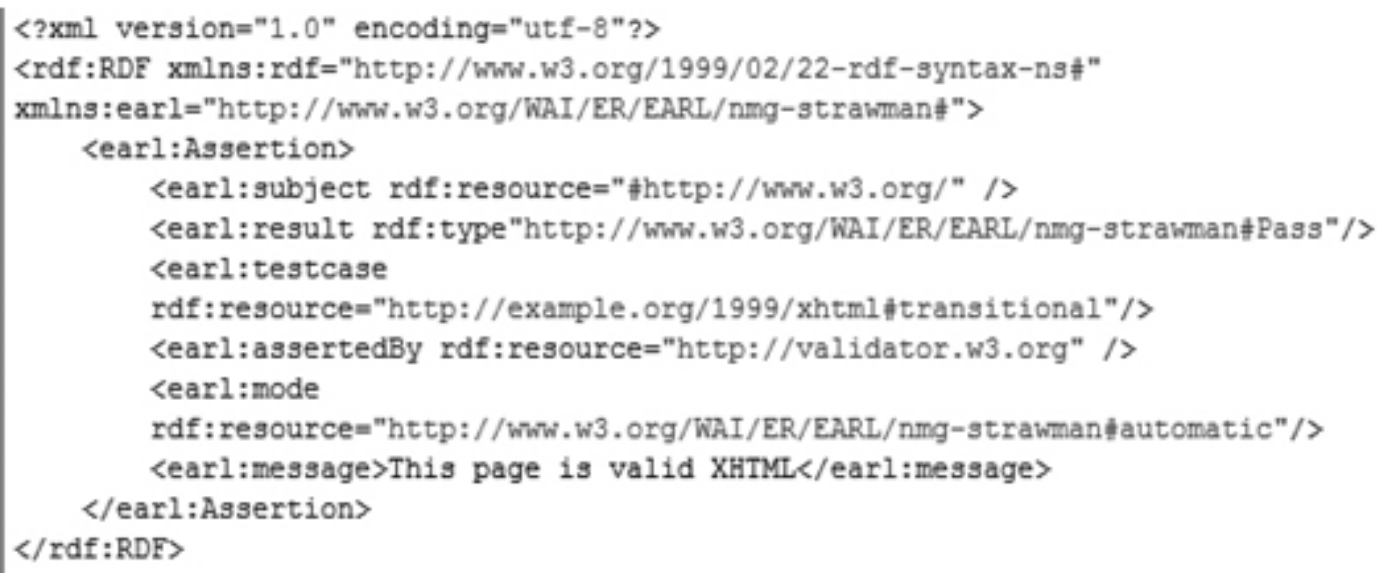

Figura 15: Exemplo completo

Verifica-se que a página http://www.w3.org/ foi testada pela ferramenta http://validator.w3.org/, a partir do critério chamado transitional, utilizado para ilustrar a explicação, e o resultado foi positivo (pass), ou seja, o conteúdo obedece ao critério verificado. 


\subsection{Considerações finais}

As avaliações, mesmo que conduzidas por ferramentas semiautomáticas, requerem grande esforço humano devido à limitação existente no âmbito computacional. Para tanto, existem inúmeros métodos que podem ser utilizados e inúmeras recomendações a se seguir, tanto para acessibilidade, quanto para usabilidade.

No próximo Capítulo é apresentado o Ambiente para Análise de Avaliações de Acessibilidade e Usabilidade na Web (A4U) desenvolvido nesta dissertação, seguido pelo seu planejamento e esforços iniciais, bem como os resultados obtidos e o estudo de caso executado, a fim de validar o ambiente. 



\subsection{Considerações iniciais}

Os estudos sobre os fundamentos teóricos relativos aos conceitos de acessibilidade, usabilidade, bem como os meios para avaliação deles em aplicações e páginas web possibilitaram uma visão da necessidade do ambiente proposto neste mestrado. Assim, foi elaborado o planejamento do ambiente, que visa contribuir com o desenvolvedor e com o especialista em acessibilidade e/ou usabilidade para produzirem relatórios concretos sobre as avaliações, bem como para criarem conteúdo cada vez mais voltado à conformidade das recomendações em prol da acessibilidade universal.

Neste Capítulo também é descrita a ferramenta AccessibilityUtil, projetada durante o doutorado de BITTAR (2013). O desenvolvimento dessa ferramenta, em parte, também foi realizado como exercício de boas práticas sobre implementação dos requisitos de acessibilidade e, com essa colaboração foi possível o compartilhamento de bons resultados e obtenção de experiências para o desenvolvimento do A4U. Neste capítulo ainda é apresentado o estudo da relação dos critérios de sucesso das WCAG 2.0 com os conjuntos 
de deficiências, além do planejamento do ambiente e os resultados obtidos com seu desenvolvimento. Finalmente, é discutido um estudo de caso aplicado no ambiente A4U, junto aos desenvolvedores e pesquisadores da área de Interação Humano-Computação (IHC).

\subsection{Projeto inicial: AccessibilityUtil}

Com base no conceito de Design Rationale, a AccessibilityUtil possibilita a inserção de experiências dos usuários, a partir de avaliações, relatos de uso, técnicas e decisões de projeto, mediante apresentação e inserção de artefatos visíveis a todos, a fim de se obter a completude dos critérios de acessibilidade envolvendo um esforço humano colaborativo.

A base de dados modelada possibilitou a inserção de todos os princípios das diretrizes, com suas respectivas descrições, além dos critérios de sucesso, conforme documentado nas WCAG 2.0.

Optou-se pelo cadastro de artefatos Web para tornar o sistema flexível, ao invés de apoiar apenas padrões, por exemplo. São considerados artefatos, neste contexto, quaisquer elementos presentes na construção de aplicações Web, para os quais haja alguma consideração sobre acessibilidade. Também comporta os tipos de artefatos, com nome e descrição, as avaliações e seus respectivos dados, como a data de cadastro, os comentários, o nível de entendimento, a dificuldade de cada experiência relatada e as recomendações.

A ferramenta foi criada para suportar inicialmente dois idiomas, o português e o inglês, com o objetivo de ser internacional e explorar também o conhecimento de pesquisadores do exterior.

A criação de conta do usuário está condicionada ao preenchimento de sua experiência em desenvolvimento Web, dentre as opções:

1. Nenhuma - só uso Web para visualizar páginas como usuário;

2. Baixa - consigo desenvolver algo de forma simples;

3. Moderada - tenho alguma experiência no desenvolvimento e;

4. Avançada - tenho experiência (especialista). 
O formulário de cadastro do artefato pode ser visualizado na Figura 16, no qual são requeridas informações como o tipo do artefato previamente cadastrado pelo administrador, o nome, sua descrição, as imagens associadas e as referências literárias. O participante pode também realizar avaliações e comentários sobre as avaliações já realizadas.

\begin{tabular}{|l|}
\hline Cadastrar artefato Web \\
Tipo de artefato \\
\hline [ Selecione ] \\
Nome \\
\hline captcha \\
Descrição \\
\hline \\
\hline Adicionar campos em Inglês \\
\hline Adicionar imagens \\
\hline Referências literárias \\
\hline \\
\hline Cadastrar \\
\hline
\end{tabular}

Figura 16: Cadastro de artefato

Na Figura 17 é apresentada a visualização de um artefato com uma imagem associada e o formulário para avaliação. A avaliação é feita selecionando a diretriz de acessibilidade e posteriormente escolhendo os critérios de sucesso habilitados a partir da seleção da diretriz. Outros dois campos a serem preenchidos são os comentários gerais de acessibilidade e a pontuação da dificuldade em se desenvolver com acessibilidade.

Observa-se que esses campos proporcionam características de acessibilidade essenciais à ferramenta, durante seu uso. 


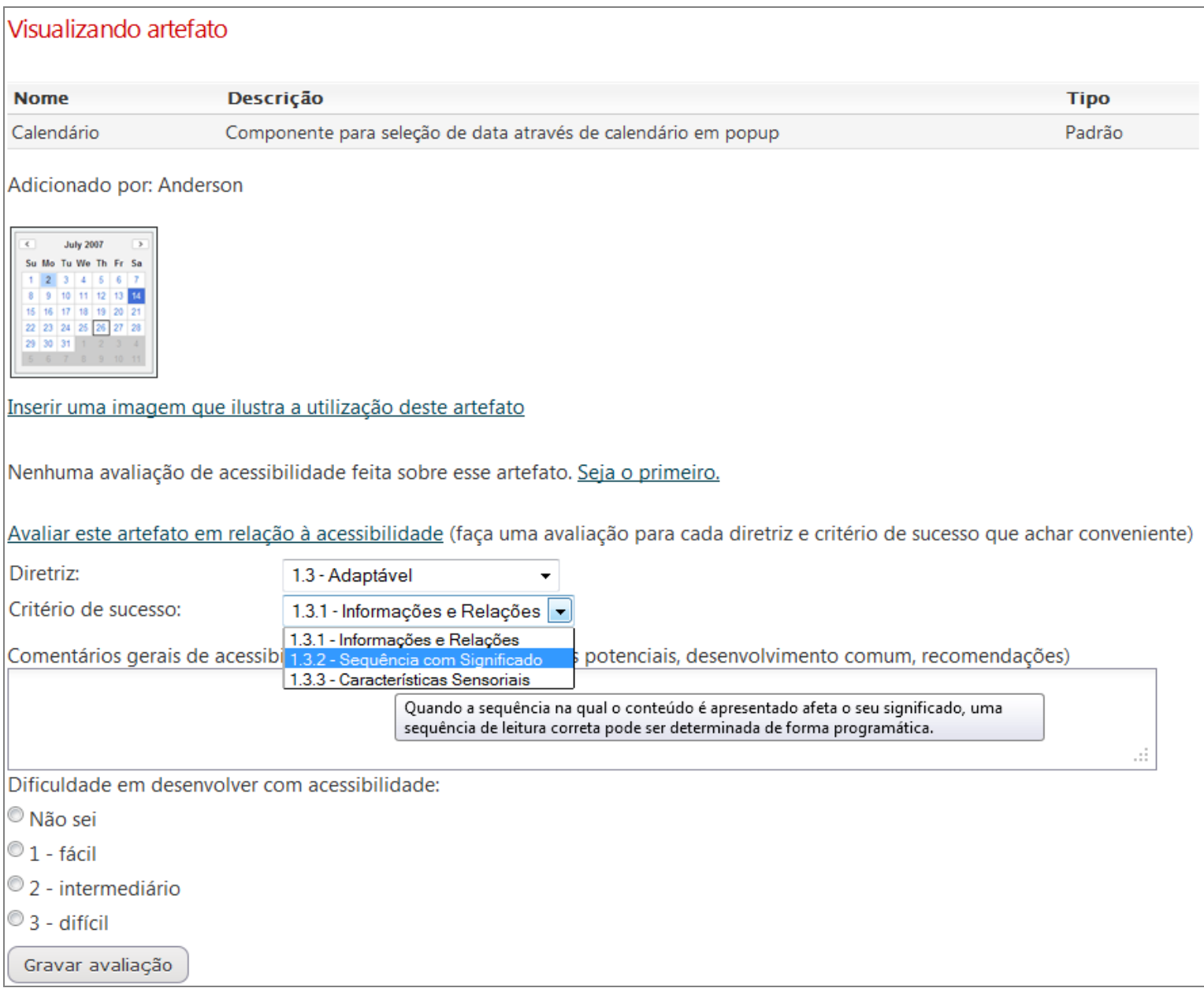

Figura 17: Visualização de artefato

É importante destacar que a interface foi planejada para apoiar aqueles que não têm conhecimento em profundidade sobre as WCAG 2.0, exibindo o texto relacionado a uma determinada diretriz, quando o usuário permanece com o foco ou o ponteiro do mouse alguns instantes em cada opção, via atributo "title". Caso fosse um requisito conhecer as diretrizes para fazer a avaliação, isso poderia se constituir em uma barreira para os desenvolvedores.

No momento, a ferramenta conta com 176 usuários cadastrados, 93 artefatos inseridos, 614 avaliações e 215 comentários $^{18}$. Com destaque para o artigo publicado: “AccessibilityUtil: a tool for sharing experiences about accessibility of web artifacts” no evento ACM Special Interest Group on Design of Communication Conference 2011

\footnotetext{
${ }^{18}$ Dados obtidos na data de 19 de fevereiro de 2014.
} 
(SIGDOC 2011), que propiciou uma divulgação no cenário internacional da ferramenta. Ainda, foi premiada no Todos@Web, Prêmio Nacional de Acessibilidade na Web, com a segunda colocação, na categoria Tecnologias assistivas / Aplicativos, em 2012.

Com o objetivo de classificar os critérios de sucesso das WCAG 2.0 utilizados na AccessibilityUtil e inseri-los no A4U, foi desenvolvida uma análise para associá-los aos conjuntos de deficiência de Visão, Audição, Motora, Cognitiva e Convulsiva. Esta análise e seus resultados são apresentados na próxima seção.

\subsection{Diretrizes WCAG 2.0 e os conjuntos de deficiências}

Existem inúmeras deficiências que prejudicam a experiência do usuário no uso da Web, incluindo visual, auditiva, física, de fala, cognitiva de linguagem, de aprendizado e neurológicas (W3C, 2008). No estudo aqui apresentado, foi percorrida a lista de critérios de sucesso das WCAG 2.0 e sugerida uma categoria dentre as principais: Visual, Auditiva, Cognitiva, Motora e Convulsiva (WebAIM, 2013b).

De acordo com o Decreto 3.298, de 20/12/1999, pessoa com deficiência é aquela que apresenta, em caráter permanente, “perda ou anormalidade de uma estrutura ou função psicológica, fisiológica ou anatômica que gere incapacidade para o desempenho de atividade, dentro do padrão considerado normal para o ser humano”.

Nas seções a seguir serão descritos os conjuntos de deficiências e os critérios de sucesso das WCAG 2.0 relacionados. Posteriormente, na Seção 5.3.6 é apresentado e discutido o estudo do professor Giorgio Brajnik, da University of Udine, Itália, que também relacionou os conjuntos de deficiências com os critérios de sucesso.

\subsubsection{Deficiência visual}

A visão é um dos sentidos que ajudam o ser humano a compreender o mundo a sua volta, colaborando na compreensão e concretização de objetos, conceitos e ideias. A comunicação por meio de imagens e elementos visuais relacionados é denominada "comunicação visual". Os humanos empregam-na desde seu nascimento e é predadora de todas as linguagens escritas. 
Deficiência visual é a perda ou redução da capacidade visual em ambos os olhos, com carácter definitivo, não sendo possível melhorar ou corrigir com o uso de lentes ou tratamentos clínicos e cirúrgicos. A legislação brasileira considera uma pessoa com deficiência visual, quando ela apresenta acuidade visual igual ou menor que 20/200 no melhor olho, após a melhor correção, ou campo visual inferior a $20^{\circ}$ (tabela de Snellen), ou ainda a ocorrência simultânea de ambas as situações (art. $3^{\circ}$, I e II, combinado com art. 4, III).

Dentre os usuários com deficiências visuais, pode-se ainda distinguir os cegos e os de visão subnormal. As possíveis causas para sua formação podem ser congênitas: Amaurose Congênita de Leber, malformações oculares, glaucoma congênito, catarata congénita; ou adquiridas: traumas oculares, catarata, degeneração senil de mácula, glaucoma, alterações relacionadas à hipertensão arterial ou diabetes (GIL, 2000).

Considerando a definição de deficiência visual, percorrendo os critérios de sucesso, lendo os objetivos e os benefícios na utilização de cada um, foi possível incluir os critérios de sucesso do Quadro 8 como benéficos para o conjunto de deficiências visuais.

Quadro 8: Critérios de sucesso para conjunto de deficiências visuais

\begin{tabular}{|l|l|}
\hline 1.1 .1 & Conteúdo Não Textual \\
\hline 1.2 .1 & Apenas Áudio e apenas Vídeo (Pré-gravado) \\
\hline 1.2 .2 & Legendas (Pré-gravadas) \\
\hline 1.2 .3 & Audiodescrição ou Mídia alternativa (Pré-gravada) \\
\hline 1.2 .5 & Audiodescrição (Pré-gravada) \\
\hline 1.2 .7 & Audiodescrição Estendida (Pré-gravada) \\
\hline 1.3 .1 & Mídia Alternativa (Pré-gravada) \\
\hline 1.3 .2 & Informações e Relações \\
\hline 1.3 .3 & Sequência com Significado \\
\hline 1.4 .1 & Características Sensoriais \\
\hline 1.4 .3 & Utilização da Cor \\
\hline 1.4 .4 & Contraste (Mínimo) \\
\hline 1.4 .5 & Redimensionar texto \\
\hline 1.4 .6 & Imagens de Texto \\
\hline 1.4 .9 & Contraste (Melhorado) \\
\hline 2.1 .1 & Imagens de Texto (Sem Exceção) \\
\hline 2.1 .2 & Teclado \\
\hline 2.1 .3 & Sem Bloqueio do Teclado \\
\hline & Teclado (Sem Exceção) \\
\hline
\end{tabular}




\begin{tabular}{|c|c|}
\hline 2.2 .1 & Ajustável por Temporização \\
\hline 2.2 .2 & Pausar, Parar, Ocultar \\
\hline 2.2 .3 & Sem Temporização \\
\hline 2.2 .4 & Interrupções \\
\hline 2.4 .1 & Ignorar Blocos \\
\hline 2.4 .2 & Página com Título \\
\hline 2.4 .3 & Ordem do Foco \\
\hline 2.4 .4 & Finalidade do Link (Em Contexto) \\
\hline 2.4 .5 & Várias Formas \\
\hline 2.4 .6 & Cabeçalhos e Etiquetas \\
\hline 2.4 .7 & Foco Visível \\
\hline 2.4 .9 & Finalidade do Link (Apenas o Link) \\
\hline 2.4 .10 & Cabeçalhos da sessão \\
\hline 3.1 .1 & Linguagem da Página \\
\hline 3.1 .2 & Linguagem das Partes \\
\hline 3.1 .3 & Palavras Incomuns \\
\hline 3.1 .4 & Abreviaturas \\
\hline 3.1 .6 & Pronúncia \\
\hline 3.2 .1 & Em Foco \\
\hline 3.2 .2 & Em Entrada \\
\hline 3.2 .3 & Navegação Consistente \\
\hline 3.2 .5 & Alteração mediante solicitação \\
\hline 3.3 .1 & Identificação do Erro \\
\hline 3.3 .2 & Etiquetas ou Instruções \\
\hline 3.3 .3 & Sugestão de Erro \\
\hline 3.3 .4 & Prevenção de Erros (Legal, Financeiro, Dados) \\
\hline 3.3 .6 & Prevenção de Erros (Todos) \\
\hline 4.1 .1 & Análise \\
\hline 4.1 .2 & Nome, Função, Valor \\
\hline
\end{tabular}

\subsubsection{Deficiência auditiva}

A deficiência auditiva constitui a diminuição na capacidade de escutar sons. Segundo muitos autores, o desenvolvimento do sistema auditivo inicia por volta da vigésima semana de gestação até o primeiro ano de vida (REDONDO, 1990).

REDONDO e CARVALHO (2000) subdividem o ouvido em três partes e explicam suas funções: 
Ouvido externo: é composto pelo pavilhão auricular e pelo canal auditivo, que é a porta de entrada do som. Neste canal, certas glândulas produzem cera, para proteger o ouvido.

Ouvido médio: formado pela membrana timpânica e por três ossos minúsculos, que são chamados de martelo, bigorna e estribo, pois são parecidos com estes objetos. Em contato com a membrana timpânica e o ouvido interno, eles transmitem as vibrações sonoras que entram no ouvido externo e devem ser conduzidas até o ouvido interno.

Ouvido interno: nele está a cóclea, em forma de caracol, que é a parte mais importante do ouvido, pois é responsável pela percepção auditiva. Os sons recebidos na cóclea são transformados em impulsos elétricos que caminham até o cérebro, onde são “entendidos” pela pessoa.

Qualquer dano a uma dessas partes pode resultar na perda de acuidade auditiva. No Quadro 9, obtido de REDONDO e CARVALHO (2000), são identificadas as intensidades que representam os limiares da audição.

Quadro 9: Limiares tonais, quadro obtido de REDONDO e CARVALHO (2000)

\begin{tabular}{|l|l|}
\hline \multicolumn{2}{|l|}{ Limiares tonais * } \\
\hline Audição normal & 0 a $15 \mathrm{~dB}$ \\
\hline Deficiência auditiva suave & 16 a $25 \mathrm{~dB}$ \\
\hline Deficiência auditiva leve & 26 a $40 \mathrm{~dB}$ \\
\hline Deficiência auditiva moderada & 41 a $55 \mathrm{~dB}$ \\
\hline Deficiência auditiva moderadamente severa & 56 a $70 \mathrm{~dB}$ \\
\hline Deficiência auditiva severa & 71 a $90 \mathrm{~dB}$ \\
\hline Deficiência auditiva profunda & acima de $91 \mathrm{~dB}$ \\
\hline * Média dos limiares tonais em $500,1.000$ e $2.000 \mathrm{~Hz}$. & \\
\hline
\end{tabular}


Considerando a definição de deficiência auditiva, percorrendo os critérios de sucesso, lendo os objetivos e os benefícios na utilização de cada um, foi possível incluir os critérios de sucesso do Quadro 10 como benéficos para conjuntos de deficiências auditivas.

Quadro 10: Critérios de sucesso para conjunto de deficiências auditivas

\begin{tabular}{|l|l|}
\hline 1.1 .1 & Conteúdo Não Textual \\
\hline 1.2 .1 & Apenas Áudio e apenas Vídeo (Pré-gravado) \\
\hline 1.2 .2 & Legendas (Pré-gravadas) \\
\hline 1.2 .3 & Audiodescrição ou Mídia alternativa (Pré-gravada) \\
\hline 1.2 .4 & Legendas (Ao Vivo) \\
\hline 1.2 .5 & Audiodescrição (Pré-gravada) \\
\hline 1.2 .6 & Linguagem de sinais (Pré-gravada) \\
\hline 1.2 .8 & Audiodescrição Estendida (Pré-gravada) \\
\hline 1.2 .9 & Mídia Alternativa (Pré-gravada) \\
\hline 1.3 .1 & Apenas áudio (Ao vivo) \\
\hline 1.4 .7 & Informações e Relações \\
\hline 2.2 .1 & Som Baixo ou Sem Som de Fundo \\
\hline 2.2 .3 & Ajustável por Temporização \\
\hline 2.2 .5 & Sem Temporização \\
\hline 3.3 .4 & Nova autenticação \\
\hline 3.3 .6 & Prevenção de Erros (Legal, Financeiro, Dados) \\
\hline 4.1 .1 & Prevenção de Erros (Todos) \\
\hline
\end{tabular}

\subsubsection{Deficiência cognitiva}

Uma pessoa com deficiência cognitiva está sujeita a ter maior dificuldade ao executar algumas tarefas mentais do que a pessoa sem essa deficiência.

Existem inúmeras variantes de deficiência cognitiva. A maioria tem como base alguma disfunção na biologia ou fisiologia do indivíduo. A ligação entre uma pessoa com relação biológica e os processos mentais é mais evidente no caso de traumatismos crânio encefálicos e as doenças genéticas, mas até mesmo as mais sutis deficiências cognitivas tem, frequentemente, uma base na estrutura química do cérebro (WebAIM, 2013a).

Uma pessoa com deficiência cognitiva profunda vai precisar de ajuda em quase todos os aspectos da vida diária, enquanto existem pessoas com tão pequena disfunção, que a influência na aprendizagem é diminuta, a ponto de nunca serem diagnosticadas. 
Há uma grande quantidade de conteúdo da Web que não pode ser acessível às pessoas com deficiências cognitivas profundas, independente do esforço do desenvolvedor (WebAIM, 2013a). Alguns conteúdos podem ser demasiados complexos para determinado público. No entanto, ainda existem ações para minimizar as questões de acessibilidade para as pessoas com deficiências cognitivas menos graves.

Considerando a definição de deficiência cognitiva, percorrendo os critérios de sucesso, lendo os objetivos e os benefícios na utilização de cada um, foi possível incluir os critérios de sucesso do Quadro 11 como benéficos para conjuntos de deficiências cognitivas.

Quadro 11: Critérios de sucesso para conjunto de deficiências cognitivas

\begin{tabular}{|l|l|}
\hline 1.1 .1 & Conteúdo Não Textual \\
\hline 1.2 .1 & Apenas Áudio e apenas Vídeo (Pré-gravado) \\
\hline 1.2 .2 & Legendas (Pré-gravadas) \\
\hline 1.2 .3 & Audiodescrição ou Mídia alternativa (Pré-gravada) \\
\hline 1.2 .4 & Legendas (Ao Vivo) \\
\hline 1.2 .7 & Audiodescrição (Pré-gravada) \\
\hline 1.2 .8 & Audiodescrição Estendida (Pré-gravada) \\
\hline 1.2 .9 & Mídia Alternativa (Pré-gravada) \\
\hline 1.3 .1 & Apenas áudio (Ao vivo) \\
\hline 1.3 .2 & Informações e Relações \\
\hline 1.4 .2 & Sequência com Significado \\
\hline 1.4 .5 & Controle de Áudio \\
\hline 1.4 .8 & Imagens de Texto \\
\hline 1.4 .9 & Apresentação Visual \\
\hline 2.2 .1 & Imagens de Texto (Sem Exceção) \\
\hline 2.2 .2 & Ajustável por Temporização \\
\hline 2.2 .3 & Pausar, Parar, Ocultar \\
\hline 2.2 .4 & Sem Temporização \\
\hline 2.2 .5 & Interrupções \\
\hline 2.4 .1 & Nova autenticação \\
\hline 2.4 .2 & Ignorar Blocos \\
\hline 2.4 .4 & Página com Título \\
\hline 2.4 .5 & Finalidade do Link (Em Contexto) \\
\hline 2.4 .6 & Várias Formas \\
\hline 2.4 .7 & Cabeçalhos e Rótulos \\
\hline 2.4 .8 & Foco Visível \\
\hline & Localização \\
\hline
\end{tabular}




\begin{tabular}{|l|l|}
\hline 2.4 .9 & Finalidade do Link (Apenas o Link) \\
\hline 2.4 .10 & Cabeçalhos da sessão \\
\hline 3.1 .1 & Linguagem da Página \\
\hline 3.1 .2 & Linguagem das Partes \\
\hline 3.1 .3 & Palavras Incomuns \\
\hline 3.1 .5 & Abreviaturas \\
\hline 3.1.6 & Nível de Leitura \\
\hline 3.2 .1 & Pronúncia \\
\hline 3.2 .2 & Em Foco \\
\hline 3.2 .3 & Em Entrada \\
\hline 3.2 .4 & Navegação Consistente \\
\hline 3.2 .5 & Identificação Consistente \\
\hline 3.3 .1 & Alteração mediante solicitação \\
\hline 3.3 .2 & Identificação do Erro \\
\hline 3.3 .3 & Etiquetas ou Instruções \\
\hline 3.3 .4 & Sugestão de Erro \\
\hline 3.3 .5 & Prevenção de Erros (Legal, Financeiro, Dados) \\
\hline 3.3 .6 & Ajuda \\
\hline
\end{tabular}

\subsubsection{Deficiência motora}

Diferentes condições motoras que acometem as pessoas comprometendo a mobilidade, a coordenação motora geral e da fala, em consequência de lesões neurológicas, neuromusculares, ortopédicas, ou más formações congênitas ou adquiridas (MEC, 2006).

De acordo com o Decreto n 5.296 de 2 de dezembro de 2004, deficiência motora é a alteração completa ou parcial de um ou mais segmentos do corpo humano, acarretando o comprometimento da função física, apresentando-se sob a forma de paraplegia, paraparesia, monoplegia, monoparesia, tetraplegia, tetraparesia, triplegia, triparesia, hemiplegia, hemiparesia, ostomia, amputação ou ausência de membro, paralisia cerebral, nanismo, membros com deformidade congênita ou adquirida, exceto as deformidades estéticas e as que não produzam dificuldades para o desempenho de funções.

Considerando a definição de deficiência motora, percorrendo os critérios de sucesso, lendo os objetivos e os benefícios na utilização de cada um, foi possível incluir os critérios de sucesso do Quadro 12 como benéficos para conjuntos de deficiências motoras. 
Quadro 12: Critérios de sucesso para conjunto de deficiências motoras

\begin{tabular}{|l|l|}
\hline 1.1 .1 & Conteúdo Não Textual \\
\hline 1.3 .1 & Informações e Relações \\
\hline 2.1 .1 & Teclado \\
\hline 2.1 .2 & Sem Bloqueio do Teclado \\
\hline 2.1 .3 & Teclado (Sem Exceção) \\
\hline 2.2 .1 & Ajustável por Temporização \\
\hline 2.2 .3 & Sem Temporização \\
\hline 2.2 .4 & Interrupções \\
\hline 2.4 .1 & Ignorar Blocos \\
\hline 2.4 .2 & Página com Título \\
\hline 2.4 .3 & Ordem do Foco \\
\hline 2.4 .4 & Finalidade do Link (Em Contexto) \\
\hline 2.4 .6 & Cabeçalhos e Etiquetas \\
\hline 2.4 .7 & Foco Visível \\
\hline 2.4 .9 & Finalidade do Link (Apenas o Link) \\
\hline 2.4 .10 & Cabeçalhos da sessão \\
\hline 3.2 .1 & Em Foco \\
\hline 3.2 .5 & Alteração mediante solicitação \\
\hline 3.3 .3 & Sugestão de Erro \\
\hline 3.3 .4 & Prevenção de Erros (Legal, Financeiro, Dados) \\
\hline 3.3 .5 & Ajuda \\
\hline 3.3 .6 & Prevenção de Erros (Todos) \\
\hline
\end{tabular}

\subsubsection{Transtornos convulsivos}

Algumas pessoas são suscetíveis a convulsões causadas devido à exposição visual de luzes estroboscópicas, luzes tremulantes, ou efeitos de "pisca pisca”. Esta disfunção muitas vezes é chamada de convulsão fotoepiléptica ou fotoepilepsia porque é causada devido aos pulsos de luz interagindo com os olhos, neurônios e com o sistema nervoso central (WebAIM, 2013c).

Considerando a definição de transtorno convulsivo, percorrendo os critérios de sucesso, lendo os objetivos e os benefícios na utilização de cada um, foi possível incluir os critérios de sucesso do Quadro 13 como benéficos para conjuntos de transtornos convulsivos. 
Quadro 13: Critérios de sucesso para conjunto de transtornos convulsivos

\begin{tabular}{|l|l|}
\hline 2.2.2 & Pausar, Parar, Ocultar \\
\hline 2.3 .1 & Três Flashes ou Abaixo do Limite \\
\hline 2.3 .2 & Três Flashes \\
\hline
\end{tabular}

\subsubsection{Estudo relacionado e discussão}

BRAJNIK (2009) listou as possíveis barreiras de acessibilidade e propôs uma avaliação heurística baseada nelas. Parte do trabalho que ele teve foi justamente associar os critérios de sucesso das WCAG (1.0 e 2.0) a essas barreiras, possibilitando um conjunto para contraste dos resultados obtidos na seleção feita pelo autor desta dissertação.

No estudo, Brajnik divide a gama de deficiências em conjuntos mais específicos: cegos, pessoas com baixa visão, com daltonismo, com deficiências motoras, surdos, pessoas com problemas cognitivos, e estende para pessoas independente de deficiência, que tenham o JavaScript desabilitado em seu navegador, e avaliações considerando motores de busca.

Para cada uma dessas categorias, Brajnik lista possíveis barreiras a serem avaliadas quanto ao impacto, persistência e gravidade, de maneira a construir uma checklist baseada nas barreiras percebidas por cada conjunto de deficiência.

Considerando a divisão específica que Brajnik adotou, e generalizando cegueira, pessoas com baixa visão e daltonismo como problemas relacionados à visão, chegou-se a categorização feita nesta dissertação e pôde-se realizar uma comparação, no sentido de confirmar a seleção ou identificar casos contraditórios que precisaram ser analisados com mais cuidado, a fim de identificar razões de contraste.

A comparação dos estudos resultou em quatro divergências que merecem destaque para uma discussão mais aprofundada sobre o que as WCAG 2.0 objetivaram com estes critérios de sucesso, a fim de atribuí-los ou não às categorias aqui dispostas.

\subsubsection{Legendas (ao vivo)}

Descrição disponibilizada pelo W3C: são fornecidas legendas para a totalidade do áudio ao vivo existente num conteúdo em mídia sincronizada (Nível AA). Como benefícios, o W3C especifica que este critério colabora com pessoas com surdez ou que 
tenham perda de audição no sentido de possibilitar que elas possam acessar a informação do áudio em conteúdo textual (legenda) sincronizado.

Brajnik associa este critério aos problemas de visão, mais especificamente aos usuários cegos, além de apontar para problemas auditivos. Aqui, foi descartada a possibilidade de o critério corresponder a melhorias aos usuários cegos, tendo em vista que não se trata de uma descrição de cenário pré-gravada, que possibilitaria a compreensão da cena por pessoas com deficiências visuais, mas sim uma analogia textual do áudio, em tempo de execução. Entretanto, a outra proposição é válida, conforme o W3C mesmo afirma, a legenda contribui para que pessoas com deficiência auditiva tenham o entendimento da mídia. Pode-se afirmar, também, que colabora com pessoas com diferentes problemas cognitivos, pois é um auxiliar à apresentação em áudio.

\subsubsection{Audiodescrição (Pré-gravada)}

Descrição disponibilizada pelo W3C: é fornecida audiodescrição para a totalidade do vídeo pré-gravado existente num conteúdo em mídia sincronizada (Nível AA). Como benefícios, o W3C especifica que este critério colabora com pessoas cegas ou com baixa visão, como também com pessoas que tenham limitações cognitivas que apresentam dificuldade de interpretar visualmente o que está ocorrendo, sendo beneficiados pela descrição de áudio da informação visual.

Este critério é atribuído por Brajnik ao conjunto de deficiências auditivas, visuais e cognitivas. Em primeiro momento a associação com deficiências auditivas foi descartada, porém notou-se a pré-disposição errada que se teve, pois ao se destacar problemas auditivos, é habitual que se associe, de maneira direta, com a surdez completa, desconsiderando a baixa audição, que pode se beneficiar da audiodescrição, já que essa corresponde à descrição dos fatos de maneira a indicar novos meios de entendimento a pessoas com deficiências que não possam compreender por completo o áudio. As demais indicações foram correspondentes.

\subsubsection{Audiodescrição Estendida (Pré-gravada)}

Descrição disponibilizada pelo W3C: quando as pausas no áudio do primeiro plano forem insuficientes para permitir que as audiodescrições transmitam o sentido do vídeo, é 
fornecida uma audiodescrição estendida para a totalidade do vídeo pré-gravado existente num conteúdo em mídia sincronizada (Nível AAA). Como benefícios, o W3C especifica que este critério colabora com pessoas cegas e com baixa visão, que não possam ver a tela, além das pessoas com limitações cognitivas, que tenham dificuldade de interpretação visual do que está ocorrendo, sendo beneficiados pela descrição de áudio da informação visual.

Além de associar este critério a problemas visuais e cognitivos, Brajnik também interpreta que o critério colabora com pessoas que tenham deficiência auditiva. Em primeiro momento, como ocorreu no critério de sucesso 1.2.5, foi considerado o problema absoluto de audição, que não se beneficia de qualquer áudio, entretanto o equívoco foi observado e a proposição do Brajnik foi correspondida, pois a audiodescrição contribui para a percepção de conteúdo que tenha sua compreensão dificultada pela baixa audição.

\subsubsection{Apenas áudio (ao vivo)}

Descrição disponibilizada pelo W3C: é fornecida uma alternativa para mídia baseada no tempo que apresenta informações equivalentes para o conteúdo composto por apenas áudio ao vivo (Nível AAA). O W3C não descreve os benefícios deste critério, porém exemplifica-o, contribuindo com o entendimento.

Brajinik interpreta que este critério colabora com pessoas com deficiências visuais, assim como auditivos e com limitações cognitivas. Este critério de sucesso assemelha-se muito com o 1.2.4, pois corresponde à disponibilização de conteúdo alternativo textual (legenda) à mídia de áudio e, por conseguinte é verificada a mesma contradição, pois pessoas com deficiência visual não são beneficiadas pelo conteúdo transcrito em tempo de execução, pois o entendimento do áudio é suficiente.

Feita a comparação com o estudo realizado por Brajnik, com a catalogação de critérios de sucesso por conjuntos de deficiência, é possível identificar que as WCAG 2.0 priorizam problemas visuais em sua composição, ou que existem mais barreiras a serem cobertas por esta categoria, seguidos de problemas cognitivos, motores, auditivos e por fim convulsivos, conforme se pode observar pelo gráfico apresentado na Figura 18. As barreiras visuais se mostram mais numerosas, pois a Web é composta, provavelmente, em sua maioria, por conteúdo visual. 


\section{Distribuição de problemas cobertos pelas WCAG 2.0}

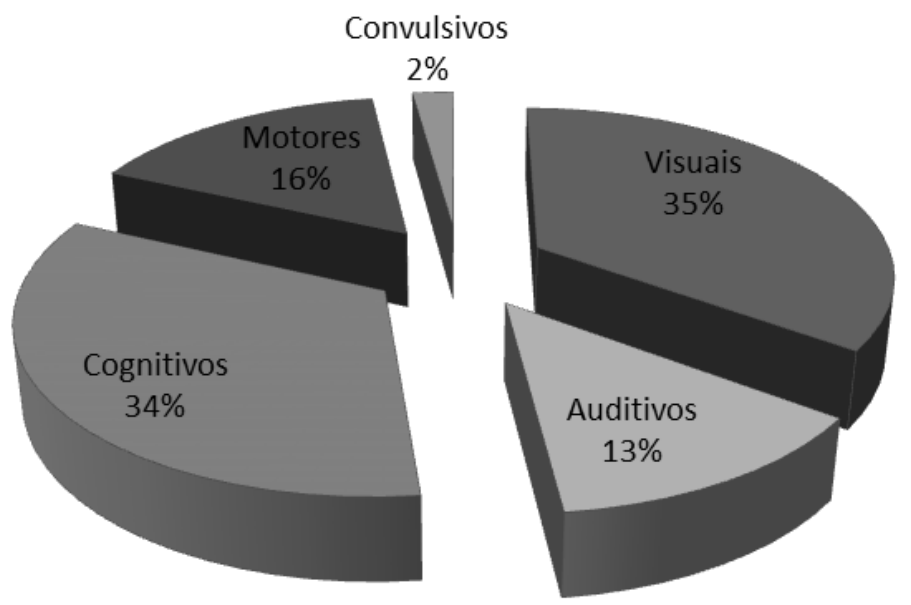

Figura 18: Gráfico de distribuição de problemas cobertos pelas WCAG 2.0

Na próxima seção, o projeto do $\mathrm{A} 4 \mathrm{U}$ é descrito em detalhes, a partir do planejamento e tomadas de decisões, com o intuito de tornar a ferramenta acessível e produzir uma experiência de fácil utilização, para a contribuição da análise e avaliação de conteúdos em benefício da usabilidade e da acessibilidade Web.

\subsection{Projeto do ambiente}

O planejamento inicial considerou a utilização de conceitos de Engenharia de Requisitos, para identificar as necessidades dos elementos que deveriam ser desenvolvidos na ferramenta (SOMMERVILLE e SAWYER, 1997). Em seguida, foi feita a análise para compreensão e inferência dos dados, iniciando a condução do projeto, a partir da proposta da arquitetura e o modelo conceitual dos dados.

Os requisitos sugeridos foram convertidos em casos de uso da ferramenta, que são exibidos pelo diagrama da Figura 19. 


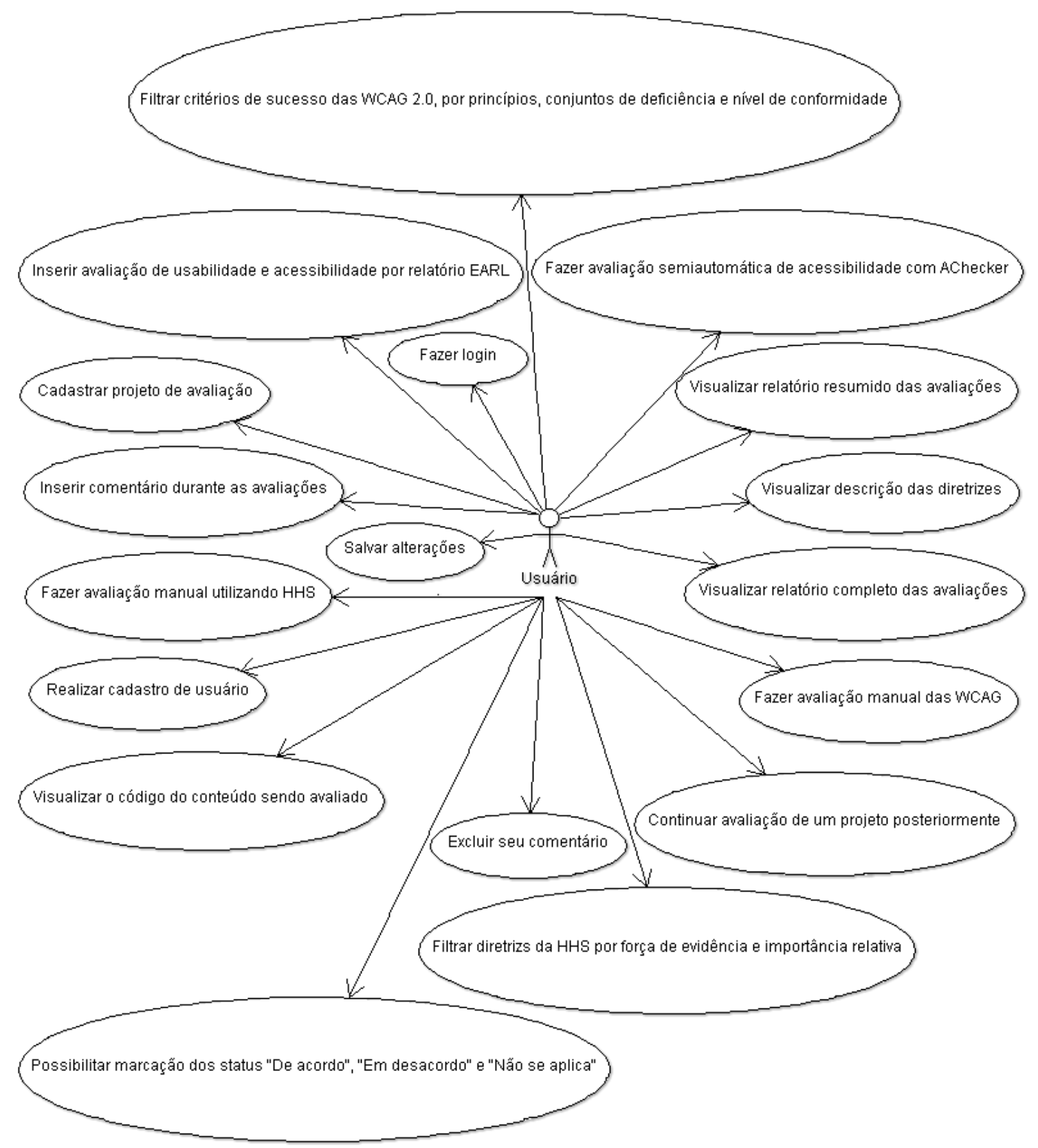

Figura 19: Diagrama de casos de uso do A4U

Um requisito não funcional que permeou o desenvolvimento da ferramenta foi a necessidade em se buscar a usabilidade e a acessibilidade em seu conteúdo, a partir de tomadas de decisões e a implantação de artefatos que buscassem atender estas expectativas. 
Considerando a reusabilidade de código e a separação de conceitos, com relação ao que é visual do que é mediador da entrada para processamento da informação e, do que é armazenamento de dados, optou-se pela utilização do modelo de arquitetura de software Model View Controller (MVC), conforme apresentado na Figura 20.

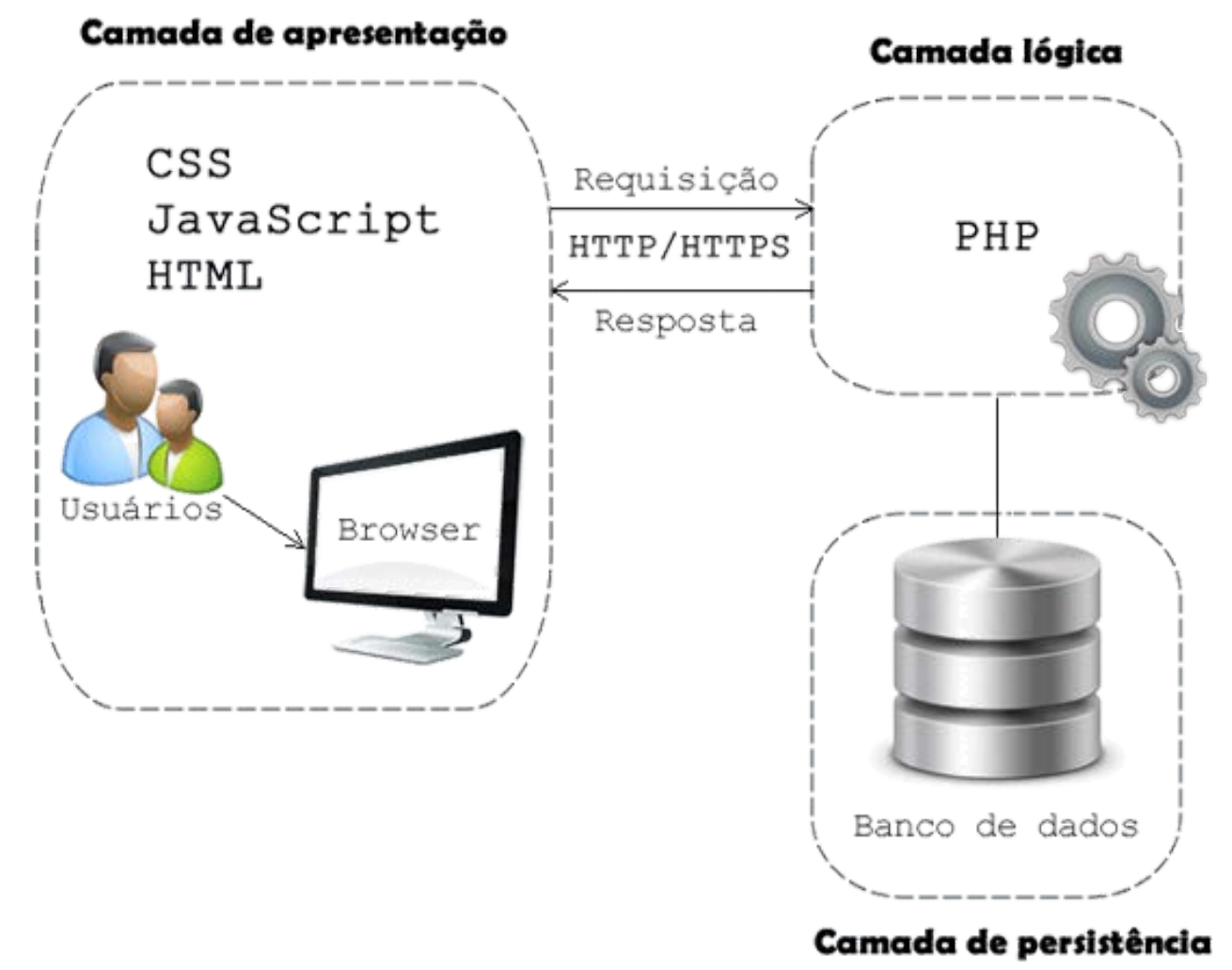

Figura 20: Arquitetura da A4U

A camada de apresentação foi desenvolvida a partir das linguagens HTML, CSS e JavaScript, com frameworks de apoio para CSS, o YAML e para JavaScript, o jQuery. O YAML contribui na construção de sites responsivos, ou seja, que adequam seu conteúdo de acordo com as dimensões da tela do dispositivo. Em usabilidade, nos dias atuais, em que o mercado de smartphones já supera o de computadores pessoais, tornar a aplicação responsiva, de maneira a aumentar a experiência e facilidade de acesso por diversos dispositivos, é uma necessidade. Outra questão que o YAML se propõe é contribuir com a acessibilidade, fazendo uso de artefatos implementados já acessíveis. 
A camada lógica, ou de controle, utiliza a linguagem de programação PHP, muito difundida entre desenvolvedores Web e de fácil compreensão. Por fim, a camada de persistência fica a cargo do Sistema Gerenciador de Banco de Dados (SGBD) MySQL.

Softwares gratuitos foram utilizados para o desenvolvimento do ambiente de avaliação proposto. O Codelobster PHP Edition 3.7, como ferramenta de autoria PHP e o VertrigoServ 2.23, pacote de instalação PHP, Apache e MySQL. No desenvolvimento, as linguagens utilizadas foram: CSS e o Framework CSS YAML, HTML, JavaScript e o Framework JavaScript jQuery, PHP, EARL e como Sistema Gerenciador de Banco de Dados, o MySQL. Ainda, foi incorporada a biblioteca Gettext, que é uma biblioteca no Projeto GNU que propõe a escrita de múltiplos idiomas em softwares, com o apoio da ferramenta Poedit, utilizada em processos de internacionalização de software para simplificar operações de tradução por meio do catálogo Gettext.

Considerando o objetivo de avaliar e analisar avaliações de usabilidade e acessibilidade, buscaram-se recomendações no modelo checklist para avanço em ambos os conceitos, a fim de metrificar a análise e torná-la mais objetiva, a ponto de usuários sem experiência poderem utilizar o ambiente para aperfeiçoar suas aplicações. Desta maneira, as WCAG 2.0 foram escolhidas como conjunto de diretrizes de acessibilidade, por serem um conjunto oficial do W3C e um dos documentos mais difundidos da área. Em usabilidade, por sua vez, a HHS foi atribuída, pois pouco se conhece de diretrizes objetivas em usabilidade e a HHS se mostrou muito eficiente nos critérios.

Após a escolha dos conjuntos de recomendações, foi possível recuperar o conjunto de dados referentes às WCAG 2.0, a partir da ferramenta AccessibilityUtil, que já tinha mapeada as diretrizes e inseridas em seu banco de dados. A HHS, entretanto não pôde ser recuperada tão facilmente. Assim, foi desenvolvido um Web crawler para fazer a leitura do site da HHS e recuperar o código das diretrizes, seus títulos, suas descrições, os índices de força de evidência e os de importância relativa, além dos capítulos e suas descrições. Com os dados, criou-se o modelo relacional do ambiente, Figura 21, e após instanciar o banco, os dados foram atribuídos. 


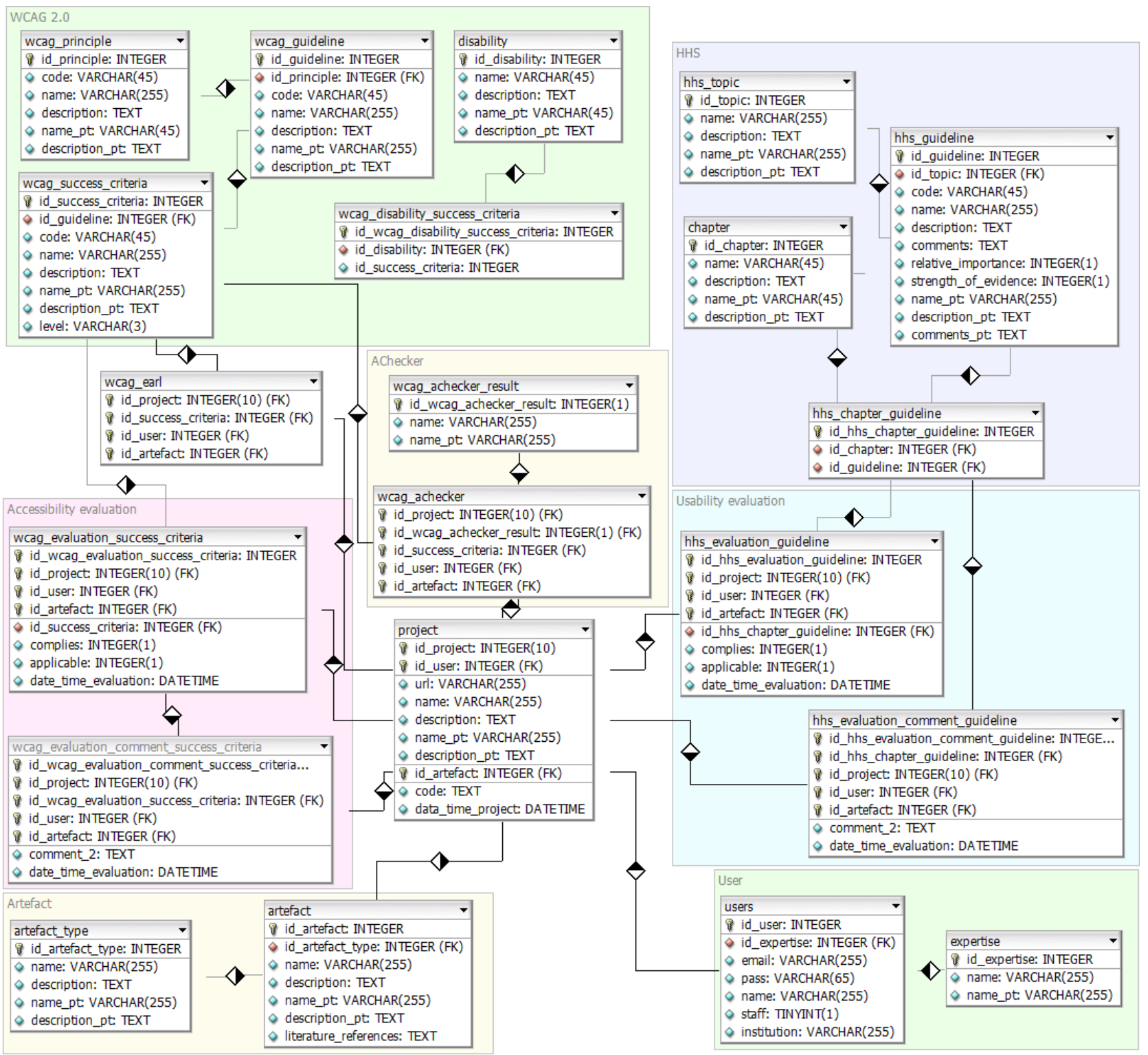

Figura 21: Diagrama relacional do A4U

A modelagem foi criada já enfatizando a internacionalização da ferramenta, assim os campos das WCAG e HHS consideraram o inglês e o português, porém a HHS não disponibiliza seu conteúdo em português. Portanto, um esforço adicional na tradução foi requerido. O autor desta dissertação traduziu todo o conteúdo da HHS para português a fim de disponibilizar os dois idiomas na ferramenta. 
O Diagrama Relacional do A4U, exibido na Figura 21, considera os pacotes de tabelas das diretrizes WCAG 2.0, HHS, do AChecker, das avaliações, dos artefatos e dos usuários discriminados.

Tendo criada a base de dados, o servidor foi configurado para facilitar a internacionalização do conteúdo textual via código, a partir da instalação do Gettext. Em PHP, é criada uma marcação nas strings e com o apoio da ferramenta Poedit, pode-se recuperar todas as strings e traduzí-las facilmente. Ao salvar o projeto, o Poedit gera o arquivo de extensão .MO, que é o arquivo de strings compilado, utilizado pela Gettext no servidor.

O logo, apresentada na Figura 22, foi criado com base na corporação “accessible Applications Design and Development"19, com ícones de elementos que indicam as deficiências auditivas, motoras e visuais. O numeral 4 representa as quatro iniciais de Ambiente, Análise, Avaliação e Acessibilidade, entretanto ao mesmo tempo simboliza, quando lido, a proposição “for" e o "U”, de usabilidade, pode simbolizar "YOU”, do inglês, conduzindo a "Accessibility for you”. Em relação às cores, foram escolhidas aquelas que denotam a bandeira do Brasil, por ser uma ferramenta genuinamente brasileira.

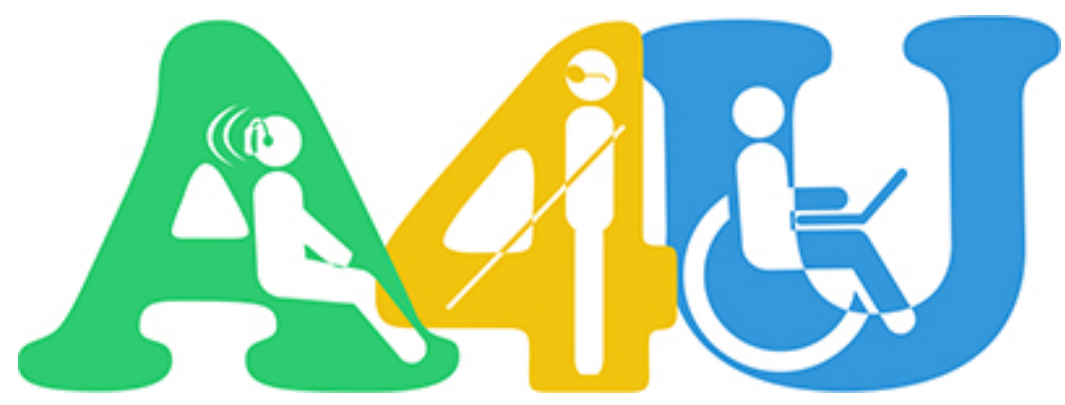

Figura 22: Logo da ferramenta A4U

O objetivo do design foi ser simples, intuitivo e responsível. Assim, o layout foi construído baseado em grids, a partir do YAML, para que a adequação ao conteúdo da tela fosse perfeita. Dependendo do tamanho da tela, a grid se dispõe dinamicamente, otimizando a utilização do espaço disponibilizado horizontalmente e fazendo uso do crescimento vertical.

\footnotetext{
${ }^{19}$ http://www.accessible-eu.org/
} 
A página inicial da ferramenta, que pode ser acessada pelo endereço http://www.leandroagt.com.br/a4u/, exibida na Figura 23, ilustra a simplicidade, porém não dispensa nenhuma funcionalidade requerida pela ferramenta. Nela é possível verificar a barra de navegação e os formulários de login e cadastro, todos sensíveis à tecla Tab e as imagens significativas, ou seja, que não têm o papel básico de composição de cenário, recebem a tag "alt”, com seu respectivo conteúdo textual descritivo.

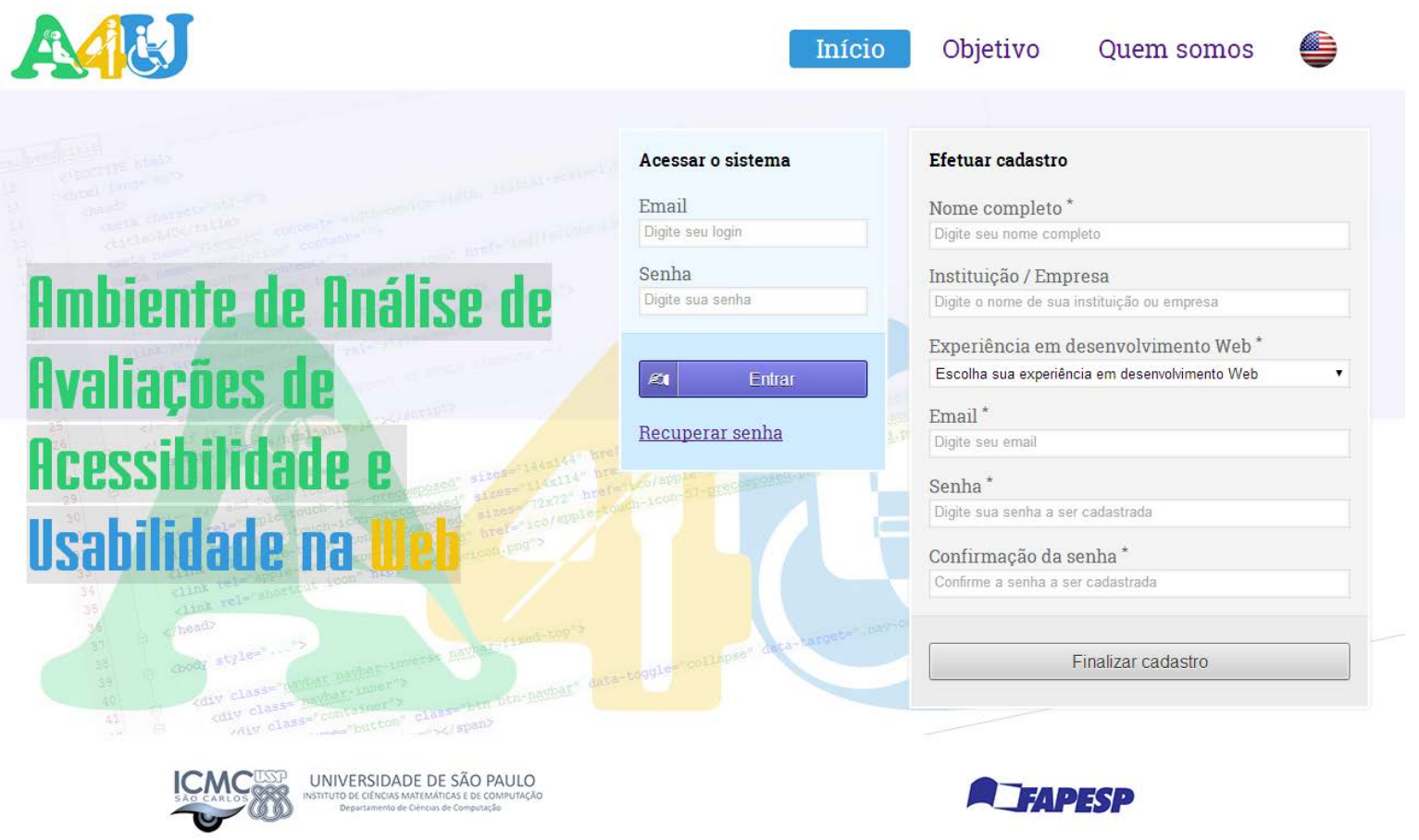

Figura 23: Página inicial da ferramenta

Na Figura 24 é apresentada a mesma página, porém na experiência de utilização em um dispositivo de tela menor. 


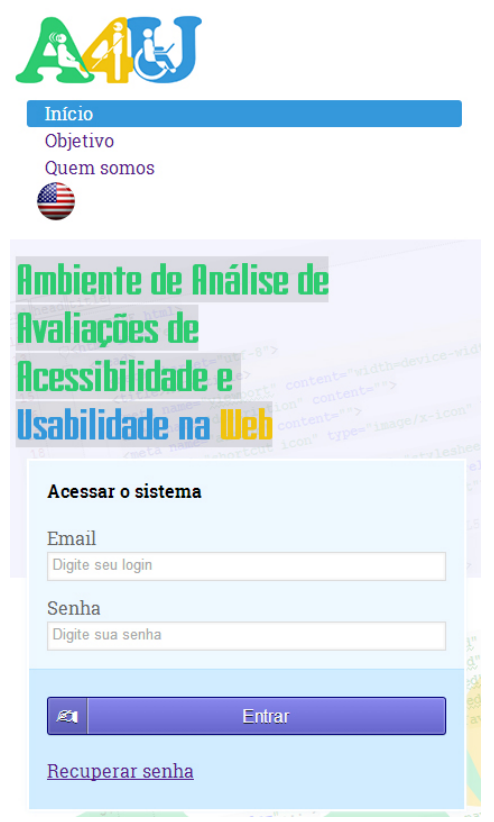

Figura 24: Página inicial visualizada em um dispositivo com dimensões menores

Os formulários foram programados com verificação de campos obrigatórios e os erros foram dispostos em lista de elementos descritíveis e clicáveis, que conduzem ao campo identificado com problema. Todos os rótulos foram associados ao campo de entrada correspondente, respeitando uma das diretrizes de acessibilidade. Na Figura 25 é apresentada a lista de problemas ao submeter o formulário de login, sem preencher os campos obrigatórios.

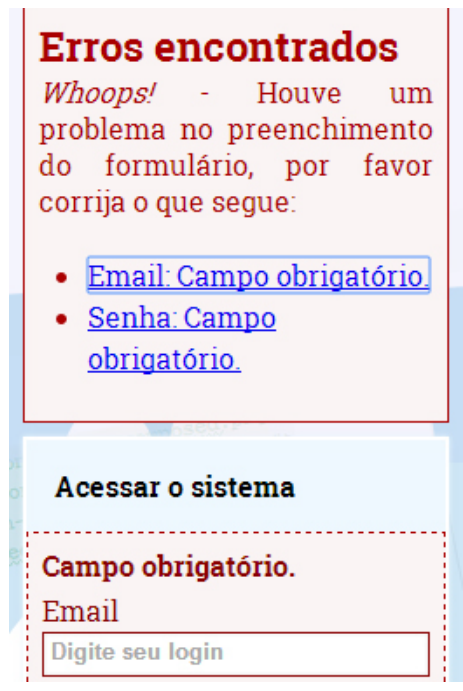

Figura 25: Tratamento de erros de formulário 
Outro elemento importante na condução de acessibilidade são as mensagens de erros claras, que proporcionam um feedback ao usuário, conduzindo-o a perceber os resultados de suas ações no ambiente, seja de sucesso ou de erro. É importante observar que as caixas de mensagem limitam a área de foco a elas, a fim de inibir a perda de contexto na utilização de leitores de conteúdo. Um exemplo de caixa de mensagem é exibido na Figura 26.

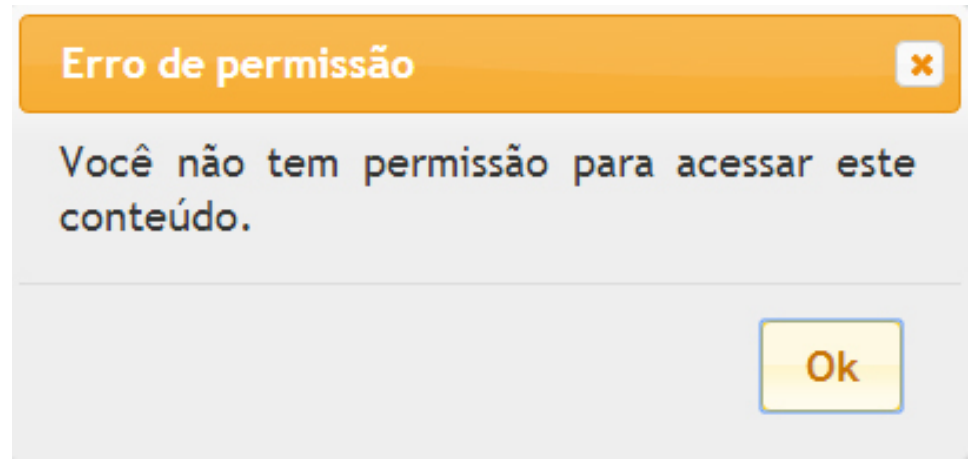

Figura 26: Exemplo de caixa de mensagem

Assim, como na AccessibilityUtil, o cadastro está condicionado à informação da expertise do usuário em desenvolvimento, para evitar vieses na análise dos resultados, pois é incoerente avaliar a experiência de um usuário avançado, com um usuário que não conhece o alicerce de Web, produzindo resultados e registrando experiências não confiáveis de usabilidade e acessibilidade, pois desconhece padrões básicos.

Finalizando o cadastro, o ambiente disponibiliza a função de criação de um projeto de avaliação e exibe uma mensagem informando que não existem avaliações feitas até o momento. A ferramenta salva todas as avaliações, para caso o usuário queira continuar em um momento posterior ou para consulta de histórico de avaliações. A Figura 27 corresponde à tela principal após o login.

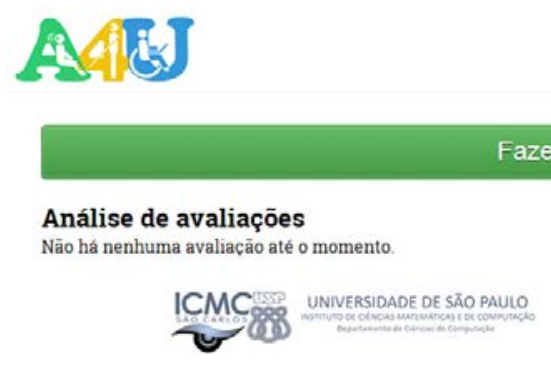


A criação da avaliação, indicada pela Figura 28, possibilita a inserção de dados em dois idiomas, obrigando o preenchimento do idioma corrente da aplicação. A URL a ser inserida, será posteriormente avaliada pela ferramenta AChecker, embutida no ambiente, produzindo alertas nos critérios de sucesso que apresentem incompatibilidades. Ainda na criação da avaliação, é possível identificar o objeto a ser avaliado, seja uma página inteira ou um artefato. Os artefatos, foram aproveitados do catálogo existente na AccessibilityUtil.
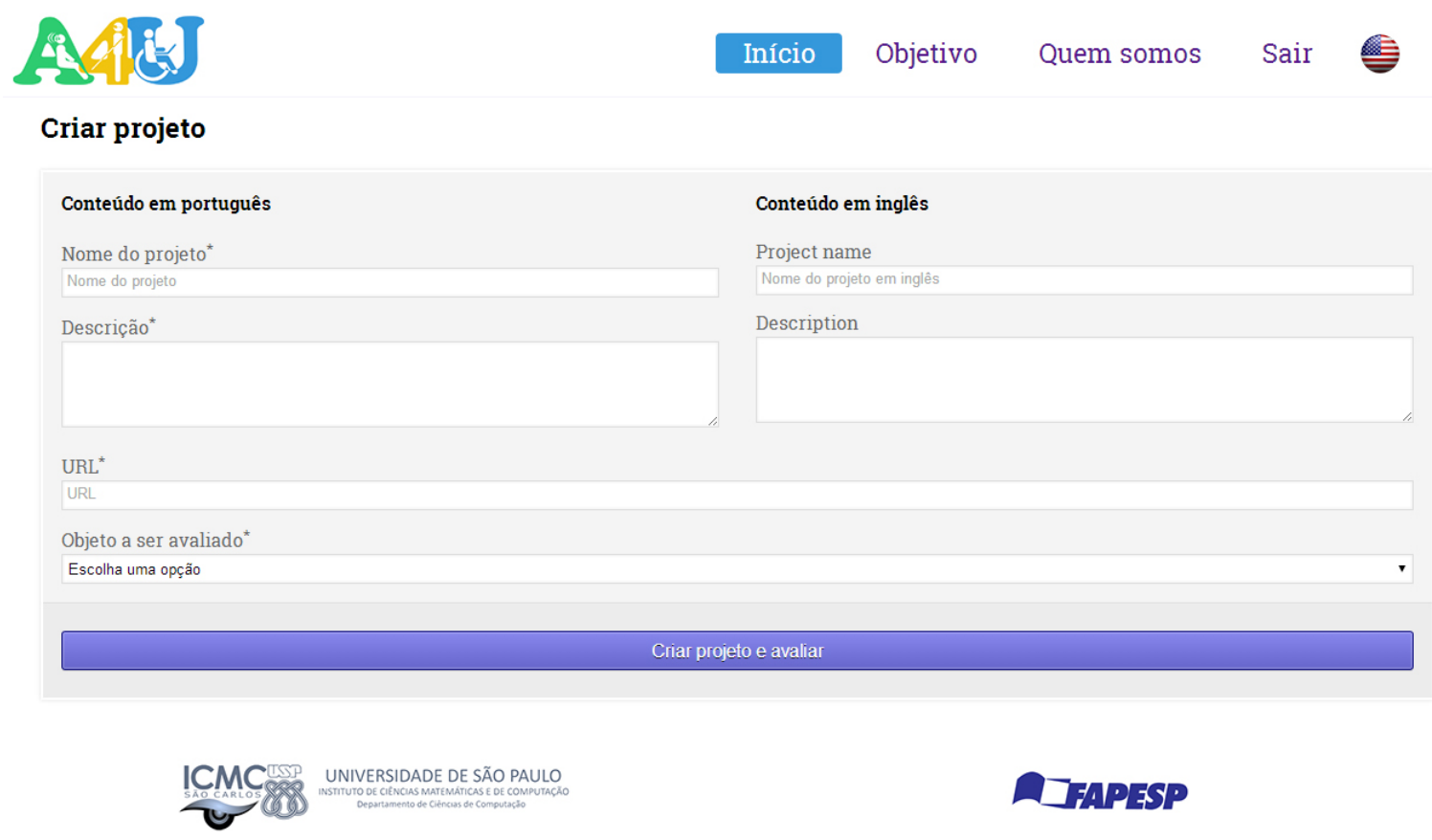

Figura 28: Tela de criação de projeto

Ao criar o projeto, a ferramenta indaga o usuário se ele quer abrir a URL avaliada em outra aba do navegador, a fim de facilitar a validação da avaliação e conduzir novas análises de acordo com as recomendações disponibilizadas.

O ambiente dispõe as opções de funcionalidades da ferramenta em um widget de abas, reproduzido na Figura 29. Esse widget foi tratado para ser acessível, sensível à tecla Tab. As opções fornecidas são Acessibilidade (WCAG 2.0), para avaliação de acessibilidade, conduzida pelas recomendações do W3C; Usabilidade (HHS), para avaliação de usabilidade a partir da checklist HHS; Código, onde o código fonte fornecido pela URL avaliada é disponibilizado; Incluir avaliação EARL, onde é possível carregar arquivo XML ou RDF, produto de avaliações em ferramentas semiautomáticas e Relatório, 
onde é gerado um relatório resumido do andamento da avaliação, com a possibilidade de geração de um relatório completo.

Início Objetivo Quem somos Sair

\section{Portal do Governo do Estado de São Paulo - http://www.saopaulo.sp.gov.br}

O sistema fez uma avaliação automática de acessibilidade utilizando o AChecker 1.3, considerando os critérios do nível de conformidade AAA (mais alto) da WCAG 2.0 (reproduza o teste para verificar os problemas com detalhes: http//achecker.ca/checker/

Possíveis resultados para os critérios de sucesso (estão destacados na cor vermelha nesta ferramenta)

- Problemas conhecidos: São problemas que foram identificados com certezas de serem barreiras de acessibilidade

- Prováveis problemas: São problemas que tem sido identificados como possíveis barreiras, porém requerem uma decisão humana. Você provavelmente

precisará modificar sua página para corrigir esses problemas;

- Potenciais problemas: São problemas que o AChecker não pode identificar, que requerem uma decisão humana. Você pode ter que modificar sua página para esses problemas, mas em muitos casos você apenas precisará confirmar que o problema descrito não está presente.

\section{Acessibilidade (WCAG 2.0) $\quad$ Usabilidade (HHS) $\quad$ Código $\quad$ Incluir avaliação em EARL $\quad$ Relatório}

Filtros

Princípio

Todas

Nível de conformidade

Todos

1.1 - Alternativas em Texto

Figura 29: Tela principal de avaliação

Ainda na Figura 29, é informado ao usuário que o sistema fez a avaliação com o AChecker e é disponibilizada a lista de possíveis problemas resultantes de sua avaliação. A aba principal, de acessibilidade, possibilita a filtragem das diretrizes e de seus critérios de sucesso pelo Princípio das WCAG 2.0, das deficiências, conforme resultado produzido pelo estudo descrito na Seção 4.3.6 e pelo Nível de conformidade.

Todos os princípios, conjuntos de deficiências, níveis de conformidade, diretrizes e critérios de sucesso são descritos, seja por ação do mouse durante o foco, ou opção de botão, a fim de que mesmo pessoas com baixo grau de conhecimento em acessibilidade, possam conduzir a avaliação.

Ao selecionar a opção de “Avaliar critérios de sucesso”, presente em cada diretriz, uma lista de critérios de sucesso é disponibilizada na coluna ao lado e o foco é atribuído à primeira opção. Na Figura 30 são ilustrados os critérios de sucesso obtidos a partir da diretriz “1.2 - Mídias com base no tempo”, na qual o usuário é conduzido a validar o 
Critério de sucesso, indicar desacordo ou considerar não aplicável aos elementos presentes no objeto avaliado.

Ainda nos critérios de sucesso, o usuário tem a possibilidade de fazer a leitura da descrição fornecida pela documentação do W3C, tanto para os critérios de sucesso, quanto para as diretrizes, além de produzir comentários, a fim de colaborar com um modelo de Design Rationale, onde documentará suas tomadas de decisão.

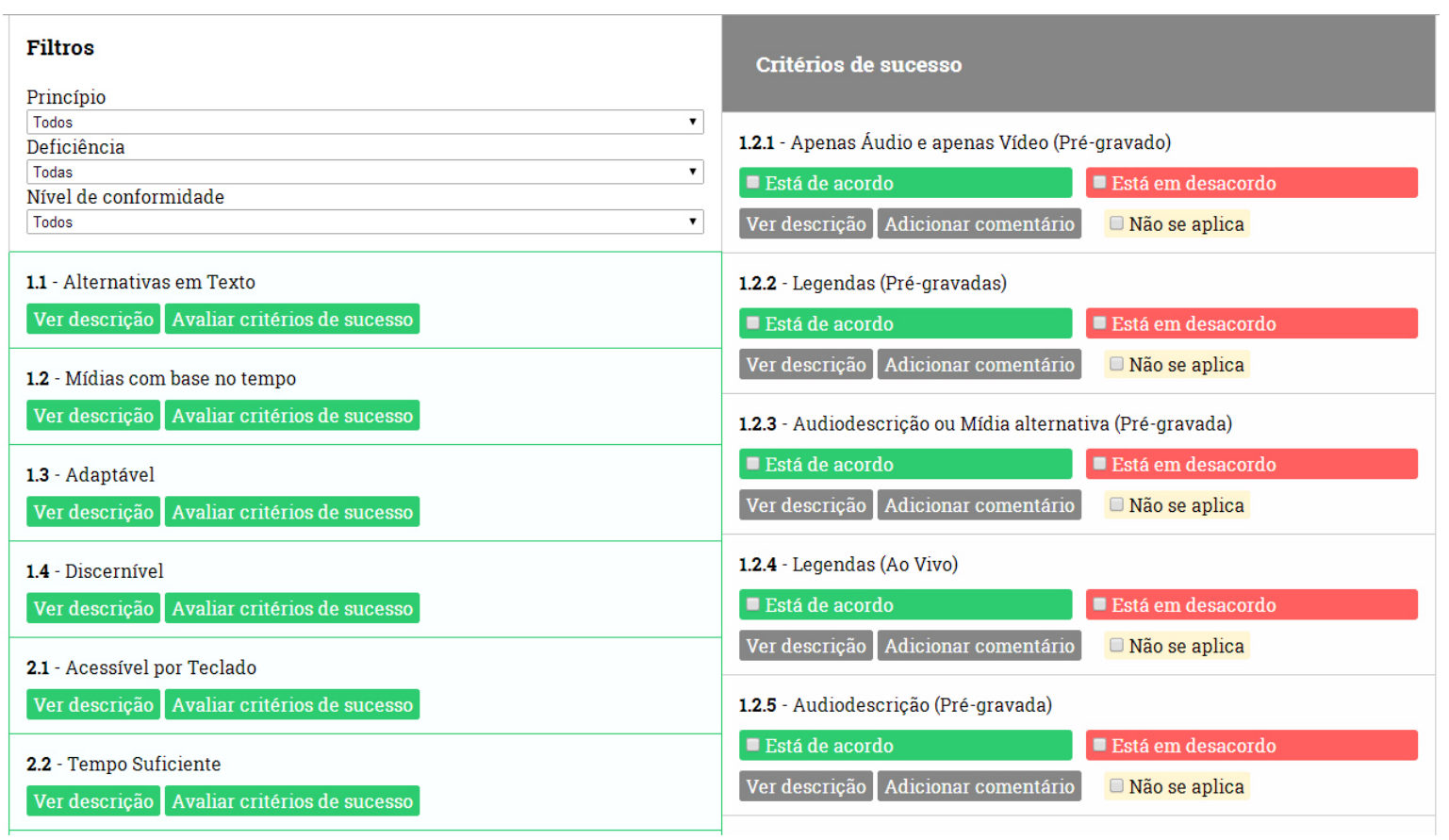

Figura 30: Tela de análise de acessibilidade

Toda ação do usuário é salva e informada a ele em tempo de execução, a fim de evitar esforços em vão, ao fechar a aplicação sem que as informações tenham sido salvas.

Para evitar desgaste do usuário causado pelo refresh da página a cada ação, a interface foi desenvolvida com submissões tratadas em $\operatorname{Ajax}^{20}$, assim o sistema salva as alterações sem interromper o fluxo de avaliação. O refresh só é executado ao mudar opções no filtro de diretrizes.

Os comentários podem ser inseridos e removidos de acordo com a vontade do usuário, com a informação do horário de inserção disponibilizada e, ao selecionar o

${ }^{20}$ Faz uso de tecnologias como Javascript e XML, para tornar páginas Web mais interativas com o usuário, utilizando-se de solicitações assíncronas de informações. 
conjunto de critérios de sucesso de outra diretriz, a lista de critérios de sucesso é atualizada sem recarregar a página, porém as ações do usuário já salvas, podem ser recuperadas ao voltar para a lista anterior.

A experiência de usabilidade se repete na avaliação das diretrizes HHS, com os capítulos da HHS fazendo o papel das diretrizes da WCAG 2.0 e as diretrizes HHS, no papel de critérios de sucesso, conforme visualizado na Figura 31.

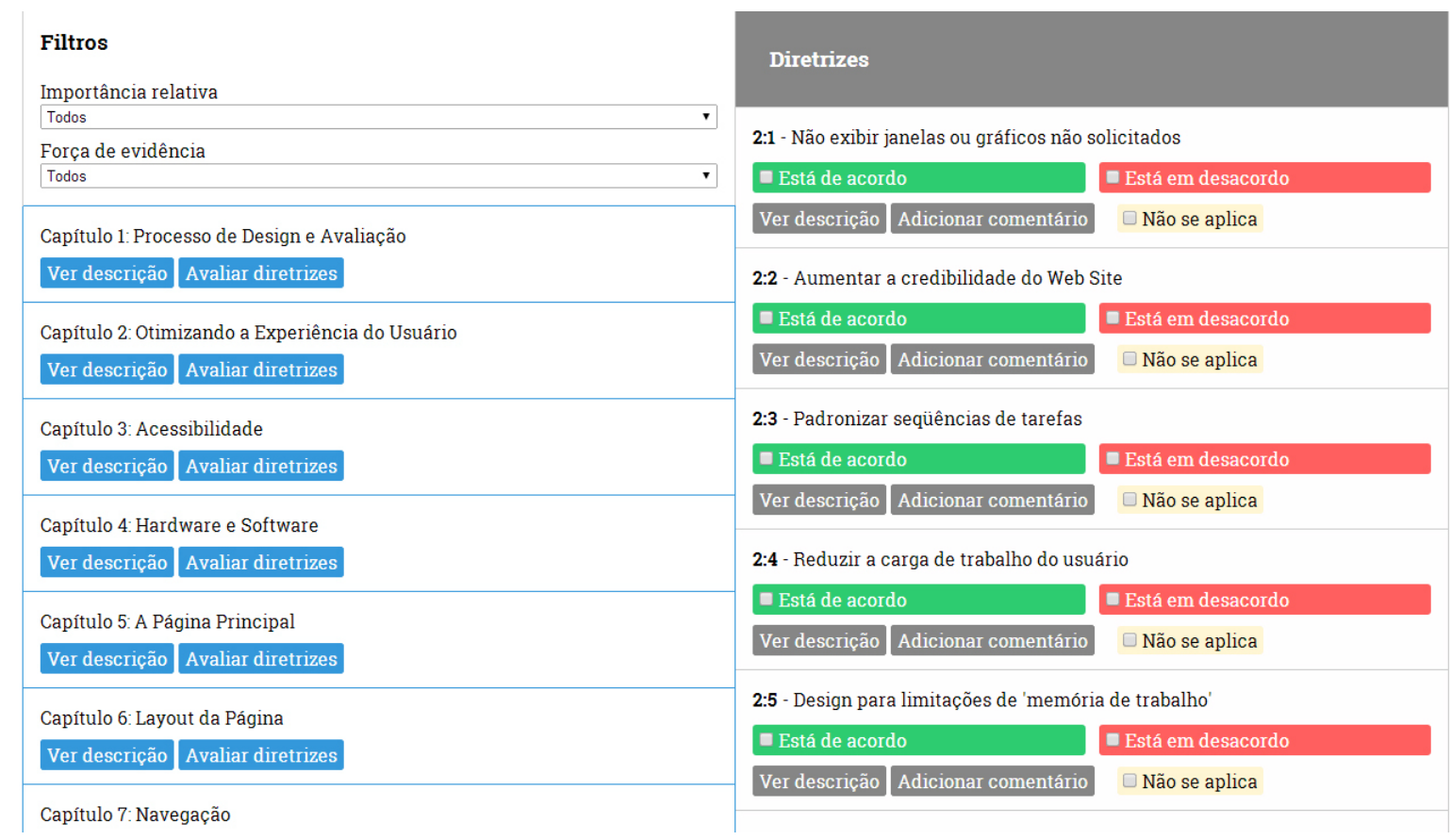

Figura 31: Tela de análise de usabilidade

Os filtros presentes na avaliação de usabilidade correspondem ao grau de importância relativa e à força de evidência, definidos na Seção 2.3.2. Todos os níveis de importância relativa, força de evidência, capítulos e diretrizes são descritos, seja por ação do mouse durante o foco, ou opção de botão, a fim de que mesmo pessoas com baixo grau de conhecimento em usabilidade, possam conduzir a avaliação.

A aba seguinte reproduz o código fonte da URL objeto da avaliação, a fim de facilitar a análise de critérios de sucesso ou diretrizes de usabilidade que precisam de apoio e verificação do código fonte da aplicação, como, por exemplo, a atribuição textual descritiva aos elementos de imagem, como recomendação de acessibilidade. 
Outra opção disponibilizada pelo ambiente é carregar avaliações feitas por outras ferramentas que disponibilizem os resultados na linguagem EARL, conforme descrita na Seção 3.6. A atribuição de resultados de outras ferramentas possibilita uma experiência mais rica na avaliação, pois evita vieses ao priorizar resultados de uma fonte única. É necessário frisar, neste ponto, que para a atribuição de outros resultados, seja do AChecker, seja de outras ferramentas a partir da EARL, o ambiente não dispensa a avaliação manual do usuário, pois conforme indicado nos trabalhos relacionados no Capítulo 2, a avaliação humana, manual, é imprescindível para a validade do teste (ALMEIDA e BARANAUSKAS, 2010). Na Figura 32 é indicado como a representação de problemas encontrados nas recomendações aparece ao usuário.

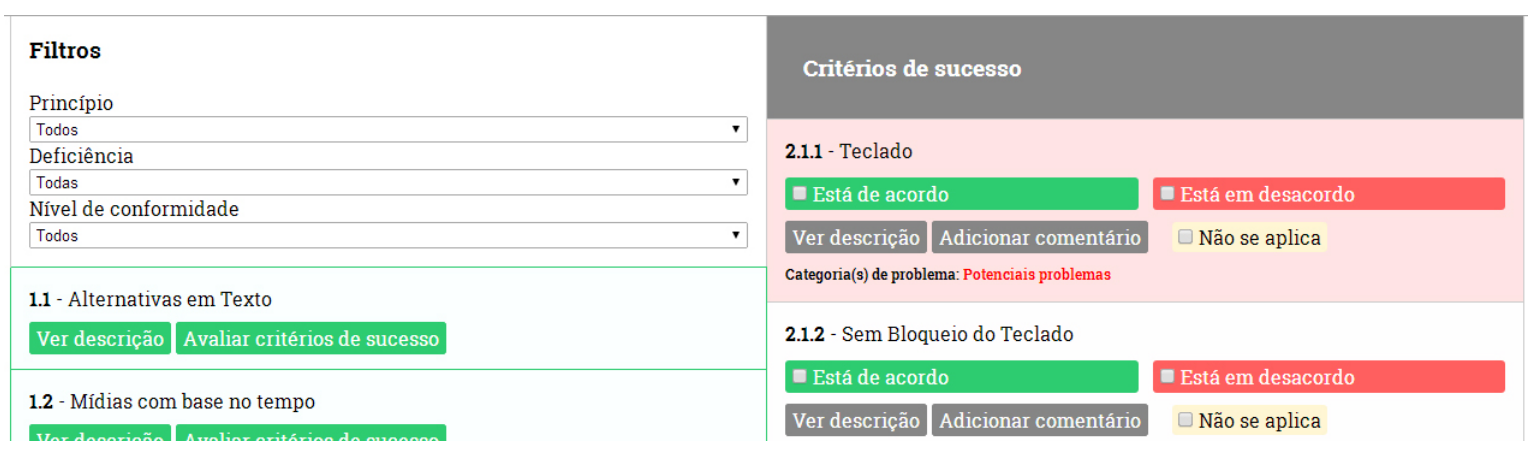

Figura 32: Representação de problemas resultantes da avaliação por outras ferramentas

A recomendação indicada com problemas recebe a cor de fundo avermelhada e a categoria do problema é apresentada abaixo. Assim, o A4U não substitui a ferramenta de avaliação semiautomática, mas tem o papel de apoio para as avaliações humanas.

A ferramenta sugerida para produção de relatórios de acessibilidade em EARL, é a WaaT, vista na Seção 4.5.1, pois junto à AChecker, considera as WCAG 2.0 e produz o relatório nessa linguagem. Conforme identificado na Figura 33, a informação sobre a EARL é direcionada ao usuário. 


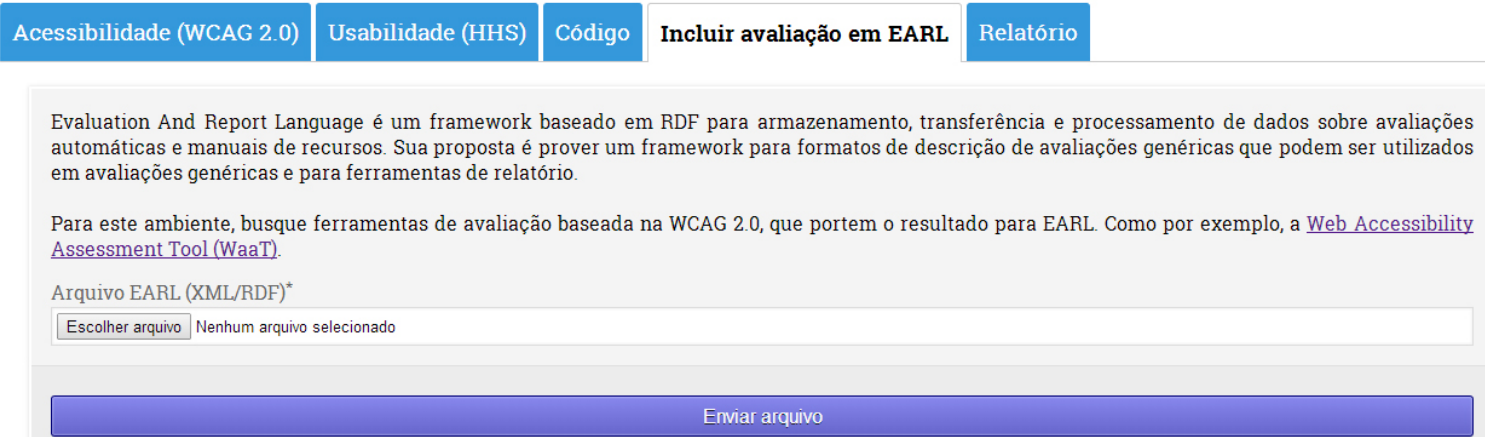

Figura 33: Tela para inclusão de relatórios em EARL

Por fim, a aba Relatório conduz o usuário à visualização estatística de sua avaliação, com dados como recomendações atendidas, em desacordo, não aplicáveis e ainda não avaliadas. Gráficos são produzidos para ilustrar essa situação, conforme exibido na Figura 34.

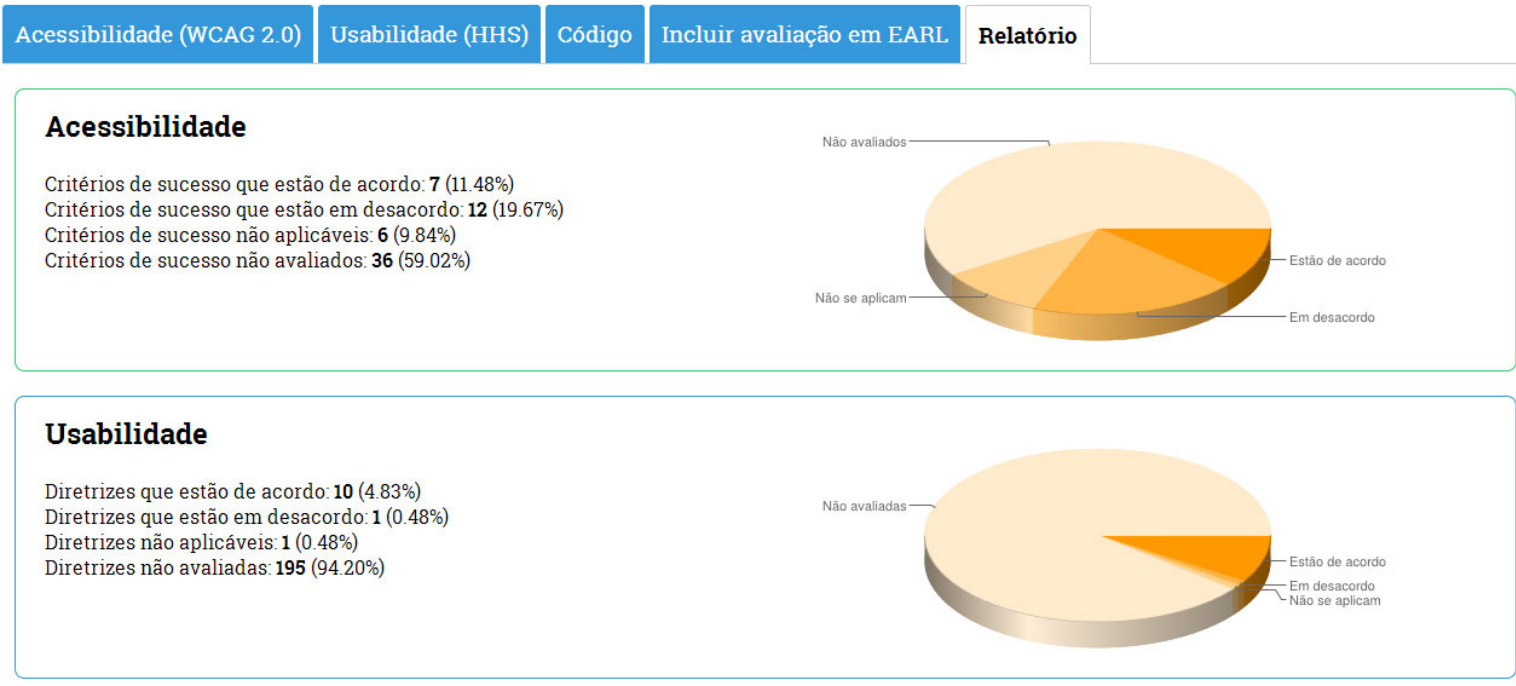

\section{Gerar relatório completo}

Figura 34: Tela de relatório resumido

Ainda na Figura 34, é possível gerar o relatório completo da avaliação pela opção “Gerar relatório completo”. O relatório produzido é gerado em PDF, com as estatísticas de completude da avaliação, bem como todas as recomendações, categorizadas por seu status, seja de acordo, em desacordo, não aplicáveis ou não avaliadas. As recomendações são seguidas dos respectivos comentários que o usuário realizou durante a análise. Na Figura 35 é apresentado um relatório onde não existiu nenhuma avaliação. 
Nome do projeto avaliado: Portal São Paulo

Descrição: Projeto do Portal do Governo do Estado de São Paulo

Data da avaliação: 19/02/2014 - 18:32:23

Página avaliada: http://www.saopaulo.sp.gov.br/

Autor da avaliação:

\section{Acessibilidade}

Critérios de sucesso que estāo de acordo: 7 (11.48\%)

Critérios de sucesso que estão em desacordo: 12 (19.67\%)

Critérios de sucesso não aplicáveis: 6 (9.84\%)

Critérios de sucesso não avaliados: 36 (59.02\%)

\section{Critérios de sucesso atendidos, separados por conjunto de deficiência}

Visual: 7 (14.58\%)

Auditiva: 1 (5.56\%)

Cognitiva: 4 (8.70\%)

Motora: 1 (4.55\%)

Convulsiva: $0(0.00 \%)$

\section{Critérios de sucesso atendidos, separados por Nível de conformidade}

A: $25(100.00 \%)$

AA: $(0.00 \%)$

AAA: $(0.00 \%)$

Figura 35: Relatório completo em PDF

Os relatórios completos podem ser utilizados como histórico de decisões e comparados com resultados de outros avaliadores, com a finalidade de conduzir ao maior grau de conformidade possível.

A ferramenta se propôs inovar com a avaliação de acessibilidade e usabilidade no mesmo ambiente, conduzindo o usuário a pensar nos dois conceitos, de maneira a guiá-lo ao que é chamado de usabilidade universal. A condução de avaliações indicará se existem questões que implicam em contrastes de recomendações e colaborará na identificação da configuração do Diagrama de $\mathrm{Venn}^{21}$, considerando os conjuntos de conceitos de acessibilidade e usabilidade.

${ }^{21}$ São usados em matemática para simbolizar graficamente propriedades, axiomas e problemas relativos aos conjuntos e sua teoria. 
Com o propósito de iniciar a verificação das questões de contrastes dos conceitos e validar o uso do ambiente, foi proposto o estudo de caso descrito na próxima seção.

\subsection{Estudo de caso}

Nesta seção é apresentado o estudo de caso, utilizado para validar o A4U, envolvendo duas categorias como público alvo, os pesquisadores e os desenvolvedores. A atividade consistiu em avaliar o portal do governo do Estado de São Paulo ${ }^{22}$ em acessibilidade e usabilidade, registrando o histórico de tomadas de decisões e a posterior discussão sobre os resultados obtidos na experiência dos usuários com a ferramenta.

Antes de iniciar a condução do estudo de caso, a utilização do A4U foi submetida, como estudo piloto, a um desenvolvedor. Suas ações diante da ferramenta foram supervisionadas pelo autor desta dissertação, possibilitando encontrar algumas questões que deveriam ser tratadas antes de iniciar o procedimento formalizado. As questões levantadas e posteriormente tratadas, foram:

1. O usuário não achou intuitivo abrir uma aba com o site objeto da avaliação, conduzindo o procedimento a partir do código disponibilizado na aplicação;

2. Quando as recomendações eram filtradas, a completude da operação nos conjuntos (diretrizes ou capítulos) não eram informadas;

3. Ao filtrar os resultados de usabilidade, o filtro previamente selecionado na seção de acessibilidade era perdido;

4. Havia um erro no filtro de força de evidência, em usabilidade e;

5. O sistema não considerava o timeout da sessão, possibilitando que o usuário continuasse a avaliação, sem salvá-la.

Depois de corrigidas as questões anteriores, o ambiente foi disponibilizado aos usuários que formaram o público estudado.

\footnotetext{
${ }^{22}$ http://www.saopaulo.sp.gov.br
} 


\subsubsection{Condução}

Como previamente mencionado, a escolha do portal, como objeto a ser avaliado, deu-se a partir da obrigatoriedade de sites da administração pública serem acessíveis, e pelo endereço constar entre os sites governamentais mais acessados, no ranking da ferramenta Alexa ${ }^{23}$.

Após o término da avaliação, os participantes foram convidados a completar um questionário sobre a atividade. O questionário (APÊNDICE A) foi composto de 8 questões utilizando a Likert Scale (LIKERT, 1932), considerando o conhecimento em acessibilidade Web, usabilidade Web, a quantidade de itens expostos para avaliação, a dificuldade em se entender os critérios de sucesso das WCAG 2.0 e as diretrizes HHS. Ainda, indaga sobre a cobertura da avaliação por ferramentas semiautomáticas e a experiência do usuário em considerar acessibilidade e usabilidade no mesmo ambiente.

Duas perguntas objetivas foram inseridas no questionário para classificar o avaliador em pesquisador ou desenvolvedor e, verificar se durante a análise, houve a percepção de ao menos um conflito entre as tomadas de decisão envolvendo os dois conceitos, acessibilidade e usabilidade. Mais de 5 campos livres também estão presentes, para comentários sobre a quantidade de itens avaliados, a cobertura das ferramentas semiautomáticas, a experiência em considerar os dois conceitos no mesmo ambiente, a interface do A4U e impressões gerais da atividade.

O estudo envolveu três pesquisadores da área, sendo esses um professor da Universidade Federal de Goiás, uma doutoranda e uma mestranda do Instituto de Ciências Matemáticas e de Computação - USP; e 7 desenvolvedores de software que trabalham em uma empresa de desenvolvimento Web.

A atividade consistiu em seguir um roteiro (APÊNDICE B) preparado pelo autor desta dissertação. O roteiro disponibilizou um vídeo de apresentação do ambiente e da ferramenta WaaT, utilizada como apoio na atividade; listou alguns materiais para consulta, e restringiu os itens de avaliação ao nível de conformidade A, das WCAG 2.0, ao nível 5

\footnotetext{
${ }^{23}$ http://www.alexa.com/
} 
de importância relativa e 4 para o nível de força de evidência, pois 5 neste último, representaria um número muito reduzido de diretrizes a serem cobertas.

As restrições na avaliação contribuíram para limitar a quantidade de questões, a fim de evitar excessivo desconforto durante o procedimento, por parte dos participantes, mas ao mesmo tempo considerar as principais questões de acessibilidade e usabilidade, já que o nível de conformidade A é o básico em acessibilidade requerido e os níveis elevados dos parâmetros da HHS correspondem aos itens mais importantes a serem seguidos. Nessa configuração, 25 critérios de sucesso em acessibilidade e 12 diretrizes de usabilidade foram expostos à avaliação, conforme informado no Quadro 14.

Quadro 14: Recomendações resultantes dos filtros utilizados na avaliação

\begin{tabular}{|c|c|c|c|}
\hline \multicolumn{2}{|r|}{ Acessibilidade (WCAG 2.0) } & \multicolumn{2}{|r|}{ Usabilidade (HHS) } \\
\hline 1.1.1 & Conteúdo Não Textual & 01:02 & Estabelecer requisitos do usuário \\
\hline 1.2 .1 & Apenas Áudio e apenas Vídeo (Pré-gravado) & 03:03 & $\begin{array}{l}\text { Não usar uma única cor para transmitir } \\
\text { informacões }\end{array}$ \\
\hline 1.2 .2 & Legendas (Pré-gravadas) & & Criar uma primeira impressão positiva do seu \\
\hline & Audiodescrição ou Mídia alternativa (Pré- & 05:03 & 1 \\
\hline 1.2 .3 & gravada) & 06:02 & Posicionar itens importantes consistentemente \\
\hline 1.3.1 & Informações e Relações & & Posicionar os itens importantes no centro \\
\hline 1.3 .2 & Sequência com Significado & 06:03 & superior \\
\hline 1.3.3 & Características Sensoriais & 08:01 & Eliminar rolagem horizontal \\
\hline 1.4.1 & Utilização da Cor & 09:01 & Usar rótulos claros para as categorias \\
\hline 1.4 .2 & Controle de Áudio & $10: 01$ & Usar rótulos significativos para os "links" \\
\hline 2.1.1 & Teclado & $15: 01$ & Deixar claras as sequências de ações \\
\hline 2.1 .2 & Sem Bloqueio do Teclado & 16:01 & Organizar informações de forma clara \\
\hline 2.2 .1 & Ajustável por Temporização & 16:02 & $\begin{array}{l}\text { Facilitar a visualização (exame do conteúdo) } \\
\text { Garantir resultados de pesquisa }\end{array}$ \\
\hline 2.2 .2 & Pausar, Parar, Ocultar & $17: 01$ & utilizáveis/úteis \\
\hline 2.3.1 & Três Flashes ou Abaixo do Limite & & \\
\hline 2.4 .1 & Ignorar Blocos & & \\
\hline 2.4 .2 & Página com Título & & \\
\hline 2.4 .3 & Ordem do Foco & & \\
\hline 2.4 .4 & Finalidade do Link (Em Contexto) & & \\
\hline 3.1 .1 & Linguagem da Página & & \\
\hline 3.2.1 & Em Foco & & \\
\hline 3.2 .2 & Em Entrada & & \\
\hline 3.3.1 & Identificação do Erro & & \\
\hline 3.3.2 & Etiquetas ou Instruções & & \\
\hline 4.1.1 & Análise & & \\
\hline 4.1.2 & Nome, Função, Valor & & \\
\hline
\end{tabular}


Os participantes foram submetidos à concordância do termo de consentimento livre e esclarecido (APÊNDICE C), que explica o objetivo do estudo e coloca o participante no direito de se ausentar da atividade em qualquer momento, sem qualquer ônus. Também frisa os procedimentos do estudo e garante a preservação da privacidade do respondente.

A tarefa foi encaminhada aos avaliadores, de maneira que fizessem em suas próprias residências ou local de trabalho, em acordo com o empregador, a fim de possibilitar o melhor ambiente para que se sentissem à vontade. O tempo de execução médio foi informado, porém eram livres para executarem o procedimento no tempo que achassem necessário.

O primeiro passo foi assistir ao vídeo de apresentação do ambiente, posteriormente cadastrar uma conta de usuário na ferramenta e criar o projeto de avaliação da URL http://www.saopaulo.sp.gov.br/. O participante foi informado que a criação do projeto remete automaticamente à avaliação do objeto em estudo à ferramenta AChecker, para destacar os critérios de sucesso que necessitem de maior atenção.

Para contribuir com os resultados da AChecker, o avaliador é indicado a baixar a ferramenta WaaT, fazer a análise da URL por ela e submeter o relatório gerado em EARL, ao A4U. Assim, o ambiente discrimina todos os critérios de sucesso que ficaram em desacordo em alguma das duas ferramentas semiautomáticas de avaliação. Um vídeo de utilização da Waat foi produzido e disponibilizado através do roteiro. Em seguida, os usuários são conduzidos a filtrarem os critérios de sucesso, a partir do nível de conformidade A e os de usabilidade, a partir do índice 5 para importância relativa e 4 para força de evidência.

Ao seguir todas as recomendações expostas pelos filtros, avaliando se essas se encontram em acordo ou desacordo, ou mesmo não se aplicam ao objeto de teste, o usuário é submetido à geração do relatório completo de sua avaliação e solicitado a responder o questionário de impressões durante a análise.

Os resultados obtidos deste estudo de caso são ilustrados na próxima subseção, onde também é realizada uma discussão sobre o que foi evidenciado com o experimento, envolvendo pesquisadores e desenvolvedores. 


\subsubsection{Resultados da avaliação}

Os resultados aqui apresentados são distribuídos primeiramente considerando a avaliação do portal do governo de São Paulo, com relação a sua concordância ou não aplicabilidade com as recomendações de acessibilidade e usabilidade.

Os respondentes indicaram sua expertise em desenvolvimento Web, obtendo a classificação geral a seguir, exposta no Quadro 15. É possível observar, a partir das atribuições nesse critério, que em sua maioria, os participantes se disseram avançados em desenvolvimento Web, porém isso não implica no conhecimento de técnicas de promoção de usabilidade ou acessibilidade.

Quadro 15: Classificação de expertise dos respondentes em desenvolvimento Web

\begin{tabular}{|l|r|}
\hline Baixa - consigo desenvolver algo de forma simples & 1 \\
\hline Moderada - tenho alguma experiência no desenvolvimento & 2 \\
\hline Avançada - tenho experiência (especialista) & 7 \\
\hline
\end{tabular}

As avaliações resultaram na análise de 37 recomendações, sendo 25 de acessibilidade e 12 de usabilidade, ilustradas no Quadro 16. A partir do somatório das respostas correspondentes nos critérios de "Em acordo", "Em desacordo" e "Não se aplica”, verificou-se que 4 pessoas não finalizaram a atividade, pois restringiram-se unicamente à avaliação de acessibilidade.

Quadro 16: Quadro com as respostas obtidas pelos usuários

\begin{tabular}{|c|c|c|c|}
\hline \multicolumn{5}{|c|}{ Acessibilidade (WCAG 2.0) } \\
\hline Critério & Em acordo & Em desacordo & Não se aplica \\
\hline $\mathbf{1 . 1 . 1}$ & 5 & 5 & 0 \\
\hline $\mathbf{1 . 2 . 1}$ & 4 & 2 & 4 \\
\hline $\mathbf{1 . 2 . 2}$ & 2 & 3 & 5 \\
\hline $\mathbf{1 . 2 . 3}$ & 3 & 3 & 4 \\
\hline $\mathbf{1 . 3 . 1}$ & 4 & 6 & 0 \\
\hline $\mathbf{1 . 3 . 2}$ & 5 & 3 & 2 \\
\hline $\mathbf{1 . 3 . 3}$ & 3 & 6 & 1 \\
\hline $\mathbf{1 . 4 . 1}$ & 8 & 2 & 0 \\
\hline $\mathbf{1 . 4 . 2}$ & 5 & 0 & 5 \\
\hline $\mathbf{2 . 1 . 1}$ & 3 & 7 & 0 \\
\hline $\mathbf{2 . 1 . 2}$ & 4 & 5 & 1 \\
\hline $\mathbf{2 . 2 . 1}$ & 1 & 4 & 5 \\
\hline $\mathbf{2 . 2 . 2}$ & 1 & 7 & 2 \\
\hline
\end{tabular}

\begin{tabular}{|c|c|c|c|}
\hline \multicolumn{5}{|c|}{ Usabilidade (HHS) } \\
\hline Diretriz & Em acordo & Em desacordo & Não se aplica \\
\hline $\mathbf{0 1 : 0 2}$ & 4 & 2 & 0 \\
\hline $\mathbf{0 3 : 0 3}$ & 4 & 2 & 0 \\
\hline $\mathbf{0 5 : 0 3}$ & 5 & 1 & 0 \\
\hline $\mathbf{0 6 : 0 2}$ & 5 & 1 & 0 \\
\hline $\mathbf{0 6 : 0 3}$ & 5 & 1 & 0 \\
\hline $\mathbf{0 8 : 0 1}$ & 4 & 1 & 1 \\
\hline $\mathbf{0 9 : 0 1}$ & 6 & 0 & 0 \\
\hline $\mathbf{1 0 : 0 1}$ & 4 & 2 & 0 \\
\hline $\mathbf{1 5 : 0 1}$ & 2 & 2 & 2 \\
\hline $\mathbf{1 6 : 0 1}$ & 4 & 2 & 0 \\
\hline $\mathbf{1 6 : 0 2}$ & 5 & 1 & 0 \\
\hline $\mathbf{1 7 : 0 1}$ & 3 & 2 & 1 \\
\hline
\end{tabular}




\begin{tabular}{|l|l|l|l|}
\hline 2.3.1 & 7 & 2 & 1 \\
\hline 2.4.1 & 3 & 6 & 1 \\
\hline $\mathbf{2 . 4 . 2}$ & 9 & 1 & 0 \\
\hline 2.4 .3 & 3 & 4 & 3 \\
\hline 2.4 .4 & 2 & 8 & 0 \\
\hline 3.1 .1 & 9 & 1 & 0 \\
\hline 3.2 .1 & 7 & 1 & 2 \\
\hline 3.2 .2 & 7 & 3 & 0 \\
\hline 3.3 .1 & 4 & 4 & 2 \\
\hline 3.3 .2 & 4 & 6 & 1 \\
\hline $\mathbf{4 . 1 . 1}$ & 6 & 4 & 0 \\
\hline $\mathbf{4 . 1 . 2}$ & 5 & 5 & 0 \\
\hline
\end{tabular}

A partir do Quadro 16, considerando que a maioria dos resultados em comum indicam a observância daquele estado da recomendação e, nos casos em que dois ou mais estados se equivalem não é possível verificar a condição, têm-se então 7 recomendações de acessibilidade e uma de usabilidade em que não se pode abstrair um estado de concordância ou não aplicabilidade, como exibe o Quadro 17, para acessibilidade.

Quadro 17: Resultados de acessibilidade indicando o estado de "Não foi possível verificar"

\begin{tabular}{|c|c|c|c|}
\hline \multicolumn{5}{|c|}{ Acessibilidade (WCAG 2.0) } \\
\hline Em acordo & Em desacordo & Não se aplica & Não foi possível verificar \\
\hline 1.3 .2 & 1.3 .1 & 1.2 .2 & 1.1 .1 \\
\hline 1.4 .1 & 1.3 .3 & 2.2 .1 & 1.2 .1 \\
\hline 2.3 .1 & 2.1 .1 & & 1.2 .3 \\
\hline 2.4 .2 & 2.1 .2 & & 1.4 .2 \\
\hline 3.1 .1 & 2.2 .2 & & 2.4 .3 \\
\hline 3.2 .1 & 2.4 .1 & & 3.3 .1 \\
\hline 3.2 .2 & 2.4 .4 & & 4.1 .2 \\
\hline 4.1 .1 & 3.3 .2 & & \\
\hline
\end{tabular}

É importante observar que as ferramentas semiautomáticas identificaram algumas incompatibilidades e, todas as questões claramente caracterizadas como erros, também foram consideradas em desacordo pelos avaliadores humanos, o que não aconteceu com os possíveis problemas que as ferramentas solicitam intervenção humana. Por exemplo, os critérios de sucesso 1.4.1, que corresponde a não utilização de cor como único meio de transmitir informações; 2.3.1, que corresponde à utilização de flash; 2.4.2, que indica a utilização de título na página que descreva seu conteúdo e 3.2.2, que indica a variação de contexto pela alteração em algum componente de interface. A ferramenta AChecker 
indicou prováveis problemas nesses critérios e os avaliadores humanos os classificaram como em acordo. O Quadro 18, a seguir, apresenta os resultados para a avaliação de usabilidade.

Quadro 18: Resultados de usabilidade indicando o estado de "Não foi possível verificar"

\begin{tabular}{|c|c|}
\hline \multicolumn{2}{|c|}{ Usabilidade (HHS) } \\
\hline Em acordo & Não foi possível verificar \\
\hline $01: 02$ & $15: 01$ \\
\hline $03: 03$ & \\
\hline $05: 03$ & \\
\hline $06: 02$ & \\
\hline $06: 03$ & \\
\hline $08: 01$ & \\
\hline $09: 01$ & \\
\hline $10: 01$ & \\
\hline $16: 01$ & \\
\hline $16: 02$ & \\
\hline $17: 01$ & \\
\hline
\end{tabular}

Como não houve auxílio de ferramentas semiautomáticas na avaliação de usabilidade, a percepção dos contrastes foi totalmente atribuída à avaliação manual. Os respondentes não souberam identificar se o portal tem sequências de ações óbvias (15:01), contribuindo com a impossibilidade de verificação a partir dos resultados da avaliação.

Considerando o fluxo sugerido, de verificação do conjunto de acessibilidade em primeira instância, seguida da validação das recomendações de usabilidade e da não existência de ferramentas semiautomáticas, no roteiro, que apoiassem a validação dessas, pode-se supor que os quatro usuários que não finalizaram o procedimento de usabilidade, encontraram dificuldades ou excessivo esforço na execução das tarefas.

Com relação aos problemas encontrados, afirma-se que o portal do governo de São Paulo apresenta concordância com a maioria das recomendações aqui consideradas, pois das 37 recomendações e dos resultados obtidos e apresentados no Quadro 16 e no Quadro 17, 51,36\% estão de acordo, 5,40\% não se aplicam, 21,62\% não foram identificadas, pois resultaram em empate das decisões do usuário com relação à concordância ou não da página com as recomendações, enquanto as outras 21,62\% resultaram em discordância. 
Em seguida, as impressões dos usuários, informadas no questionário após a utilização do A4U, serão discutidas.

\subsubsection{Questionário}

A partir do questionário (APÊNDICE A), buscou-se verificar as impressões que os pesquisadores e desenvolvedores tiveram na utilização do A4U. Para tanto, oito questões foram integradas no modelo de escala, de 1 a 5, podendo o 1 ser "de menor grau”, "ruim” ou “mais difícil”, e 5 o “de maior grau”, “ótimo” ou “mais fácil”. Os resultados destas questões são apresentados no Quadro 19.

Quadro 19: Resultados das impressões dos participantes pelas respostas ao questionário

\begin{tabular}{|l|c|c|}
\cline { 2 - 3 } \multicolumn{1}{c|}{} & \multicolumn{1}{c|}{$\begin{array}{c}\text { Mediana } \\
\text { (Likert Scale) }\end{array}$} & $\begin{array}{c}\text { Moda } \\
\text { (Likert Scale) }\end{array}$ \\
\hline 1 - Sobre seu conhecimento em acessibilidade Web & 3,5 & 3 (30\%) e 5 (30\%) \\
\hline 2 - Sobre seu conhecimento em usabilidade Web & 4 & $4(60 \%)$ \\
\hline 3 - Sobre a quantidade de itens a serem avaliados & 4,5 & $4(40 \%)$ \\
\hline $\begin{array}{l}\text { 4 - Sobre a dificuldade em entender o que cada sucesso } \\
\text { de critério da WCAG 2.0 significa, apenas ao ler seu } \\
\text { nome e descrição }\end{array}$ & 4,5 & 4 (50\%) \\
\hline $\begin{array}{l}\text { 5 - Sobre a dificuldade em entender o que cada diretriz da } \\
\text { HHS significa, apenas ao ler seu nome e descrição }\end{array}$ & 4 & $40 \%)$ \\
\hline $\begin{array}{l}\text { 6 - Sobre a cobertura da avaliação das ferramentas } \\
\text { semiautomáticas }\end{array}$ & 4 & $4(60 \%)$ \\
\hline $\begin{array}{l}\text { 7 - Sobre a experiência de tratar acessibilidade e } \\
\text { usabilidade no mesmo ambiente de avaliação }\end{array}$ & 5 & 5 (70\%) \\
\hline 8 - Sobre a interface do A4U & 4,5 & 4 (50\%) e 5 (50\%) \\
\hline
\end{tabular}

Como resultado, pode-se observar que a população que conduziu a avaliação é formada por conhecedores de acessibilidade e usabilidade; mais da metade dos respondentes consideraram que a quantidade de recomendações a serem analisadas é alta e que as ferramentas semiautomáticas de avaliação utilizadas têm boa cobertura quanto à detecção de problemas. Ainda, não encontraram tanta dificuldade em entender os critérios de sucesso referentes à acessibilidade e as diretrizes de usabilidade, apenas pela leitura de sua descrição fornecida pela respectiva documentação de seus criadores. Já, ao considerar o A4U, a grande maioria indicou a experiência em se tratar acessibilidade e usabilidade 
como próximo do excelente, além de qualificarem como ótima a interface utilizada no ambiente.

Adicionalmente às questões utilizando Likert Scale, houve cinco questões de resposta livre para que os participantes pudessem imprimir suas percepções com maior detalhe, contribuindo com as respostas objetivas. Na sequencia, são levantados os tópicos das questões e o resumo dos comentários.

\section{Comentários sobre a quantidade de itens a serem avaliados}

a. A quantidade de itens a serem considerados é demasiada alta se o teste não envolver filtros;

b. Mesmo considerando a quantidade alta de recomendações, elas são importantes, pois o domínio exige esse número. Não há como se ter uma ferramenta completa com menos exigências;

c. A ferramenta prover filtros, possibilitar salvar e continuar a avaliação em outro momento facilita muito o processo.

2. Comentários sobre a cobertura da avaliação das ferramentas semiautomáticas

a. As ferramentas semiautomáticas resultaram em falsos positivos, evidenciando a importância da percepção humana na avaliação;

b. Mesmo com algumas indicações incoerentes, em sua maioria as ferramentas colaboraram com destaques relevantes, porém muitos critérios não são analisados por elas;

c. Evidenciar ao usuário a importância da inserção de relatórios EARL antes de começar a avaliação é relevante, para que o fluxo colabore com menos esforço do avaliador.

3. Comentários sobre a experiência de tratar acessibilidade e usabilidade no mesmo ambiente de avaliação 
a. Questões de usabilidade, muitas vezes, influem em acessibilidade, portanto tratar os dois contextos no mesmo ambiente é bastante importante;

b. Os dois conjuntos de critérios se complementam;

c. Talvez pessoas com menos conhecimento nos conceitos, possam confundir a divisão de critérios.

\section{Comentários sobre a interface do A4U}

a. Interface muito amigável e interativa, porém a avaliação é bastante cansativa;

b. Interface leve e bem fácil de usar, com abas e outros padrões clássicos (bem conhecidos). Os filtros auxiliam muito ao avaliador que tem condições de avaliar por partes e de modo organizado. Há explicações para as diretrizes WCAG 2.0 e HHS, isso facilita e viabiliza o processo, pois por mais especialista que o avaliador seja, ele não sabe de memória todas as condições a serem vistas. Ou seja, a ferramenta é avaliativa e também educativa, pois guia e dá suporte ao processo de avaliação. A inclusão dos relatórios automáticos é ótimo, pois auxilia no trabalho muito desejado em indústrias: "que os avaliadores não percam tempo analisando questões que poderiam ser checadas automaticamente";

c. Interface amigável, com boa utilização de cores, tamanho dos objetos e elementos do site, tão como uma boa forma de exibir os "boxes", com a descrição dos critérios ao passar o mouse por cima dos links e ao clicar no botão. Interessantes como foram separados os "critérios de sucesso" do lado direito do site e o modo como é feita a avaliação de cada um deles, juntamente com o comentário opcional; 
d. A ferramenta teria um ganho considerável se as questões com problemas fossem exibidas com exemplos na página avaliada e as linhas do código fossem apontadas.

\section{Comentário geral}

a. Bastante interessante, pois a ferramenta possibilita selecionar os critérios que você quer avaliar, e também, comparar acessibilidade com usabilidade;

b. Alguns critérios devem ser mais explicativos, considerando exemplos, pois há casos em que o entendimento é prejudicado, contribuindo com uma avaliação duvidosa;

c. Ferramenta bastante promissora e interface bastante dinâmica;

d. "Gostei muito de realizar a avaliação nesta ferramenta, que é totalmente Web e em diferentes linguagens. E também juntando acessibilidade e usabilidade, algo que não havia encontrado em outro lugar. Gostei de ver também as definições da HHS em português, algo inédito em meus trabalhos investigativos”;

e. “Já fiz alguns testes de usabilidade e achei muito útil uma ferramenta como esta que, ao mesmo tempo em que o guia durante a realização da avaliação, proporciona em cada etapa sempre uma descrição do critério sendo tratado naquele momento. No entanto, achei algumas destas descrições muito técnicas ou outras muito breves de maneira que em certos momentos tive que parar por um minuto para entender exatamente o que o critério avaliava. Talvez, se a ferramenta se direcionar também a um público com pouco conhecimento de usabilidade, tão como de desenvolvimento Web, fosse interessante pensar em descrever alguns destes critérios de uma forma um pouco mais prática ou próxima do usuário”;

f. “A ferramenta é primeiramente bastante útil. Em segundo lugar a centralização de várias metodologias de análise é sem dúvida uma 
*killer feature*. Acredito que adicionar outros testes de conformidade de código seria útil ao programador (como por exemplo o validador HTML5) mas confesso não saber se isso seria de fato um ganho ou perda de foco. Por fim, acredito que a disponibilização da ferramenta para o público combinada com sua abertura de código em algum repositório open source (como github) contribuiria para o projeto. Penso que sua divulgação em grupos de estudantes e/ou pesquisadores de acessibilidade/usabilidade poderia angariar desenvolvedores com conhecimento na área que podem tanto ajudar, quanto utilizar a ferramenta. Enfim parabéns pela iniciativa”.

Ainda, uma questão objetiva foi levantada, sobre a percepção de conflitos entre elementos de acessibilidade comparados aos elementos de usabilidade. Quatro dos respondentes afirmaram que verificaram ao menos um contraste, um deles exemplificou no comentário referente à experiência de se tratar os dois conceitos, que encontrou disparidade na avaliação de campos de preenchimento de texto no portal. Enquanto parecia estar de acordo com acessibilidade, seu uso não correspondeu de maneira adequada.

Na próxima seção são apresentadas as considerações finais referentes ao Capítulo, incluindo a discussão sobre a catalogação de conjunto de deficiências com relação aos critérios de sucesso das WCAG 2.0, o A4U e os resultados do estudo de caso.

\subsection{Considerações finais}

O envolvimento do aluno de mestrado no projeto AccessibilityUtil foi de fundamental importância para ganho de experiência em acessibilidade, voltada aos critérios sugeridos pelo W3C e no desenvolvimento da ferramenta, que posteriormente poderá ser integrada ao A4U, como contribuição a ser dirigida aos desenvolvedores durante sua avaliação, possibilitando que esses encontrem comentários nos objetos relacionados, que viabilizem o máximo grau de acessibilidade a ser alcançado.

A interpretação dos critérios de sucesso em conjuntos de deficiência foi realizada com o objetivo de atribuir esta funcionalidade ao $\mathrm{A} 4 \mathrm{U}$, de maneira que o desenvolvedor 
possa priorizar seu público alvo, caso tenha esta necessidade, ou mesmo identificar quem será beneficiado a cada critério de sucesso atendido.

No desenvolvimento do ambiente, buscou-se levar em consideração as recomendações de acessibilidade e usabilidade, e apresentar de forma amigável ao usuário, possibilitando o relacionamento dos dois conceitos, de maneira a favorecer um pensamento em conjunto, a fim de viabilizar o ganho na tomada de decisão nas duas frentes, por parte do desenvolvedor, seja ele inexperiente ou especialista.

A ferramenta procurou ainda, por meio de descrições oficiais, alcançar o desenvolvedor inexperiente, no intuito que esse pudesse compreender e exercer as avaliações, sem tantos problemas. Entretanto, pelo estudo de caso, notou-se que para pessoas com pouco conhecimento na área, entender a descrição oficial das recomendações pode ser uma tarefa difícil.

A possibilidade de salvar a avaliação e continuar posteriormente foi considerada um avanço, pois a quantidade de recomendações é demasiadamente alta para um teste completo, sem interrupções.

A correlação concreta dos conceitos de acessibilidade e usabilidade, de maneira a observar limitações entre essas frentes, só será possível em ambiente de produção intenso, ou seja, com muitas avaliações, com o propósito de identificar padrões de respostas a serem considerados.

No Capítulo 5 são delineadas as considerações finais desta dissertação, as limitações encontradas durante o projeto, as impressões pessoais, os trabalhos futuros e as publicações resultantes do mestrado. 


\subsection{Considerações iniciais}

O objetivo principal deste trabalho foi considerar a acessibilidade em conjunto com a usabilidade, como conceitos que precisam ser alinhados nas avaliações de aplicativos Web. Como proposta para contribuir com os principais envolvidos e responsáveis pelas avaliações de acessibilidade e usabilidade (os desenvolvedores), neste mestrado foi desenvolvido um ambiente para obtenção de resultados que contrastam perspectivas para reflexão e análise das questões de acessibilidade e usabilidade

Por meio do estudo de caso, pôde observar que as recomendações são, em geral, de fácil compreensão, entretanto desenvolvedores inexperientes nos conceitos envolvidos têm maiores dificuldades de compreensão e acreditam que o número de recomendações é muito alto, porém concordam que os pontos abordados são essenciais para obtenção de uma experiência mais agradável a todos os usuários.

As contribuições atendidas pela pesquisa, lições aprendidas, impressões pessoais, limitações e trabalhos futuros contemplam o assunto deste capítulo e são tratados nas próximas seções.

\subsection{Principais contribuições}

Conforme as considerações do Capítulo 2, sobre os trabalhos relacionados que apontaram o esforço humano como fundamental na verificação da observância das recomendações de 
acessibilidade e usabilidade, o Ambiente para Análise de Avaliações de Acessibilidade e Usabilidade na Web (A4U) conduz os avaliadores a validarem os resultados obtidos pelas ferramentas semiautomáticas e contribui com o testador manual, a fim de finalizar a verificação dos critérios não observados.

Ainda com relação ao $\mathrm{A} 4 \mathrm{U}$, ele produziu o avanço de, no mesmo ambiente, considerar recomendações de acessibilidade e usabilidade, visando introduzir ao desenvolvedor a preocupação em considerar a observância dos dois conceitos durante o desenvolvimento de sua aplicação.

O A4U é uma contribuição importante para o desenvolvedor, pois o permite incorporar resultados de avaliações de diferentes ferramentas semiautomáticas em um mesmo ambiente, relacionando seus apontamentos em forma de apoio a sua avaliação, que não consistirá apenas na correção de erros. A ferramenta instiga o desenvolvedor a pensar nos problemas, contribuindo para que as recomendações sejam consideradas previamente em futuros desenvolvimentos. Esta contribuição relaciona-se à problemática encontrada no estudo dos trabalhos relacionados, no propósito de diminuir a lacuna entre pesquisas no meio acadêmico e o ambiente profissional.

A relação ente os conceitos não foi explicitamente observada, pois, por mais que o estudo de caso tenha apontado algumas contraposições, apenas um estudo mais aprofundado, com um número elevado de avaliações, possibilitará um conjunto mais representativo de resultados, sem as limitações plausíveis de serem questionadas. Todavia, a relação é fortemente observada na posição do desenvolvedor, que deverá analisar todas as recomendações para que sua avaliação seja completa.

A pesquisa por ferramentas atuais foi uma contribuição relevante, pois viabilizou identificar a possibilidade de integração de resultados de avaliações por intermédio da EARL, bem como listar ferramentas que adotam os critérios atuais das recomendações do W3C, as WCAG 2.0.

Entender os critérios de sucesso em relação aos conjuntos de deficiência favorecidos também pode significar uma maior compreensão das WCAG 2.0, já que o A4U faz esta relação se tornar bem clara, através de filtros, que possibilitem ao desenvolvedor priorizar seu público alvo. 
Outro avanço da pesquisa foi a tradução das recomendações HHS para o português, e sua integração ao ambiente, tornando-a melhor compreensível pelo desenvolvedor brasileiro, já que a tradução considera também a descrição dos capítulos e as diretrizes.

\subsection{Lições aprendidas e impressões pessoais}

Durante o desenvolvimento desta dissertação, a proposta foi adaptada para se tornar mais objetiva e resultar em contribuições efetivas, o ambiente foi remodelado para cumprir com critérios de usabilidade, além dos que já eram considerados, no caso os da acessibilidade. A correlação entre a acessibilidade foi imposta por meio do desenvolvimento do ambiente, entretanto uma visibilidade massiva da ferramenta, a fim de contribuir com expressivas avaliações ainda não foi possível, impossibilitando a identificação concreta da correlação dos dois conceitos em âmbito mais geral.

A submissão do estudo de caso em um experimento piloto foi primordial, pois foram evidenciadas falhas que poderiam inviabilizar o procedimento. Como exemplo de problema, o não tratamento do timeout da sessão, que é considerado uma questão de usabilidade. Com esse problema, o usuário continua sua avaliação, sem feedback do servidor, o qual não salva as alterações.

Como impressão pessoal, participar de eventos de acessibilidade, como o Todos@Web, e presenciar entrevistas de pessoas com deficiências, que mostraram a dificuldade em acessar o conteúdo na Web foi bastante importante e motivacional para o desfecho desta pesquisa. Investigar acessibilidade, sem ter a experiência de lidar com o público alvo é frustrante e superficial. Foi gratificante a possibilidade de contribuir nesta área tão essencial. É importante colaborar na experiência diária dessas pessoas, que são visivelmente prejudicadas pela falta de interesse e conhecimento das empresas para tornar seus conteúdos acessíveis.

Outra lição muito importante foi a integração com o grupo de pesquisa, com reuniões presenciais e discussões online, que auxiliaram no amadurecimento do trabalho, a partir de contribuições significativas de pesquisadores de diferentes níveis, de graduação, mestrado e doutorado, possibilitando maximizar os resultados. 


\subsection{Limitações e trabalhos futuros}

A partir dos estudos aqui realizados, percebeu-se que para correlacionar os conceitos de acessibilidade e usabilidade, de maneira a qualificá-los de modo mais generalizado possível, um profundo estudo com desenvolvedores e especialistas deve ser conduzido, a partir do ambiente proposto. Assim, a divulgação da ferramenta em listas de discussão dos temas, em conjunto à submissão do conteúdo em fóruns de desenvolvimento de software, aplicação em disciplinas nas universidades, além da utilização de outros meios de tornar a ferramenta conhecida, é essencial para obter resultados expressivos que conduzam ao objetivo final.

O A4U foi submetido à avaliação por especialistas em acessibilidade, contribuindo com resultados importantes para aprimorar sua interface, assim, como trabalho futuro, estas recomendações deverão ser avaliadas e cumpridas.

A AccessibilityUtil deverá ser integrada ao A4U, possibilitando que resultados de avaliações de artefatos nela conduzidos, possam ser portados ao ambiente aqui desenvolvido e, na avaliação de artefatos pelo A4U, seja indicada a referência do artefato na AccessibilityUtil, contribuindo na visualização do Design Rationale lá empregado.

O A4U deverá incorporar uma licença de software open source e ser disponibilizado à comunidade, a fim de que outros pesquisadores e desenvolvedores possam fazer uso da ferramenta e contribuir com ela.

Em geral, este trabalho possibilitou, a partir da pesquisa bibliográfica, identificar a escassez de pesquisas que relacionam acessibilidade e usabilidade Web, e a lacuna que existe entre o meio acadêmico e o profissional. É importante contribuir, no meio acadêmico, com soluções que se tornem viáveis para que o desenvolvedor considere a teoria, na prática do seu desenvolvimento.

\subsection{Publicações resultantes}

Além dos resultados atingidos com o desenvolvimento desta dissertação, pode-se citar contribuições na forma de publicações científicas, as quais estão diretamente relacionadas à dissertação: 
1. BITTAR, T. J.; AMARAL, L. A., LOBATO, L. L. e FORTES, R. P. M. Applying an approach to support good practices during the development of accessible Web applications. Proceedings of $15^{\text {th }}$ International Conference on Human-Computer Interaction, Las Vegas, USA. (BITTAR et al., 2013).

2. BITTAR, T. J.; AMARAL, L. A.; FARIA, F. B. e FORTES, R. P. M. Supporting the Developer in an Accessible Edition of Web Communications: a Study of Five Desktop Tools In: Workshop of Information Systems and Design of Communication (ISDOC2012 EuroSIGDOC), 2012, Lisboa. Proceedings of Workshop of Information Systems and Design of Communication (ISDOC2012 - EuroSIGDOC). Nova York: ACM, 2012. v.1. p.3-9. (BITTAR et al., 2012a).

3. BITTAR, T. J.; AMARAL, L. A. e FORTES, R. P. M. Evolução da ferramenta AccessibilityUtil: apoio a projetos, moderação de conteúdos e verificações de uso. In: Conferência IADIS Ibero Americana WWW/INTERNET 2012, 2012, Madrid. Actas da Conferência IADIS Ibero Americana WWW/INTERNET 2012. Lisboa: IADIS, 2012. v. 01. p. 107-114. (BITTAR et al., 2012c).

4. AMARAL, L. A.; BITTAR, T. J. e FORTES, R. P. M. Um ambiente de análise para comparar resultados de avaliações de acessibilidade e usabilidade na Web. In: Conferência IADIS Ibero Americana WWW/INTERNET 2012, 2012, Madrid. Actas da Conferência IADIS Ibero Americana WWW/INTERNET 2012. Lisboa: IADIS, 2012. v. 01. p. 166-170. (AMARAL et al., 2012).

5. BITTAR, T. J., FARIA, F. B., AMARAL, L. A. e FORTES, R. P. M. Uma verificação de acessibilidade em formulários de contato de universidades brasileiras. In: 7a Conferencia Ibérica de Sistemas y Tecnologías de Información (CISTI), 2012, Madrid. Actas de la 7a Conferencia Ibérica de Sistemas y Tecnologías de Información. Braga, Portugal: APPACDM, 2012. v. 01. p. 783 - 788. ISBN: 978-989-96247-6-4. (BITTAR et al., 2012d).

6. BITTAR, T. J.; AMARAL, L. A. e FORTES, R. P. M. AccessibilityUtil: a tool for sharing experiences about accessibility of Web artifacts. $29^{\text {th }}$ ACM international conference on Design of communication, 2011, Pisa. 
Proceedings of $29^{\text {th }}$ ACM international conference on Design of communication, 2011. v. 1. p. 17-24. (BITTAR et al., 2011a).

7. BiTTAR, T. J.; LOBATO, L. L.; AMARAL, L. A. e FORTES, R. P. M. Desenvolvimento e Aplicação da Ferramenta AccessibilityUtil.com: colaboração e experiências em acessibilidade na Web. Conferência IADIS Ibero Americana WWW/INTERNET 2011, Rio de Janeiro. Actas da Conferência IADIS Ibero Americana WWW/INTERNET 2011, 2011. (BITTAR et al., 2011b).

8. BITTAR, T. J.; AMARAL, L. A.; LOBATO, L. L. e FORTES, R. P. M. AccessibilityUtil.com: uma ferramenta para colaboração de experiências de acessibilidade na Web. In: Simpósio Brasileiro de Sistemas Multimídia e Web - Webmedia 2011, Workshop on Tools and Applications. 2011, Florianópolis. Anais do Simpósio Brasileiro de Sistemas Multimídia e Web Webmedia 2011, 2011. (BITTAR et al., 2011c). 


\section{REFERÊNCIAS BIBLIOGRÁFICAS}

ABOU-ZAHRA, S. SemanticWeb Enabled Web Accessibility Evaluation Tools. World Wide Web Consortium, 2004.

ABOU-ZAHRA, S. Web Accessibility Evaluation. Web Accessibility: A Foundation for Research, [S.l.]: Springer, 2008. p. 80. ISBN: 978-1-84800-049-0.

ALEXANDER, D. Usability and accessibility: best friends or worst enemies? Proceedings of the International Cross-Disciplinary Conference on Web Accessibility, 2006.

ALMEIDA, L. D. A.; BARANAUSKAS, M. C. C. Universal design principles combined with web accessibility guidelines: a case study. In: SIMPÓSIO DE FATORES HUMANOS EM SISTEMAS COMPUTACIONAIS, 9., 2010, Porto Alegre. Anais... Porto Alegre: Sociedade Brasileira de Computação, 2010. p. 169-178.

BASTIEN, C.; SCAPIN, D. Ergonomic Criteria for the Evaluation of Human Computer Interfaces. Institut National de Recherche en Informatique et en Automatique, France, 1993.

BITTAR, T. J. Uma abordagem de apoio a boas práticas para desenvolvimento de aplicações Web acessíveis. 2013. Tese (Doutorado em Ciências de Computação e Matemática Computacional) - Instituto de Ciências Matemáticas e de Computação, Universidade de São Paulo, São Carlos, 2013. Disponível em: <http://www.teses.usp.br/teses/disponiveis/55/55134/tde-19042013-150117/>. Acesso em: 2014-03-04.

BOSCH, J. Software architecture: The next step. In Proceedings of the 1st European Workshop on Software Architecture (EWSA’04). Springer, 2004. 
BURGE, J. e BROWN, D. Design rationale types and tools, ai in design group. 1998. Disponível em: <http://web.cs.wpi.edu/Research/aidg/DR-Rpt98.html>. Acesso em dezembro de 2013.

BRAJNIK, G. Barrier Walkthrough. 2009. Disponível em: $<$ http://sole.dimi.uniud.it/ giorgio.brajnik/projects/bw/bw.html>. Acesso em 12 de novembro de 2013.

BRANDÃO, E. R.; MORAES, A. Publicidade on-line, ergonomia e usabilidade: o efeito de seis tipos de banner no processo humano de visualização do formato do anúncio na tela do computador e de lembrança da sua mensagem. 2006. $2 \mathrm{v}$. Dissertação (Mestrado)-Pontifícia Universidade Católica do Rio de Janeiro, Departamento de Artes e Design, 2006.

CANDAN, K.S.; DONDERLER, M.E.; HEDGPETH, T.; KIM, J.W.; LI, Q.; SAPINO, M.L. SEA: Segment-enrich-annotate paradigm for adapting dialog-based content for improved accessibility. ACM Trans. Inf. Syst. 27, 3, Article 15, 2009. DOI $=10.1145 / 1508850.1508853$

CONKLIN, J. AND BEGEMAN, L. M. gIBIS: A hypertext tool for exploratory policy discussion. Em Proceedings of the ACM Conference on Computer-Supported Cooperative Work, 1988.

CONKLIN, E. J.; BURGESS-YAKEMOVIC, K. C. A process-oriented approach to design rationale. In Moran, T. P., \& Carroll, J. M. (Eds.), Design rationale: Concepts, techniques, and use, 1996. p. 393-427.

CARVALHO, C. V. Dados sobre Deficiência no Brasil. 2008. Brasília-DF. Disponível em <http://bd.camera.gov.br/bd/bitstream/handle/bdcamera/1383/dados_deficiencia_vi veiros.pdf?sequence=1>. Acesso em abril de 2010.

Disability Rights Commission The Web: access and inclusion for disabled people. London: The Stationery Office, 2004.

DUTOIT A., MCCALL R., MISTÍK I., PAECH B. Rationale Management in Software Engineering: Concepts and Techniques. A. H. Dutoit and R. McCall and I. Mistrík and B. Paech (eds.), Rationale Management in Software Engineering, Springer, 2006, p. 1-48. 
E-MAG. Modelo de Acessibilidade de Governo Eletrônico. 2010. Disponível em: $<$ http://www.governoeletronico.gov.br/acoes-e-projetos/e-MAG>. Acesso em fevereiro de 2014.

FØLSTAD, A., LAW, L-C., \& HORNBÆK, K. Analysis in practical usability evaluation: a survey study. In Proc. CHI 2012, 2012. p. 2127-2136.

GAIGG, M. Web Content Accessiblity Guidelines (WCAG) 2.0: Overview and Structure. $2008 . \quad$ Disponível em: http://www.michaelgaigg.com/blog/2008/12/19/web-content-accessiblityguidelines-wcag-20-overview-and-structure/> . Acesso em fevereiro de 2013.

GIL, M. Deficiência Visual. Cadernos da TV escolar, MINISTÉRIO DA EDUCAÇÃO SECRETARIA DE EDUCAÇÃO A DISTÂNCIA, 2000, p. 6-7. ISSN 1518-4692.

GORTON, I. Essential Software Architecture. Springer, 2006.

GRUBBER, T. R.; RUSSEL, D. M. Design Knowledge and Design Rationale: A Framework for Representation, Capture, and Use. Technical Report KSL 90-45, Knowledge Systems Laboratory, Standford, California, 1991, 40p.

HARPER, S.; YESILADA, Y. Web accessibility : a foundation for research. London: Springer, 2008, p. 84-91.

HHS. Research-Based Web Design \& Usability Guidelines. 2006. U.S. Health and Human Services Department. Disponível em: <http://guidelines.usability.gov>. Acesso em dezembro de 2013.

HORNER, J. ATWOOD, M. E. Design Rationale: the rationale and the barriers. In: Proceedings of the 4th ACM Nordic conference on Human-computer interaction: changing roles, 2006.

IBGE. Censo 2010: número de católicos cai e aumenta o de evangélicos, espíritas e sem religião. 2010. Disponível em: <http://cod.ibge.gov.br/23463>. Acesso em fevereiro de 2014.

ISO. ISO 9241-210:2010 - Ergonomics of human-system interaction -- Part 210: Human-centred design for interactive systems. 2010. Disponível em: < 
http://www.iso.org/iso/catalogue_detail.htm?csnumber=52075>. Acesso em: fevereiro de 2014.

ISO/IEC. ISO/IEC 40500:2012 - Information technology -- W3C Web Content Accessibility Guidelines (WCAG) 2.0. 2012. Disponível em: $<$ http://www.iso.org/iso/iso_catalogue/catalogue_tc/catalogue_detail.htm?csnumber =58625 $>$. Acesso em: fevereiro de 2014 .

JANSEN, A., BOSCH, J., AND AVGERIOU, P. Documenting after the fact: Recovering architectural design decisions. J. Syst. Softw. 81, 4, 2008, p.536-557.

KITCHENHAM, B.; CHARTERS, S. Guidelines for performing systematic literature reviews in software engineering. Relatório Técnico EBSE 2007-001, Keele University and Durham University Joint Report, 2007.

KOUTSABASIS, P.; VLACHOGIANNIS, E.; DARZENTAS, J. S. Beyond Specifications: Towards a Practical Methodology for Evaluating Web Accessibility. J. Usability Studies 5, 4, Article 16, 2010.

LANGDON, P.; PERSAD, U.; CLARCKSON, P. J. Developing a model of cognitive interaction for analytical inclusive design evaluation. Interact. Comput. 22, 6, 2010, p.510-529. DOI=10.1016/j.intcom.2010.08.008

LEE, J. Design Rationale Systems: Understanding the Issues. IEE expert/Intelligent Systems ans Their Applications, v. 12, n. 3, 1997, p. 78-85.

LEE, L. e KRUCHTEN, P. Capturing software architectural design decisions. In Proceedings of the Canadian Conference on Electrical and Computer Engineering (CCECE’07), 2007.

LEEDY, P. D.; ORMROD, J. E. Practical research: Planning and design (8th ed.). Upper Saddle River, NJ: Prentice Hall, 2005.

LIKERT, R. A Technique for the Measurement of Attitudes. Archives of Psychology 140, 1932, p. 1-55.

MACLEAN, A. et al. Questions, Options and Criteria: Elements of Design Space Analysis. Human-Computer Interaction, v. 6, n. 3-4, 1991, p. 201-250. 
MEC. A inclusão escolar de alunos com necessidades educacionais especiais DEFICIÊNCIA FÍSICA. Ministério da Educação, Secretaria de Educação Especial. Brasília-DF, 2006.

MELODY, Y.; IVORY, M. A. Hearst: The State of the Art in Automating Usability Evaluation of User Interfaces. ACM Computing. Survey. vol. 33, No. 4, 2001, p. 470-516.

MORAN, T. P.; CARROL, J. M. Design Rationale: Concepts, Techniques, and Use Computers, Cognition, and Work. New Jersey: Lawrence Erlbaum Associates, 1996, 659p.

NIELSEN, J. Heuristic evaluation. In J. Nielsen and R.L. Mack (Eds.), Usability inspection methods. New York: John Wiley and Sons, 1994.

NIELSEN, J. Usability 101: introduction to usability, 2003a. Disponível em: < http://www.useit.com/alertbox/20030825.html>. Acesso em mar. 2011.

NIELSEN, J. Usability Engineering. Boston - USA: Academic Press, 2003b, 362 p.

PETRIE, H.; KHEIR, O.: The relationship between accessibility and usability of websites. In: Proc. CHI 2007. ACM, CA, 2007, p. 397-406.

POWER, C.; PETRIE, H. Accessibility in non-professional web authoring tools: a missed web 2.0 opportunity?. In: Proceedings of the 2007 international crossdisciplinary conference on Web accessibility (W4A) (W4A '07). New York: ACM, 2007, p. 116-119.

QUESENBERY, W. What does usability mean: looking beyond 'ease of use', 2002.

Disponível em: <http://www.wqusability.com/articles/more-than-ease-of-use.html>. Acesso em mar. 2011.

REDONDO, M. C. F. O deficiente auditivo e o mercado de trabalho. Tese de mestrado. São Paulo, Pontifícia Universidade Católica de São Paulo, 1990.

REDONDO, M. C. F.; CARVALHO, J. M. Deficiência Auditiva. Cadernos da TV escola MINISTÉRIO DA EDUCAÇÃO - SECRETARIA DE EDUCAÇÃO A DISTÂNCIA, 2000. p. 6-7. ISSN 1518-4706 
REGLI, W. C. et al. A Survey of Design Rationale Systems: Approaches, Representation, Capture and Retrieval. Engineering with Computers: An International Journal for Simulation-Based Engineering, special issue on Computer Aided Engineering in Honor of Professor Steven J. Fenves, v. 16, 2000, p. 209-235.

ROCHA, J. A. P. (In) Acessibilidade na web para pessoas com deficiência visual: um estudo de usuários à luz da Cognição situada. Dissertação de mestrado, UFMG, 2013. Disponível em: <http://hdl.handle.net/1843/ECIC-9BFKDS>.

ROCHA, J. A. P.; LIMA, T. F. M. Análise da relação entre acessibilidade web e usabilidade para pessoas com deficiência visual. SIMPÓSIO DE FATORES HUMANOS EM SISTEMAS COMPUTACIONAIS, 9., 2010, Belo Horizonte. Anais. Porto Alegre: SBC, 2010. p. 257-258

SEVILLA, J. et al. Web accessibility for individuals with cognitive deficits: A comparative study between an existing commercial Web and its cognitively accessible equivalent. ACM Trans. Comput.-Hum. Interact. 14, 3, Article 12, 2007. DOI=10.1145/1279700.1279702

SHIPMAN, F.; MCCALL, R. Integrating Different Perspectives on Design Rationale: Supporting the Emergence of Design Rationale from Design Communication. Artificial Intelligence in Engineering Design, Analysis, and Manufaturing, v. 11, n. 2, 1997, p. 141-154.

SLATIN, J.; LEWIS, K.: Challenges of accessible web design: Standards, guidelines, and user testing. In: Technology and Persons with Disabilities Conference, Los Angeles, USA. CSUN, California State University Northridge, 2002.

SOMMERVILLE, I. Engenharia de Software. 8a. ed. [S.l.]: Pearson, v. 1, 2007. 568 p. ISBN 9788588639287.

THATCHER, J. 508 Web Accessibility, 2004. Disponível em: $<$ http://www.jimthatcher.com/webcourse1.htm>. Acesso em mar. 2011.

THATCHER, J. et al. Constructing accessible web sites. San Francisco: glasshaus, 2003.

THATCHER, J. et al. Web Accessibility: Web Standards and Regulatory Compliance, Friends of ED, 2006. 
TYREE, J. AND AKERMAN, A. Architecture decisions: Demystifying architecture. IEEE Softw. 22, 2, 2005, p. 19-27.

VANDERDONCKT, J., BEIREKDAR, A., NOIRHOMME-FRAITURE, M.: Automated Evaluation of Web Usability and Accessibility by Guideline Review. In: Proc. of 4th Int. Conf. on Web Engineering ICWE'04 (Munich, 28-30 July 2004), SpringerVerlag, Berlin. 2004, p. 17-30.

W3C EARL - The Evaluation And Report Language, 2011a. Disponível em: <http://www.w3.org/2001/03/earl/>. Acesso em out. 2012.

W3C Recomendações de Acessibilidade para Conteúdo Web (WCAG) 2.0, 2009. Disponível em: <http://www.ilearn.com.br/TR/WCAG20/>. Acesso em jun. 2011.

W3C Web Accessibility Initiative, 2011b. Disponível em: <http://www.w3.org/WAI/>. Acesso em jun. 2011.

W3C Web Content Accessibility Guidelines (WCAG) 2.0, 2008. Disponível em: <http://www.w3.org/TR/WCAG20/>. Acesso em out. 2010.

WebAIM. Cognitive. 2013a. Disponível em: <http://webaim.org/articles/cognitive/>. Acesso em 10 de setembro de 2013.

WebAIM. Introduction to Web Accessibility. 2013b. Disponível em: $<$ http://webaim.org/intro/>. Acesso em 10 de setembro de 2013.

WebAIM. Seizure Disorders. 2013c. Disponível em: <http://webaim.org/intro/>. Acesso em 10 de setembro de 2013.

WebAIM. Accessibility Evaluation Tools. 2013d. Disponível em: < http://webaim.org/articles/tools/>. Acesso em 10 de setembro de 2013.

WATTENBERG, T. Beyond standards: reaching usability goals through user participation. SIGACCESS Access. Comput. 79, 2004. DOI=10.1145/1040053.1040055

WINCKLER, M.; PIMENTA, M. S. Livro Texto da X Escola de Informática da SBCSul, Sociedade Brasileira de Computação, Porto Alegre - RS, 2002, p. 85-137. 



\section{A. Questionário}

\section{A4U - Registro de impressões}

Este formulário é anônimo, o respondente não será identificado.

* Required

\section{Categoria que está inserido *}

Se você é um pós-graduando ou professor que estuda/estudou um dos conceitos aqui abordados, marque a opção Pesquisador; se é desenvolvedor profissional ou freelancer, marque a opção Desenvolvedor

Pesquisador

Desenvolvedor

Sobre seu conhecimento em Acessibilidade Web *

Escala de 1 a 5, sendo que 1 representa nenhum conhecimento e 5, conhecimento avançado.

$$
\begin{array}{lllll}
1 & 2 & 3 & 4 & 5
\end{array}
$$

Nenhum conhecimento $\bigcirc \bigcirc \bigcirc \bigcirc$ Conhecimento avançado

Sobre seu conhecimento em Usabilidade Web *

Escala de 1 a 5, sendo que 1 representa nenhum conhecimento e 5, conhecimento avançado.

$\begin{array}{lllll}1 & 2 & 3 & 4 & 5\end{array}$

Nenhum conhecimento $\bigcirc 0000$ Conhecimento avançado 
Sobre a quantidade de itens a serem avaliados*

Escala de 1 a 5 , sendo que 1 representa pouca quantidade e 5 muita quantidade

$\begin{array}{lllll}1 & 2 & 3 & 4 & 5\end{array}$

Pouca quantidade $\bigcirc \bigcirc \bigcirc \bigcirc \bigcirc$ Muita quantidade

Comentários sobre a quantidade de itens a serem avaliados

Caso tenha algo a comentar sobre a quantidade de itens a serem avaliados, deixe aqui sua opiniãc

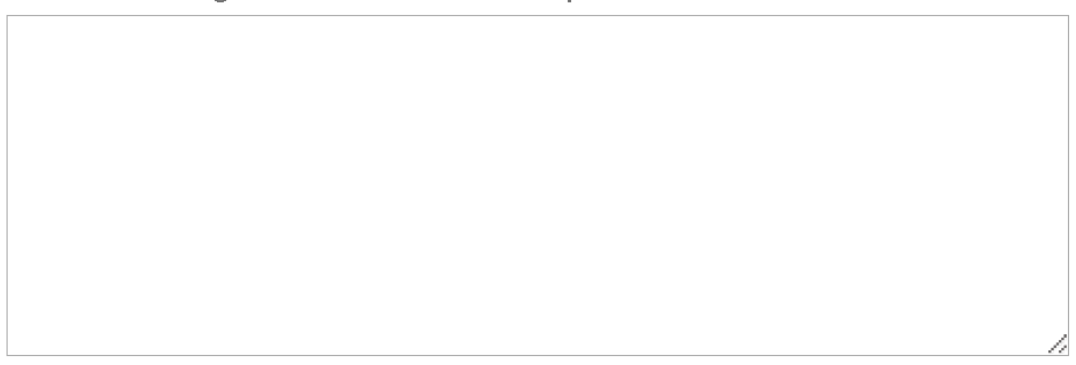

Sobre a dificuldade em entender o que cada sucesso de critério da WCAG 2.0 significa, apenas ao ler seu nome e descrição *

Escala de 1 a 5 , sendo que 1 representa Muito difícil e 5 Muito fácil.

$\begin{array}{lllll}1 & 2 & 3 & 4 & 5\end{array}$

Muito difícil $\bigcirc \bigcirc \bigcirc \bigcirc$ Muito fácil

Sobre a dificuldade em entender o que cada diretriz da HHS significa, apenas ao ler seu nome e descrição *

Escala de 1 a 5 , sendo que 1 significa Muito difícil e 5 Muito fácil

$$
\begin{array}{lllll}
1 & 2 & 3 & 4 & 5
\end{array}
$$

Muito difícil $\bigcirc \bigcirc \bigcirc \bigcirc$ Muito fácil

Sobre a cobertura da avaliação das ferramentas semiautomáticas *

Escala de 1 a 5 , sendo que 1 representa baixíssima cobertura e 5 alta cobertura (obs. se as ferramentas de avaliação encontraram muitos ou poucos dos problemas que a página apresenta)

$$
\begin{array}{lllll}
1 & 2 & 3 & 4 & 5
\end{array}
$$

Baxíssima cobertura $\bigcirc \bigcirc \bigcirc \bigcirc$ Alta cobertura 
Comentários sobre a cobertura da avaliação das ferramentas semiautomáticas

Caso tenha algo a comentar sobre a cobertura da avaliação das ferramentas semiautomáticas, deixe aqui sua opinião.

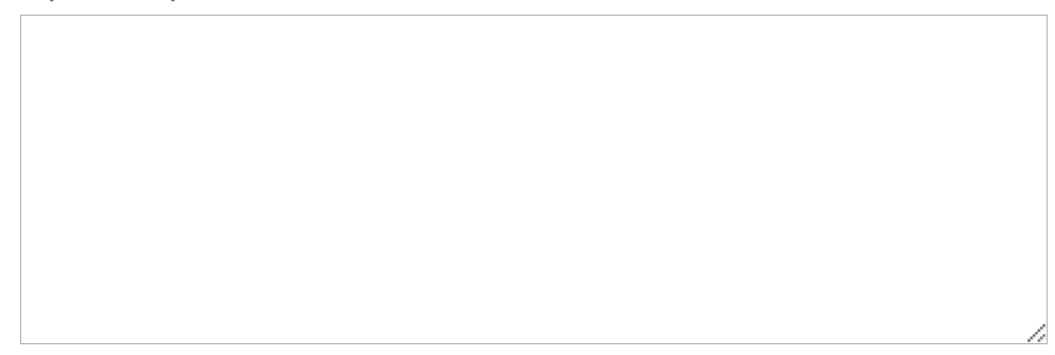

Sobre a experiência de tratar Acessibilidade e Usabilidade no mesmo ambiente de avaliação *

Escala de 1 a 5 , sendo que 1 representa ruim e 5 excelente.

$\begin{array}{lllll}1 & 2 & 3 & 4 & 5\end{array}$

Ruim $\bigcirc \bigcirc \bigcirc \bigcirc \bigcirc$ Excelente

Encontrou algum conflito entre diretrizes de acessibilidade que prejudicassem a usabilidade ou vice versa? *

Sim

Não

Comentários sobre a experiência de tratar Acessibilidade e Usabilidade no mesmo ambiente de avaliação *

Comente sobre qual foi sua experiência de tratar Acessibilidade e Usabilidade no mesmo ambiente de avaliação, se houve alguma dificuldade, ou quaquer comentário que achar relevante.

\section{Sobre a interface do $\mathrm{A4U}$ *}

Escala de 1 a 5 , sendo que 1 representa ruim e 5 ótimo.

$$
\begin{array}{lllll}
1 & 2 & 3 & 4 & 5
\end{array}
$$

\section{Ruim $\bigcirc \bigcirc \bigcirc \bigcirc$ Ótimo}




\section{Comentários sobre a interface do A4U *}

Comente sobre o que achou da interface do $\mathrm{A} A \mathrm{U}$, se é ou nẫo amigável, e em que poderia melhorar.

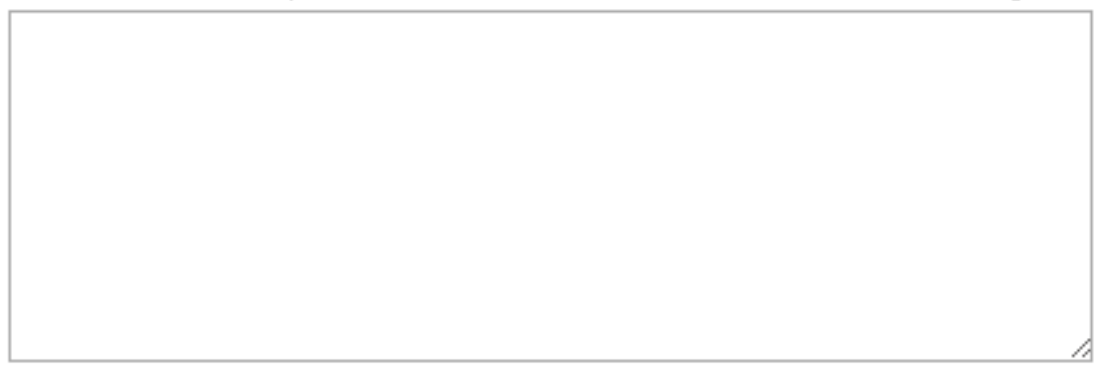

\section{Comentário geral *}

Deixe um comentário geral da sua experiência com essa avaliaçẫo.

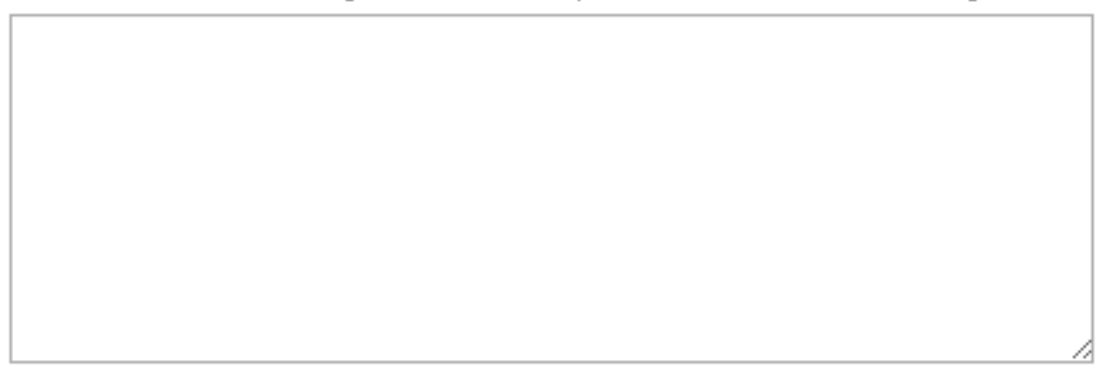




\section{B. ROTEIRO DO ESTUDO DE CASO}

O estudo de caso consiste em utilizar o Ambiente para Análise de Avaliações de Acessibilidade e Usabilidade na Web (A4U) para a avaliação do portal do governo do Estado de São Paulo (http://www.saopaulo.sp.gov.br/).

Abaixo disponibilizo um vídeo explicativo da ferramenta para que assistam antes de iniciarem o procedimento. Não comecem antes de finalizar o vídeo, o Roteiro mais abaixo deve ser seguido.

\section{http://youtu.be/McaQZ466LRs}

O tempo de execução da avaliação será medido através do intervalo de criação do projeto e da última avaliação feita, então procure fazer a avaliação de forma contínua (tempo aproximado de uma hora e meia).

\section{Material de apoio:}

- WCAG 2.0 (INGLÊS: http://www.w3.org/TR/WCAG20/ - PORTUGUÊS: http://www.ilearn.com.br/TR/WCAG20/)

- Section 508 (INGLÊS: http://www.hhs.gov/web/508/)

- HHS (INGLÊS: http://guidelines.usability.gov/)

- Estão livres a utilizarem qualquer outro material de pesquisa (ex. Google)

\section{Roteiro:}

1. Cadastre-se na ferramenta: http://www.leandroagt.com.br/a4u/

2. Em Fazer avaliação de site ou artefato, crie o projeto do portal do governo do Estado de São Paulo (URL: http://www.saopaulo.sp.gov.br/ ) e em “Objeto a ser avaliado" selecione a opção "Página inteira”.

3. Ao criar o projeto, o A4U faz a avaliação da página utilizando o AChecker e você deve inserir um arquivo em EARL, para complementar a avaliação. Faça download da WaaT ( http://www.leandroagt.com.br/a4u/download/WaaT.zip ) e assista o vídeo que mostra a utilização da ferramenta: http://youtu.be/YpMNP2xy3aA 
4. Na WaaT, faça a avaliação do portal do governo do Estado de São Paulo (URL: http://www.saopaulo.sp.gov.br/ ) e submeta o arquivo .XML no A4U, a partir da opção “Incluir avaliação em EARL”.

5. Feito estes passos, na Aba "Acessibilidade (WCAG 2.0), escolha a opção de Filtro “Nível de conformidade”, com o mais baixo, “A” (Para o Nível A de conformidade (o nível mínimo de conformidade), a página Web cumpre todos os critérios de Sucesso de Nível A, ou uma versão alternativa em conformidade é fornecida)

6. Ao finalizar a avaliação de Acessibilidade no Nível de conformidade A, prossiga com a avaliação de usabilidade, na aba Usabilidade (HHS), selecionando os filtros: Importância relativa $=5$ e Força de evidência $=4$.

7. Ao finalizar a avaliação, vá na Aba Relatório, e clique no botão Gerar relatório completo. O sistema irá gerar um arquivo PDF geral, com todos seus resultados. Faça download do arquivo PDF e envie para: leandromaral@gmail.com

Preencha o formulário final sobre a avaliação e utilização do A4U em: http://www.leandroagt.com.br/a4u/form/ 


\section{TERMO DE CONSENTIMENTO LIVRE E ESCLARECIDO}

Você está sendo convidado(a) a participar, como voluntário(a), desta pesquisa.

Caso concorde em participar, favor assinar ao final do documento. Sua participação não é obrigatória e, a qualquer momento, poderá desistir e retirar seu consentimento.

Sua recusa não trará nenhum prejuízo à sua relação com o pesquisador (a) ou com a instituição. Você receberá uma cópia deste termo onde consta o telefone e endereço do pesquisador(a) principal, podendo tirar dúvidas do projeto e de sua participação.

NOME DA PESQUISA: Estudo de caso no Ambiente de Análise de Avaliações de Acessibilidade e Usabilidade na Web

PESQUISADOR RESPONSÁVEL: Leandro Agostini do Amaral

ENDEREÇO: Rua Major José Inácio, 1461 - Ap. 301, Centro - São Carlos-SP

TELEFONE: (16) 98122-0785

OBJETIVO: Analisar a utilização da ferramenta A4U por desenvolvedores e pesquisadores nas áreas de Acessibilidade e Usabilidade Web.

PROCEDIMENTOS DO ESTUDO: Se concordar em participar da pesquisa, você terá que utilizar a ferramenta A4U para completar a avaliação de acessibilidade e usabilidade da URL: http://www.saopaulo.sp.gov.br e, ao final, responder um questionário sobre suas impressões durante sua atuação. Os dados serão utilizados para verificar a consistência da ferramenta, bem como analisar possíveis problemas de entendimento relacionados aos critérios de avaliação e contrastes entre eles.

CONFIDENCIALIDADE DA PESQUISA: O questionário final não pede identificação, com o intuito de preservar a privacidade dos correspondentes e utilizar apenas os dados obtidos de suas respostas. 